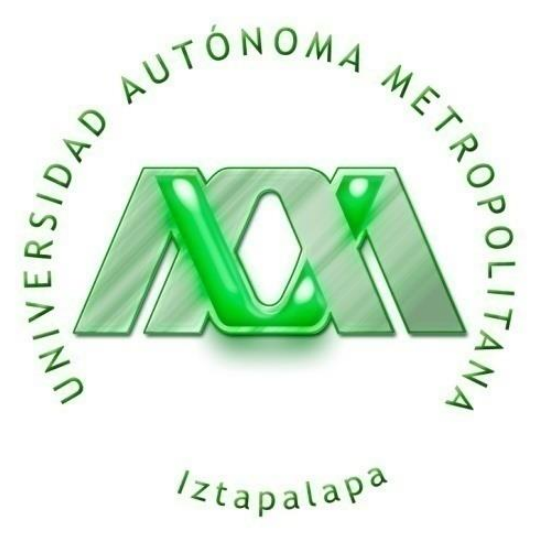

DIVISIÓN DE CIENCIAS BIOLÓGICAS Y DE LA SALUD

\title{
OXIDACIÓN Y ADSORCIÓN SIMULTÁNEA DE AMONIO Y AZUL ÁCIDO 74 EN UN REACTOR HÍBRIDO DE FLUJO ASCENDENTE
}

Tesis

Para obtener el grado de

Doctora en Biotecnología

Presenta

M. en B. Sylvia Karina Téllez Pérez

Directores de tesis

Dr. Ricardo Beristain Cardoso

Dr. Sergio Huerta Ochoa
Asesor de tesis

Dr. Carlos Omar Castillo Araiza 
El jurado designado por la División de Ciencias Biológicas y de la Salud de la Unidad Iztapalapa aprobó la tesis

Oxidación y adsorción simultánea de amonio y azul ácido 74 en un reactor hibrido de flujo ascendente

Que presentó

M. en B. Sylvia Karina Téllez Pérez

Comité Tutoral:

Director: Dr. Ricardo Beristain Cardoso

Director: Dr. Sergio Huerta Ochoa

Asesor: Dr. Carlos Omar Castillo Araiza

Jurado:

Presidente: Dr. Carlos Omar Castillo Araiza

Secretario: Dr. Carlos David Silva Luna

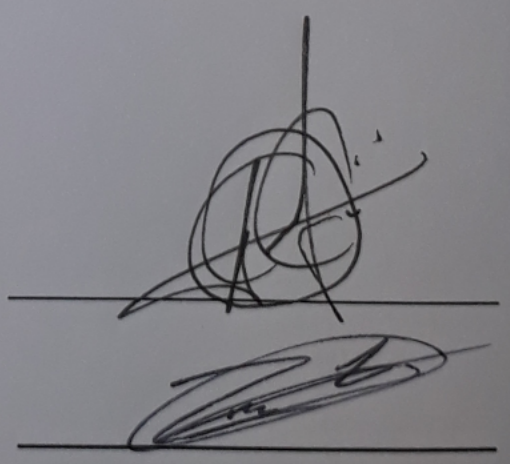

Vocal: Dra. Gehovana González Blanco

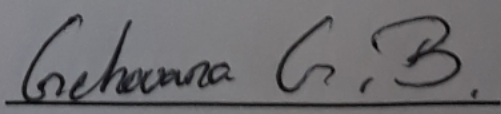

Vocal: Dr. Guillermo Quijano Govantes

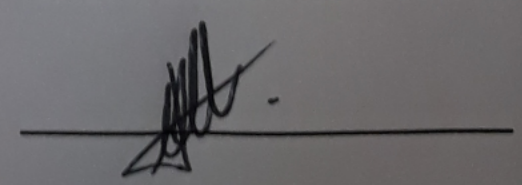


Este trabajo de tesis se llevó a cabo en la planta de Fermentación en medio sólido (Planta Piloto 4) del Departamento de Biotecnología de la Universidad Autónoma Metropolitana Iztapalapa. Con el apoyo otorgado por el Consejo Nacional de Ciencia y Tecnología.

El Doctorado en Biotecnología de la Universidad Autónoma Metropolitana está incluida en el Programa Nacional de posgrados de Calidad (PNPC) del CONACYT, con la referencia 001466 


\title{
A mis padres, Silvia y Panchito \\ Por ser mi inspiración y motivación de crecer día con día, gracias por creer en mí, por su amor y apoyo incondicional que me ha impulsado al éxito.
}

\author{
A mi hermano, Ricardo \\ Por enseñarme el significado del amor encriptado en fortaleza.
}

A quien ha hecho sonreír mi alma una vez más, Enrique

Gracias por devolverme la ilusión y hacer soñar mi corazón. 


\section{Agradecimientos}

Un ciclo más concluido, el cual no habría sido posible sin la presencia de muchas luces que iluminaron cada uno de mis pasos.

Agradezco a mis padres y a Dios que me dieron la vida y han guiado este camino.

Infinitas gracias al Dr. Sergio Huerta, que sin dudarlo, creyó en mí y en mi capacidad. Que a pesar de las diferentes áreas de investigación aceptó unirse a este reto y con su experiencia, conocimiento y compromiso, ha contribuido en mi formación académica. Gracias por las charlas y momentos de discusión profesional, así como los momentos amenos de fútbol y compañerismo en el grupo de los Huerta's. Gracias por los vínculos formados, por la experiencia en Bélgica y sobre todo gracias por la oportunidad de integrarme a su grupo de trabajo.

Al Dr. Ricardo Beristain, gracias por tu amistad y por ser un ejemplo a seguir, por participar en mi formación profesional, por compartirme tu experiencia, conocimiento y tan acertadas críticas. Por los logros, éxitos y derrotas compartidos, así como enseñarme afrontar los momentos infortunados en el camino. Pero sobre todo gracias por contagiarme esas ganas de superarme y aprender constantemente.

Al Dr. Omar Castillo, gracias por integrarte a este proyecto, sin duda tu contribución permitió darle otro enfoque interdisciplinario al trabajo, por contribuir con la experiencia en tu área, por tus comentarios y críticas, gracias por incluirme en tu grupo de trabajo y por las charlas personales y profesionales.

A los doctores en la Planta Piloto 4, Dra. Arely, Dr., Saucedo y Dr. Ernesto que en algún momento contribuyeron en mi trabajo y por los momentos de compañerismo, gracias. A mis amigos de la planta, a los Pedritos, Chris, Carlitos, David, Rubén, Uriel, Chris M., Lalo, Candy, Goyito, Oswaldo, Noemí, Monse, Juan Carlos, Dianita, Dulce, Raziel y mi Letty, gracias por su amistad y compañerismo, por compartir los momentos de trabajo, de charlas científicas, así como los momentos de frustración y felicidad. Gracias a ustedes mi trabajo siempre fue más ameno.

Finalmente agradezco a mis compañeros, amigos y ahora doctores A la Dra. Gehovanna gracias por tu amistad y tus consejos, Dr. David por sus comentarios y críticas, Dr. Perrino que me brindó la oportunidad de comenzar esta etapa, Dr. Felipe, Dr. Sepúlveda, Dra. Carmen, Dra. Gloria. Gracias por su apoyo en los momentos que mi trabajo demandó su espacio y su tiempo. Gracias a todos mis amigos de las canchas, cangres y la pandilla por los buenos momentos. A los cielos claros por siempre.

A la Universidad Católica de Lovaina y Waterleau, Bélgica, al Dr. Abhishek Dutta y Ron Gerards por la oportunidad y la experiencia de desarrollar mi formación profesional en estas instituciones.

Sin duda agradezco infinitamente a la UAM por brindarme la oportunidad de pertenecer a esta casa de estudios. Y permitirme desarrollar en todos los ámbitos. Hoy por hoy Orgullosamente UAM. 
Cuando se desea realmente algo desde lo profundo del alma, el Universo entero conspira para que pueda realizar su sueño.

Paulo Coelho. 
Índice de contenido

Pág.

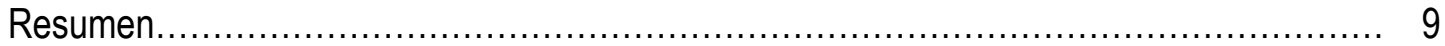

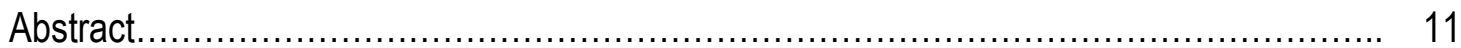

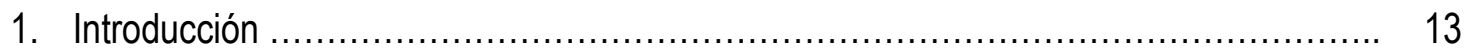

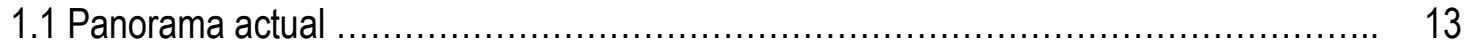

1.2 Procesos biológicos en el tratamiento de colorantes....................................... 14

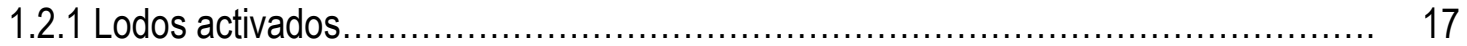

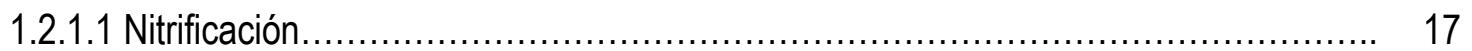

1.2.1.1.1 Factores que afectan a la nitrificación ..................................................... 19

1.2.1.2 Desnitrificación.............................................................................. 20

1.2.1.2.1 Factores que afectan la desnitrificación................................................ 21

1.3 Procesos físico-químicos en el tratamiento de colorantes.................................. 22

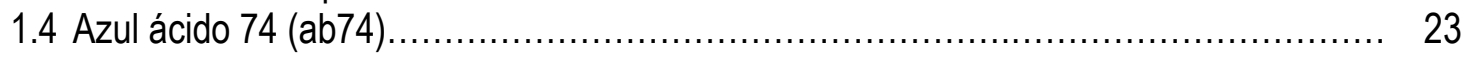

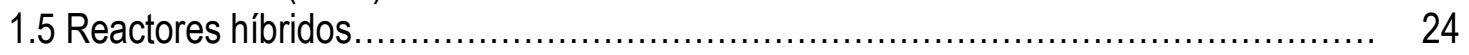

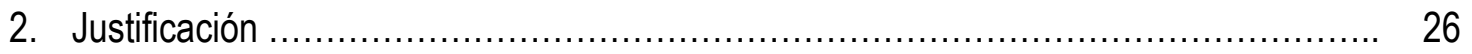

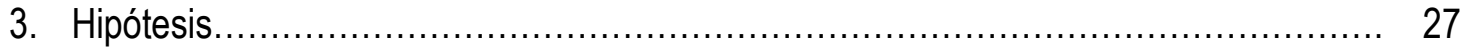

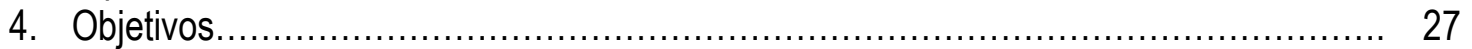

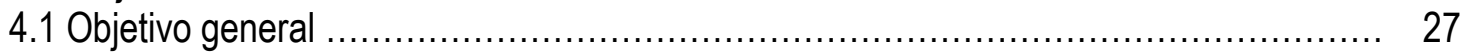

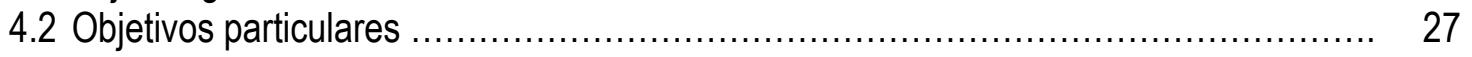

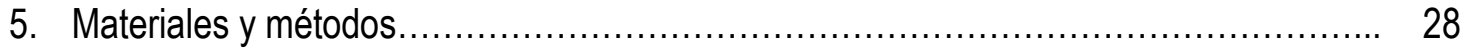

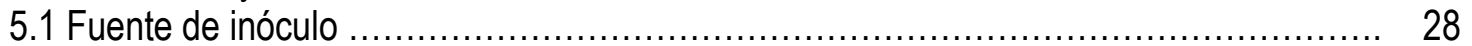

5.1 .1 Obtención de los lodos pre tratados (LPT) .............................................. 28

5.1.2 Caracterización de los inóculos: Microscopía electrónica de barrido ..................... 28

5.2 Actividad de la enzima lacasa en lote.......................................................... 28

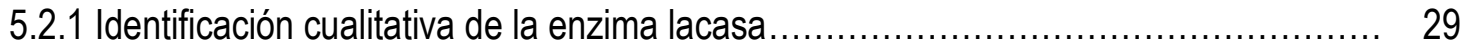

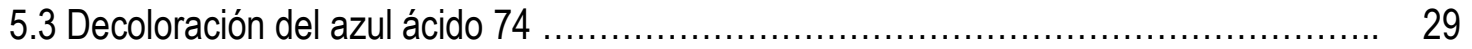

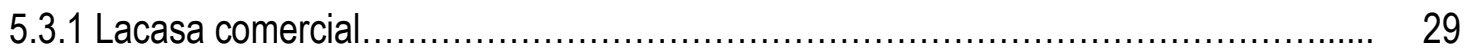

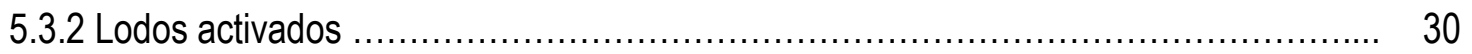

5.3.3 Lodos pre tratados........................................................................ 30

5.3.4 Control abiótico ................................................................................. 30

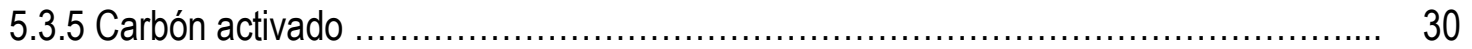

5.3.5.1 Adsorción-desorción del ab74 en CA...................................................... 31

5.3.6 Carbón activado y lodos activados ........................................................... 31

5.4 Lodos activados: Inhibición de lacasas....................................................... 31

5.5 Reactor híbrido de flujo ascendente (RHFA) ….......................................... 31

5.5.1 Módulo nitrificante-decolorante (m1) ……............................................ 33

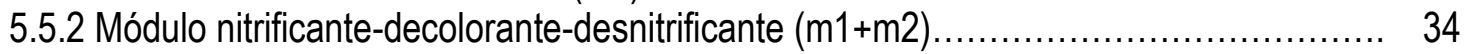

6. Métodos analíticos ............................................................................. 35

6.1 Electrodo selectivo de amoniaco: determinación de amonio................................. 35

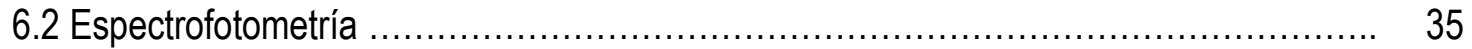

6.2.1Determinación del azul ácido 74 (ab74) …................................................ 35

6.2.2 Método de reducción de cadmio: determinación de nitrato ................................ 35

6.2.3 Método de diazotización: determinación de nitrito ............................................ 35

6.2.4 Método Lowry: Determinación de proteína microbiana ................................... 35

6.2.5 Determinación de carbono orgánico total .................................................. 36

6.3 Determinación de sólidos suspendidos volátiles (SSV) .................................... 36 


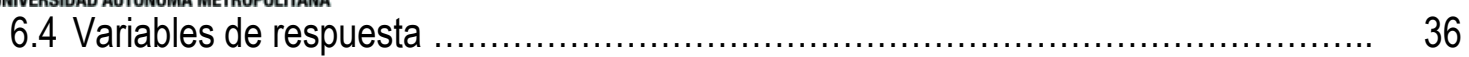

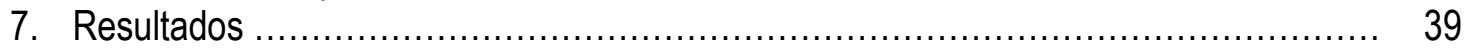

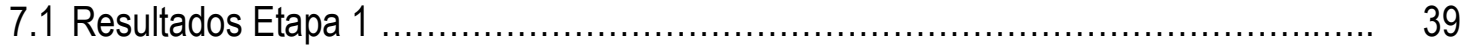

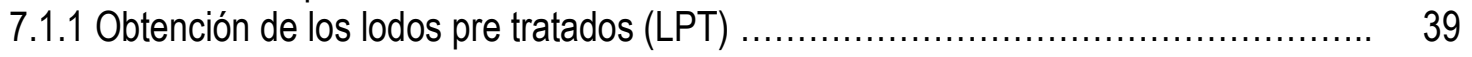

7.1.2 Caracterización de los inóculos ..................................................... 40

7.1.3 Actividad de la enzima Lacasa en Lac, LA y LPT, en cultivos lote..................... 41

7.1.4 Presencia y actividad de la enzima lacasa ................................................ 42

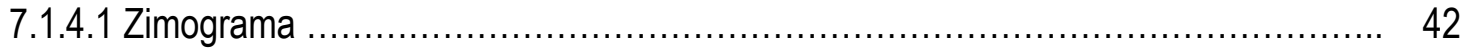

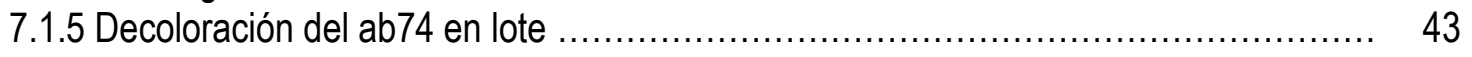

7.1.5.1 Decoloración del ab74 con Lac, LA y LPT...................................... 43

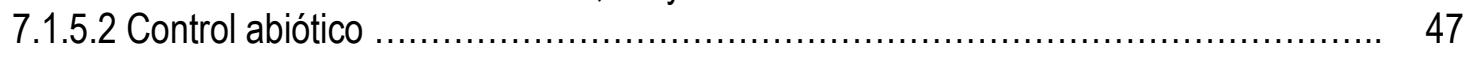

7.1.5.3 Contribución de lacasas presentes en LA y LPT para la decoloración del ab74 ...... 47

7.1.5.4 Parámetros cinéticos de la decoloración del ab74 por Lac, LA y LPT.................. 49

7.1.5.5 Decoloración con Carbón Activado ............................................. 51

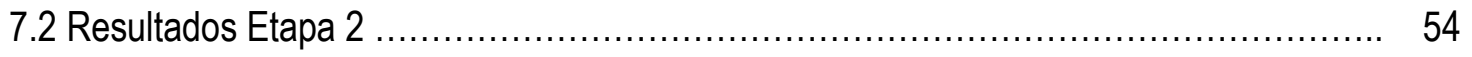

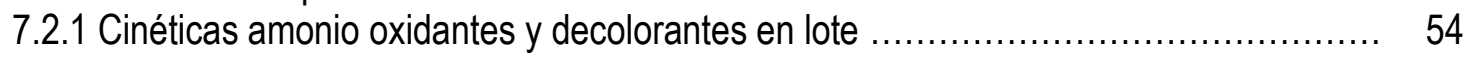

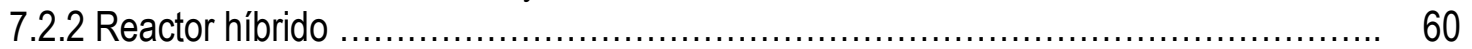

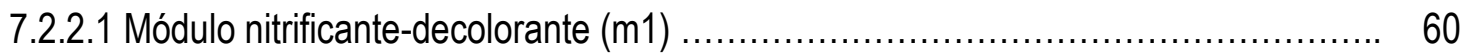

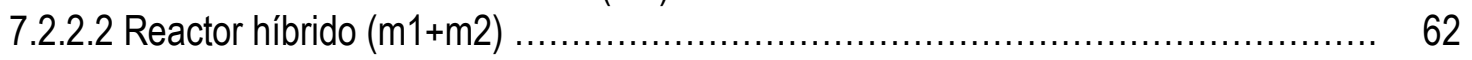

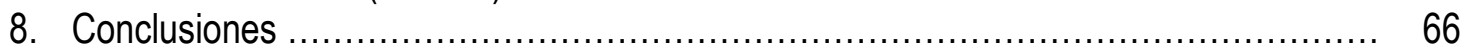

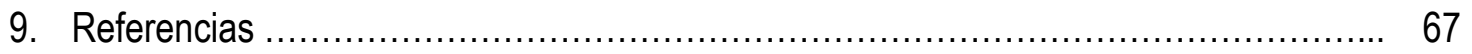




\section{Resumen}

En las últimas décadas se ha incrementado el uso de diversos compuestos en la industria química y textil, entre ellos colorantes, altas cargas de DQO, así como nitrógeno amoniacal, entre otros. Asimismo, la generación y descarga de efluentes industriales textiles a los ecosistemas acuáticos y terrestres (sin la debida supervisión de autoridades ambientales) ha incrementado de manera proporcional. Este acto ha tenido como consecuencia la perturbación de dichos ecosistemas, contaminando ríos, presas, lagos, etc., causando efectos negativos en los organismos acuáticos, limitando los procesos naturales como la fotosíntesis. Al mismo tiempo ha sido motivo de daños a la salud humana de los pueblos aledaños a estos ecosistemas. Así como también ha sido razón de la limitación del recurso hídrico. Simultáneamente, la generación e innovación de tecnologías para el tratamiento de estos efluentes antes de ser descargados, se ha incrementado últimamente, sin embargo, la mayoría de estas tecnologías debido a su ingeniería demandan costos y espacios de operación considerables por lo que su implementación a nivel industrial o piloto es escasa. En recientes estudios, se han propuesto sistemas de tratamiento de más de un contaminante a la vez en sistemas independientes o secuenciales. Sin embargo, recientemente la propuesta de sistemas híbridos se ha pensado como una tecnología que podría mejorar los costos y espacios de operación, así como el tratamiento simultáneo de diversos contaminantes.

Por lo cual, el objetivo de este estudio fue desarrollar una estrategia para tratar simultáneamente dos contaminantes, amonio y el colorante azul ácido 74 (ab74), mediante diversos tratamientos: Lacasa comercial (Lac), lodos activados (LA), lodos pre tratados (LPT), carbón activado (CA), y lodos activados soportados en carbón activado (CA+LA). Estos tratamientos fueron evaluados en sistemas en lote para obtener sus parámetros cinéticos enzimáticos y metabólicos, para determinar el tratamiento con mejores características de operación para posteriormente implementar dicho tratamiento en un reactor híbrido de flujo ascendente para la oxidación y adsorción simultánea de amonio y el colorante azul ácido 74 en una misma unidad experimental bajo condiciones aerobiasanaerobias. Esto en una fase nitrificante mediante lodos activados y carbón activado en soportes de poliuretano, y en una segunda fase anaerobia bajo condiciones desnitrificantes con lodos activados soportados en espuma de poliuretano sin carbón activado. Se han investigado adsorbentes amigables al ambiente de bajo costo como alternativas a costosos tratamientos para la eliminación de colorantes. Asimismo, se han encontrado lacasas bacterianas en lodos activados, sin embargo, su contribución aún no ha sido cuantificada. El zimograma y la oxidación de 2,2'-azinobis-(3-etilbenzotiazolin-6sulfonato) confirmaron la presencia de lacasas en LA y LPT. Ensayos de inhibición evidenciaron la contribución de lacasas para decolorar el ab74; decolorando $23.2 \%$ y $19.1 \%$ con LA y LPT, respectivamente. La decoloración del ab74 más efectiva se observó en $C A+L A$ comparada con $L A$ y LPT. CA+LA mostró un interesante efecto sinérgico en la decoloración del ab74; con una eficiencia de $76.6 \pm 11.0 \%$ y una tasa específica de decoloración de $5.9 \pm 0.4 \mathrm{mg}$ ab74 $/ \mathrm{h}$ gtratamiento. Posteriormente, estos mismos experimentos fueron evaluados en presencia de $100 \mathrm{mg} / \mathrm{L}$ de $\mathrm{N}_{-} \mathrm{NH}_{4}{ }^{+}$en el cual se observó que para el tratamiento de $\mathrm{CA}+\mathrm{LA}$ se obtuvieron las mejores eficiencias de decoloración y 


\section{$\Delta a 140$ \\ UNIVERSIDAD AUTÓNOMA METROPOLITANA}

oxidación de amonio de $88.61 \pm 0.1 \%$ y $72.62 \pm 0.11 \%$. Además, como resultado novedoso, LA fue capaz de regenerar in situ la capacidad de adsorción del carbón activado; esos resultados son prometedores para ser aplicados en el tratamiento de aguas residuales en un sistema hibrido propuesto.

En una segunda etapa del presente estudio se implementó el tratamiento de CA+LA en el reactor híbrido evaluando una concentración de amonio de $100 \mathrm{mg} \mathrm{N}-\mathrm{NH}_{4}{ }^{+} / \mathrm{L}$ en presencia de 30,60 y $90 \mathrm{mg}$ ab74/L. El sistema operó de manera eficiente a una concentración de $30 \mathrm{mg}$ ab74/L con una eficiencia de consumo de amonio de $99.2 \pm 0.5 \%$, una eficiencia consumo de nitrito $\left(\mathrm{E}_{\mathrm{NO} 2}{ }^{-2} \%\right)$ de $63.5 \pm 26.8 \%$ y una eficiencia de consumo de nitrato $\left(\mathrm{E}_{\mathrm{NO} 3} \%\right)$ de $54.8 \pm 28.6 \%$. Debido al eficiente consumo de los productos de la oxidación del amonio y a la eficiencia de consumo de amonio a la salida del reactor híbrido, los resultados sugieren que el proceso nitrificante se acopló al proceso desnitrificante en una misma unidad experimental y se apreció la oxidación simultánea del ab74 con una eficiencia de 66.6 $\pm 5.6 \%$ y una eficiencia de consumo de COT de $49.0 \pm 8.8$.

Los resultados mostraron que tratamiento $C A+L A$ implementado en el sistema híbrido tuvo la capacidad de oxidar simultáneamente de amonio y ab74 en una misma unidad experimental, y de manera in situ el CA pudo regenerarse al mismo tiempo mediante LA, lo que sugiere ser una tecnología atractiva para el tratamiento de aguas residuales de estas características, mejorando las condiciones y costos de operación. 


\section{Abstract}

In the last decades, the use of many chemistry compounds had been increased in the chemistry and textile industry, as dyes, high loads of COD, nitrogen of ammonium, etc. At the same time the generation and discharge of textile industrial effluents to the aquatic and terrestrial ecosystems have increased in the same way. This act has as result, the perturbation of those ecosystems that affect rivers, water dams, lakes, etc., and it is the reason of negative effects on aquatic organisms where the natural processes are affected, as the photosynthesis. At the same time, this act has been the cause of damages on the human health of the people who live close to these ecosystems as well as the limitation of the hydric resource. Simultaneously, the generation and innovation of technologies for the treatment of this kind of effluents before to discharge them to the ecosystems have been increased recently, however, the most of these technologies because of their engineering have costs and considerable operation spaces, and that is the reason because their implementation at industrial or pilot level have been limited. In recent studies, systems of treatment have been proposed to remove more than one pollutant in independent or sequential systems. However, the propose of hybrid systems have been thought as a technology that could improve the costs and spaces of operation and the removal of many pollutants simultaneously.

The aim of this study was, develop a strategy to treat simultaneously two pollutants, ammonium and acid blue 74 dye, through some treatments: Commercial laccase (Lac), activated sludge (LA), pre treated sludge (LPT), activated carbon (CA) and activated sludge supported into activated carbon $(C A+L A)$. These treatments were evaluated in batch to obtain the kinetic and metabolic parameters. After this, the best treatment was selected to implement it in the hybrid reactor of ascendant flow for the simultaneous oxidation of ammonium and acid blue 74 dye in the same experimental unit under aerobic-anaerobic conditions. This was in a nitrifying phase by activated sludge and activated carbon into polyurethane foam. The second phase was operated under denitrifying conditions by activated sludge supported into polyurethane foam without activated carbon. Some ecofriendly adsorbents have been reported with low costs as alternatives to high cost treatments for the removal of dyes. At the same time, bacterial laccases have been reported into activated sludge, however their contribution had not been quantified. The zymography and the oxidation of 2,2'-Azino-bis(3-ethylbenzothiazoline-6sulfonic acid) confirmed the presence of laccases into LA and LPT. Inhibition studies evidenced the contribution of laccases to discolor the acid blue 74 dye, the efficiencies of discoloration were $23.2 \%$ and $19.09 \%$ for LA and LPT respectively. The best discoloration of ab74 was observed with the treatment of $C A+L A$ in contrast with LA and LPT. CA+LA showed an interesting synergic effect in the discoloration of ab74, with a efficiency of $76.6 \pm 11 \%$ and $5.9 \pm 0.4 \mathrm{mg}$ ab74/h g treatment. The same experiments were done in presence of $\mathrm{N}^{-\mathrm{NH}_{4}}{ }^{+}$and it was observed the same behavior in the $\mathrm{CA}+\mathrm{LA}$ treatment with the best efficiencies of discoloration and ammonium oxidation of $88.61 \pm 0.1 \%$ and $72.62 \pm 0.1 \%$, respectively. Also, as a new result, LA showed the capacity to regenerate in situ the capacity of adsorption of CA, these results are promising to be applied in the waste water treatment into a hybrid system. 
101: 40

In a second stage of this study, it was implemented the CA+LA treatment into the hybrid reactor evaluating $100 \mathrm{mg} \mathrm{N}-\mathrm{NH}_{4}+/ \mathrm{L}$ in presence of 30,60 and $90 \mathrm{mg}$ ab74/L. The system was operated with high efficiency until $30 \mathrm{mg}$ ab74/L, with a efficiency of ammonium oxidation of $99.2 \pm 0.5 \%$ and the yield of products in the effluent were $Y_{\mathrm{NO} 2}$ of $0.1 \pm 0.1$ and $Y_{\mathrm{NO} 3}$ of $0.1 \pm 0.1$. Because of the low yield of products and the high efficiency of ammonium oxidation, the results suggested that the nitrifying process was linked to the denitrifying process in the same experimental unit and simultaneously it was observed the oxidation of ab74 with efficiency of $66.6 \pm 5.6 \%$ and $49.0 \pm 8.8 \%$ for COT.

The results showed that the $C A+L A$ treatment operated in the hybrid system had the capacity to oxide simultaneously ammonium and ab74 in the same experimental unit, and LA showed the capacity to regenerate in situ the adsorption capacity of $C A$. This suggests that $C A+L A$ is a novel technology for the treatment of waste water with these characteristics that improve the conditions and operation costs. 
1. Introducción

\subsection{Panorama actual}

La disposición del recurso hídrico ha sido limitada por la contaminación de mantos acuíferos. La escasa aplicación y regulación de las normas en México ha contribuido al incremento de la contaminación de los cuerpos receptores por las descargas de los efluentes de industrias textiles, farmacéuticas, químicas, alimentaria, etc. En los efluentes de la industria textil existe una gama de contaminantes como alquilfenoles, ftalatos, clorados y bromados, colorantes azoicos, compuestos organoestánicos, perfluorados, clorobencenos, disolventes clorados, clorofenoles, etc. (Greenpeace, 2012), que se han caracterizado como agentes carcinógenos, causantes de alteraciones en el sistema endócrino e inmunológico, entre otros (Castillo y col., 1998). También contienen una gran variedad de colorantes que necesitan ser tratados de manera eficiente antes de ser descargados a ríos y lagos y cumplan con los límites permisibles de descarga estipulados en la NOM-065-ECOL, que establece los límites máximos permisibles de contaminantes en las descargas de aguas residuales a cuerpos receptores provenientes de las industrias de pigmentos y colorantes, para evitar riesgos a la salud y la destrucción de la flora y fauna de estos ecosistemas (Aksu, 2005).

Actualmente, una de las zonas más contaminadas del país es la zona industrial del corredor LermaToluca en el estado de México. Para disminuir esta problemática, existen plantas de tratamiento de aguas residuales (PTAR) que intentan eliminar estos contaminantes y así tener un menor impacto sobre los cuerpos acuíferos sobre los que son descargados estos efluentes. Ya que en este tipo de efluentes no tratados se han encontrado concentraciones de colorantes entre 10-50 mg/L, concentración a la cual la penetración de la luz a los ecosistemas acuáticos se reduce, disminuyendo la vida de los organismos aeróbicos acuáticos favoreciendo las condiciones anaeróbicas (Chung and Stevens 1993; Banat et al., 1996; Zhang et al., 2012).

En la producción de colorantes se estima que su descarga al medio ambiente está entre 1-2 \%, mientras que en el uso de colorantes en industrias textiles se desperdicia de 1-10\% de éstos (Forgacs y col., 2004).

Se han implementado diversas técnicas de degradación de diferentes tipos de colorantes mediante métodos físicos (adsorción, coagulación-floculación, filtración por membrana e intercambio iónico) (Nigam P. y col., 2000; Thomas y col., 2006); métodos químicos (electroquímico, oxidación, fotoquímico y coagulación) (Kositzi y col., 2007), y métodos biológicos (bioabsorción, biodegradación y enzimático) (Cristóvão y col., 2008; Mendez-Hernandez, 2010). Desde el punto de vista biotecnológico, los procesos redox pueden ser considerados una alternativa para la biodegradación de estos colorantes en compuestos inocuos al ambiente. Frecuentemente, en estos procesos de biodegradación se han utilizado enzimas comerciales para el tratamiento biológico, como la enzima "Lacasa" (Cristóvão y col., 2009), así como otras enzimas extracelulares que generalmente se producen por hongos y plantas. Sin embargo, la implementación de tratamientos enzimáticos debe 


\section{Anil 40}

considerar cuellos de botella en su operación como son la saturación del sitio activo de la enzima utilizada en función de las cargas o concentraciones de los compuestos presentes en el efluente a tratar, así como las condiciones de la enzima o extracto enzimático, es decir si se opera de forma libre o inmovilizada, ya que en función de las condiciones, los reactores o tratamientos enzimáticos podrían requerir del recambio constante de las enzimas, debido a fenómenos de saturación del sitio activo, desactivación de la enzima, desnaturalización o limitaciones difusionales (Sadana, 1999). Lo cual tiene como consecuencia o desventaja que dichos tratamientos limiten su operación e incrementen sus costos (Olivares y col., 1997).

Por otra parte, debido a la relevancia de la disposición del recurso hídrico, así como el mantenimiento de los ecosistemas, es de fundamental importancia considerar que, de manera natural, los colorantes presentan diversas características en su estructura química que les confieren resistencia a factores como luz, agua, agentes oxidantes, ataque microbiano, etc. (Wesenberg y col., 2003); por lo que su tratamiento no es el mismo para cada tipo de colorante, y al mismo tiempo, los efluentes de tipo textil incluirán otro tipo de compuestos como sales fijadoras de estos que les dan mayor complejidad a este tipo de efluentes. Por lo cual, las investigaciones recientes han sugerido un número de enfoques biotecnológicos que pueden ser de interés potencial para combatir esta fuente de contaminación de manera ecoeficiente, la cual incluye el uso de bacterias y/o hongos en combinación de procesos fisicoquímicos (Willmott y col., 1998; McMullan, 2001; Robison y col., 2001a).

Debido a lo anterior, se ha propuesto el uso de lodos activados como una alternativa durante el tratamiento biológico, donde intervienen varios microorganismos con distintos tipos de enzimas, como la lacasa, para la decoloración de estos contaminantes (McMullan y col., 2001; Cervantes, 2008), acoplado a un tratamiento simultáneo con carbón activado para mejorar el proceso de decoloración y eliminación de nitrógeno en una misma unidad experimental.

\subsection{Procesos biológicos en el tratamiento de colorantes}

Dentro de los procesos biológicos para el tratamiento de efluentes textiles se han encontrado una amplia variedad de microorganismos incluyendo bacterias, hongos y levaduras capaces de oxidar distintos colorantes (Banat y col., 1996). Los tratamientos biológicos han sido recomendados como adecuados para la eliminación de gran cantidad de colorantes, donde la concentración del colorante, temperatura y $\mathrm{pH}$ son factores que pueden afectar el proceso de decoloración (Gutiérrez y Colín, 2012).

Existen tratamientos biológicos anaerobios y aerobios, los cuales han sido empleados en función del tipo de colorante a tratar. Los tratamientos bajo condiciones anaerobias son usados frecuentemente para la biodegradación de colorantes tipo azo, debido a que bajo estas condiciones los grupos azo son reducidos a aminas aromáticas para posteriormente ser oxidadas de manera aerobia (Field y col., 1995). Los principales grupos microbianos involucrados en la reducción de este tipo de colorantes bajo 
condiciones anaerobias incluyen a las bacterias fermentativas, las arqueobacterias metanogénicas y a las bacterias sulfato reductoras (Cervantes, 2008).

Por su parte, los procesos biológicos bajo condiciones aerobias, han sido reportados como procesos con capacidad para decolorar. Algunos de los compuestos decolorados bajo condiciones aerobias son los colorantes ácidos (rojo ácido 183, naranja ácido 51) y colorantes reactivos (azul reactivo 4) (ArslanAlaton, 2008). Bajo estas condiciones pueden participar metabólicamente ciertos grupos bacterianos o cultivos axénicos como cepas de Pseudomonas (Zimmermann y col., 1984), o como Bacillus sp. la cual se ha reportado como una cepa con capacidad decolorante del colorante azul ácido y al mismo tiempo desnitrificante (Brycki y col., 2000). En la tabla 1 se resumen ejemplos de microorganismos con capacidad decolorante.

Tabla 1. Microorganismos con actividad decolorante

\begin{tabular}{|l|l|l|l|}
\hline Microorganismo & Colorante & Condiciones & Referencia \\
\hline Paenibacillus larvae & Azul ácido $74(100 \mathrm{mg} / \mathrm{L})$ & Anaerobias & Ramya y col. $(2008)$ \\
\hline Pseudomonas GM3 & Azul ácido $74(100 \mathrm{mg} / \mathrm{L})$ & Aerobias & Yu y col. $(2001)$ \\
\hline Bacillus subtillis & Azul ácido $74(223 \mathrm{mg} / \mathrm{L})$ & Anaerobias & Cho y col. $(2011)$ \\
\hline Aeromonas hydrophila & Azul ácido $74(100 \mathrm{mg} / \mathrm{L})$ & Anaerobias & Chen y col. $(2003)$ \\
\hline Bacillus sp. & Azul ácido $74(300 \mathrm{mg} / \mathrm{L})$ & Anaerobias & Brycki y col. $(2000)$ \\
\hline Pseudomonas cepacia & Naranja ácido $12(20 \mathrm{mg} / \mathrm{L})$ & Aerobias & Ogawa y col. $(1986)$ \\
\hline $\begin{array}{l}\text { Paenibacillus polymyxa } \\
\text { Micrococcus luteus } \\
\text { Micrococcus sp. }\end{array}$ & Violeta reactivo $(100 \mathrm{mg} / \mathrm{L})$ & Anaerobias & Moosvi y col. $(2007)$ \\
\hline Bacillus lentus B/377 & Rojo reactivo $(1200 \mathrm{mg} / \mathrm{L}, 1500 \mathrm{mg} / \mathrm{L})$ & Anaerobias & Oturkar y col. $(2011)$ \\
\hline $\begin{array}{l}\text { Pseudomonas sp. SUK1* } \\
\begin{array}{l}\text { Pseudomonas sp. LBC2* } \\
\text { Pseudomonas sp. LBC3 }\end{array}\end{array}$ & Naranja Reactivo $(100 \mathrm{mg} / \mathrm{L})$ & Anaerobias & Jadhav y col. $(2010)$ \\
\hline
\end{tabular}

A través de la vía biológica, Fischer y col. (2005) propusieron el mecanismo de degradación del colorante azul ácido 74 en presencia de un consorcio bacteriano anaerobio como se observa en la siguiente figura (Fig. 1).

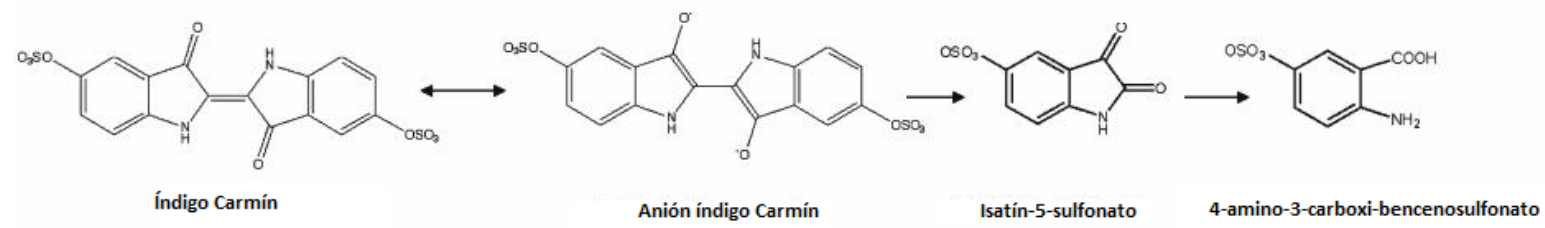

Figura 1. Mecanismo propuesto de la ruta de degradación de del azul ácido 74 mediante bacterias (Fischer y col., 2005)

Al mismo tiempo, dentro de los tratamientos biológicos enzimáticos para la eliminación de colorantes también se propuso el mecanismo de reacción de la degradación del azul ácido 74 mediante el uso de la enzima lacasa, en el cual Campos y col. (2001) utilizaron a la enzima lacasa proveniente de Trametes hirsuta y Sclerotium Rolfsii, obteniendo la ruta que a continuación se presenta (Fig. 2). 
<smiles>O=C1C(=C2Nc3ccccc3C2=O)Nc2ccccc21</smiles><smiles>C[Br+]C</smiles><smiles>O=C1C(=C2[NH2+]c3ccccc3C2=O)Nc2ccccc21</smiles>

Índigo<smiles>O=C1C(C2=Nc3ccccc3C2=O)=Nc2ccccc21</smiles><smiles>O=C1Nc2ccccc2C1=O</smiles><smiles>CC</smiles><smiles>C[TeH]</smiles><smiles>Nc1ccccc1C(=O)C(=O)O</smiles>
$\mathrm{NH}_{2}$

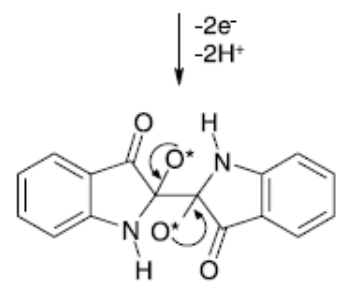

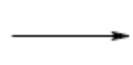<smiles>O=C1c2ccccc2NNC1(O)C1(O)Nc2ccccc2C1=O</smiles>

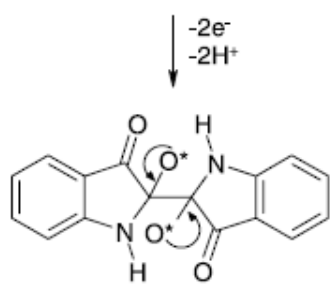<smiles>O=C1C(=C2[N-]c3ccccc3C2=O)[N]c2ccccc21</smiles><smiles>Nc1ccccc1C(=O)O</smiles>

Ácido antranílico

Figura 2. Mecanismo propuesto de la ruta de degradación de del azul ácido 74 mediante lacasa (Campos y col., 2001)

Por otra parte, se debe considerar que hay otro tipo de factores que pueden modificar la eficiencia del proceso decolorante, como, el tipo de sistema, es decir, configuración del reactor (continuo o en lote), condiciones de cultivo (aireación, $\mathrm{pH}$, temperatura, tiempo de reacción, entre otros). En la tabla 2 se resume una comparación de biorreactores para la decoloración del azul ácido 74. 
Tabla 2. Decoloración del ab74 en distintas configuraciones

\begin{tabular}{|c|c|c|c|c|c|c|}
\hline Biorreactor & ab74 & Tiempo (h) & Biomasa & Microorganismos & $\begin{array}{c}\mathbf{E} \% \\
\text { decoloración }\end{array}$ & Referencia \\
\hline Lote, aerobio & $20 \mathrm{mg} / \mathrm{L}$ & $4 d$ & $\begin{array}{c}2.4 \mathrm{mg} \text { peso } \\
\text { seco/L }\end{array}$ & $\begin{array}{c}\text { Chrysosporium } \\
\text { ph, Philinus } \\
\text { gilvus }\end{array}$ & 100 & Balan y col. (2001) \\
\hline $\begin{array}{l}\text { CSTR aerobio- } \\
\text { reactor de } \\
\text { biopelícula }\end{array}$ & $0.29 \mathrm{~g} / \mathrm{L} \mathrm{d}$ & $4 d$ & NR & Lodos activados & 75 & Khelifi y col. (2008) \\
\hline CSTR aerobio & $0.92 \mathrm{~g} / \mathrm{L} \mathrm{d}$ & $4 \mathrm{~d}$ & NR & Lodos activados & 80 & Khelifi y col. (2008) \\
\hline $\begin{array}{c}\text { Lote, } \\
\text { anaerobio }\end{array}$ & $100 \mathrm{mg} / \mathrm{L}$ & $5 d$ & $6 \mathrm{~g} \mathrm{SSV/L}$ & Lodos primarios & 85 & Manu y col. (2003) \\
\hline
\end{tabular}

${ }^{*}$ CSTR: Reactor continuo de tanque agitado, NR: No reportado

\subsubsection{Lodos activados}

Los lodos activados son una mezcla completa de microorganismos que se utilizan principalmente como tratamiento secundario en las plantas de tratamiento de aguas residuales, su nombre proviene de microorganismos activados debido a la presencia de materia orgánica y que tienen la capacidad de estabilizar un residuo en medio aerobio. Frecuentemente, los lodos activados son operados en reactores aerobios, los cuales tienen una generación de nuevas células que mezcladas con las células antiguas tienen que ser sedimentadas, separadas y/o recirculadas al sistema (Méndez y col., 2004). La composición de los lodos activados puede tener una amplia diversidad microbiana y puede variar en función del origen del inóculo, así como de los compuestos a los que se encuentre expuesto. Desde hace algunas décadas se ha tratado de caracterizar la composición microbiana los lodos activados. Van Gils (1965) reportó la diversidad bacteriana presente en lodos activados dentro de los cuales se encontraron alrededor de 100 cepas con distintas características fisiológicas. La flora microbiana que predominó fue de tipo gram-negativo del género Alcalligenes, Flavobacterium y Achromobacter. Sin embargo, en estudios más recientes, en plantas de tratamiento de aguas residuales se ha reportado la presencia de bacterias, hongos, protozoarios y nematodos (Hammaini y col., 2007). Y debido a esta diversidad microbiana, los lodos activados han sido utilizados para la eliminación de nitrógeno, carbono, fósforo y azufre mediante procesos biológicos del ciclo del nitrógeno, como lo son la nitrificación y la desnitrificación (Juretschko y col., 2002; De la Torre y col., 2013; Wang y col., 2009).

\subsubsection{Nitrificación}

La nitrificación es la formación biológica de nitrato mediante el ciclo biogeoquímico del nitrógeno, a partir de la oxidación de amonio bajo condiciones aerobias (Prosser, 1989). La generación de amonio se produce de manera natural en el suelo debido a la descomposición de compuestos orgánicos de nitrógeno tales como aminoácidos y nucleótidos (Madigan y col. 2005). A pH neutro el amonio se encuentra en su forma radical $\left(\mathrm{NH}_{4}{ }^{+}\right)$, y es en esa forma en la que se encuentra presente en la mayoría 


\section{$\Delta a 140$ \\ UNIVERSIDAD AUTÓNOMA METROPOLITANA}

de los sedimentos anóxicos. La problemática ambiental por amonio ha surgido debido a la oxidación de éste hasta nitrato, en la cual su forma de nitrato $\left(\mathrm{NO}_{3}^{-}\right)$presenta un alto nivel de solubilidad, el cual se lixivia fácilmente en el suelo, contaminando y acidificando las aguas subterráneas, lo cual conduce al incremento en la movilidad de metales tóxicos, limitando el recurso hídrico para la población (Prosser, 1989). Sin embargo, los microorganismos oxidantes de amonio al mismo tiempo pueden oxidar metano y contaminantes orgánicos dándole un mejor potencial a este proceso en la biorremediación.

La nitrificación implica la oxidación de amonio en dos etapas, la oxidación de amonio a nitrito y la oxidación de nitrito a nitrato como producto final de este proceso aerobio (Fig. 3). Estas reacciones son catalizadas por microorganismos ampliamente distribuidos en suelos y agua, denominados como amonio-oxidantes (AOB, por sus siglas en inglés) y nitrito-oxidantes (NOB, por sus siglas en inglés) (Bock y col., 1991). Los microorganismos nitrificantes son quimiolitotróficos, ya que emplean compuestos inorgánicos como fuente de energía. La principal fuente de carbono inorgánica para la ruta del anabolismo es el $\mathrm{CO}_{2}$, de esta manera también se encuentran clasificados como autotróficos. La oxidación del amonio y/o nitrito puede ser utilizada para la generación de energía (ATP) y/o biosíntesis (Fig. 4). Sin embargo, también se ha reportado la capacidad de microorganismos amonio oxidantes de metabolizar compuestos orgánicos como fuente de carbono (Prosser, 1990).

En el tratamiento de aguas residuales la nitrificación es un proceso aerobio que comúnmente se utiliza como primera etapa en los sistemas biológicos para el tratamiento del nitrógeno.

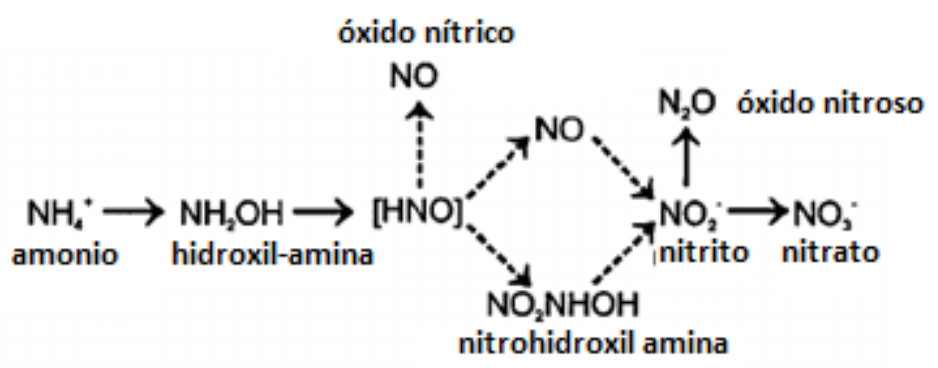

Figura 3. Ruta metabólica del proceso nitrificante (Hooper, 1984; Firestone y Davidson 1989)

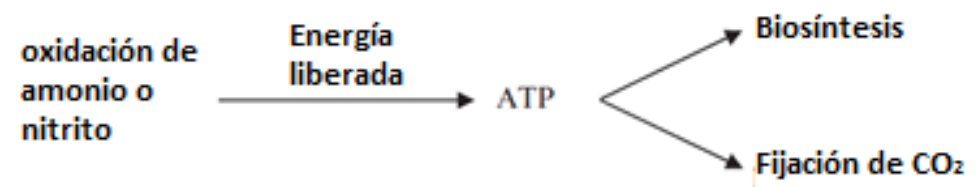

Figura 4. Utilización de la energía liberada en la amonio o nitrito oxidación. 


\section{$\Delta a 140$

$\mathrm{NH}_{4}^{+}+0.5 \mathrm{O}_{2} \rightarrow \mathrm{NH}_{2} \mathrm{OH}+\mathrm{H}^{+}$

$\mathrm{NH}_{2} \mathrm{OH}+\mathrm{O}_{2} \rightarrow \mathrm{NO}_{2}^{-}+\mathrm{H}^{+}+\mathrm{H}_{2} \mathrm{O}$

$\mathrm{NO}_{2}{ }^{-}+0.5 \mathrm{O}_{2} \rightarrow \mathrm{NO}_{3}^{-}$
Ec. (1)

Algunos géneros bacterianos nitrificantes reportados en la literatura son Nitrosomonas, Nitrosolobus, Nitrosovibrio, Nitrosococcus, y Nitrospira (Watson y col., 1989). Por su parte los géneros microbianos nitrito-oxidantes reportadas por Teske y col. (1994) son los géneros Nitrobacter, Nitrococcus Nitrospira y Nitrospina. Wagner y col. (1996) reportaron microrganismos nitrificantes aislados de aguas residuales de una planta de tratamiento en las que se incluyen estos mismos géneros.

\subsection{Factores que afectan a la nitrificación}

Algunos microorganismos nitrificantes han mostrado ser susceptibles a distintos factores ambientales como temperatura, $\mathrm{pH}$, oxígeno disuelto y/o compuestos orgánicos e inorgánicos. Algunos metales pesados como níquel y cobre han sido reportados como represores del proceso amonio-oxidante para el género Nitrosomonas europae (Lee y col., 1997). Paolo y col. (1999) reportaron el efecto de metales pesados en las tasas de consumo de amonio por lodos activados observando el efecto inhibitorio en el siguiente orden: $\mathrm{Cd}>\mathrm{Cu}>\mathrm{Zn}$ y $\mathrm{Pb}>\mathrm{Cr}$. Por su parte, la concentración de oxígeno disuelto ha sido otro factor operacional que puede afectar negativamente la nitrificación. Stenstrom y Poduska (1980) reportaron que el rango favorable en la concentración de oxígeno es $0.3-4.0 \mathrm{mg} \mathrm{O}_{2} / \mathrm{L}$. En algunos trabajos, se sugieren concentraciones basadas en la relación carbono/nitrógeno $(\mathrm{C} / \mathrm{N})$ en el cultivo. Daniel y col. (2009) en un reactor de lecho empacado evaluaron concentraciones de amonio entre 125 y $150 \mathrm{mg} / \mathrm{L}$ de con una relación $\mathrm{C} / \mathrm{N}$ de 3 y una concentración de oxígeno disuelto entre 2.0 y $2.8 \mathrm{mg} / \mathrm{L}$ alcanzando eficiencias de oxidación del amonio cercanas al 99 \% y al mismo tiempo observaron una predominancia de Nitrosomonas spp. mientras que Nitrobacter spp. no fue detectada. Nitrosomonas spp. ha sido también reportado como un género en el cual se favorece su abundancia a relaciones $\mathrm{C} / \mathrm{N}$ mayores a 3.6 y cuando las concentraciones de oxígeno disuelto se encuentran entre 3.5 y 4.5 $\mathrm{mg} / \mathrm{L}$ (Li y col. 2006).

Por otra parte, los compuestos orgánicos también han sido frecuentemente reportados como compuestos que pueden disminuir la actividad nitrificante o bien el crecimiento microbiano de los géneros nitrificantes mencionados anteriormente. La composición de las aguas residuales con compuestos como cianuros, compuestos halogenados, mercaptanos, guanidinas y tiourea; hacen que el proceso impida el desarrollo de microorganismos nitrificantes, incluso algunos aminoácidos se han reportado con un efecto de inhibición en el crecimiento de Nitrosomonas y Nitrobacter (Jensen, 1950). 


\section{$\Delta a 140$

Los colorantes de tipo orgánico e inorgánico han mostrado tener un efecto sobre los procesos respiratorios como la nitrificación y la desnitrificación. Li y Bishop (2002) evaluaron el efecto de diferentes concentraciones del colorante naranja ácido 7 sobre el proceso nitrificante mediante lodos activados bajo condiciones aerobias y observaron que a concentraciones de $1 \mathrm{mg} / \mathrm{L}$ no hubo un efecto negativo en la nitrificación, sin embargo, a concentraciones de $15 \mathrm{mg} / \mathrm{L}$ y $25 \mathrm{mg} / \mathrm{L}$ notaron una disminución significativa en la tasa de consumo de amonio, así como en el consumo de DQO en una magnitud entre 10-20\%. Topac y col. (2009) observaron la disminución del $20 \%$ del proceso nitrificante en suelos en presencia del colorante negro reactivo 5 (BR5) a concentraciones de $20 \mathrm{mg}$ BR5/Kg suelo seco y del $28 \%$ en presencia del ácido sulfanílico (SA) a $8 \mathrm{mg}$ SA/Kg de suelo seco. Sin embargo, no todos los colorantes tienen un efecto negativo sobre los procesos respiratorios, el colorante azul ácido fue reportado por González-Martínez y col. (2010) como un sustrato que mejora la eficiencia amonio-oxidante incrementando la eficiencia del $73 \%$ en ausencia del colorante a $90 \%$ con la adición de $50 \mathrm{mg} / \mathrm{L}$ del colorante en el cual las concentraciones de biomasa utilizada no fueron reportadas.

\subsubsection{Desnitrificación}

Desde los años 80 's se ha referido a la desnitrificación como un proceso respiratorio en el cual se lleva a cabo la reducción desasimilatoria de nitrato $\left(\mathrm{NO}_{3}^{-}\right)$o sus intermediarios (por ejemplo, nitrito $\left(\mathrm{NO}_{2}^{-}\right)$, óxido nítrico ( $\mathrm{NO}$ ) y óxido nitroso $\left(\mathrm{N}_{2} \mathrm{O}\right)$ ), los cuales asimismo se reducen hasta nitrógeno molecular $\left(\mathrm{N}_{2}\right)$, el cual es el producto más reducido de todo el proceso (Fig. 5). En esta ruta, los óxidos de nitrógeno pueden actuar como aceptor final de electrones en ausencia de oxígeno. Sin embargo, la fuente reductora también puede ser de tipo orgánico. Por un tiempo se asumió que la desnitrificación era un proceso exclusivo de bacterias y al mismo tiempo un proceso anaerobio debido a la expresión anóxica de los genes que codifican para las proteínas con actividad enzimática desnitrificante (Knowles, 1982; Ferguson, 1994). Sin embargo, Davies y col. (1989) evidenciaron la desnitrificación aerobia reduciendo $87 \%$ de $\mathrm{NO}_{3}$-a $\mathrm{N}_{2}$ utilizando a Paracoccus denitrificans y Peudomonas aeruginosa. De la Torre y col. (2013) también reportaron la desnitrificación mediante un proceso secuencial nitrificación-desnitrificación en un reactor de lotes secuenciados en presencia de oxígeno residual proveniente del proceso nitrificante, observando el $100 \%$ de eficiencia de consumo de nitrato en proceso acoplado nitrificante-desnitrificante. Microorganismos como Thiosphaera pantotropha, Alcaligenis faecalis, Pseudomonas putida, han sido reportados con capacidad metabólica para desnitrificar en presencia de oxígeno residual (Kim y col., 2005; Miyahara y col., 2010). La desnitrificación sigue una ruta metabólica que involucra la actividad de ciertas enzimas, la ruta desnitrificante comienza a partir de la reducción de nitrato a nitrito en la que interviene la actividad de la enzima nitrato reductasa; en la siguiente etapa, se realiza la reducción de nitrito a óxido nítrico mediante la enzima nitrito reductasa que posteriormente se reduce a óxido nitroso para ser reducido a nitrógeno molecular mediante la acción de la enzima óxido nitroso reductasa. Durante el estudio del proceso desnitrificante se han encontrado distintos microorganismos con capacidad de reducir el nitrato hasta nitrógeno molecular, tal es el caso de Alcaligenes, Paracoccus, Pseudomonas, 


\section{$\Delta a 140$ \\ UNIVERSIDAD AUTONOMA METROPOLITANA}

Thiobacillus, Thiospaera, Diaphorobacter, Nitrosomonas, etc. (Anshuman y col., 2007; Cervantes y col., 2000; Shrestha y col., 2002).

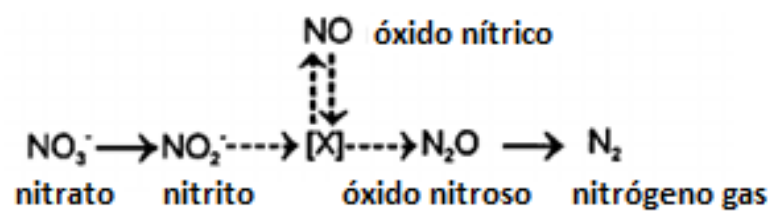

Figura 5. Ruta metabólica del proceso desnitrificante (Hooper, 1984; Firestone y Davidson 1989)

Por otra parte, la desnitrificación puede involucrar moléculas reductoras del nitrato, es decir moléculas reductoras de tipo orgánico o inorgánico, es decir un donador de electrones de tipo orgánico 0 inorgánico, cuando el donador de electrones es un compuesto orgánico (acetato, metanol, glucosa, $p$ cresol, fenol, lactato, etc.) el proceso se hace llamar desnitrificación heterotrófica (Third y col. 2003) y cuando la desnitrificación ocurre en presencia de donadores de electrones de tipo inorgánico $\left(\mathrm{S}_{2} \mathrm{O}_{3}{ }^{2-}\right.$, $\mathrm{S}^{2-;} \mathrm{S}^{0}, \mathrm{~S}_{4} \mathrm{O}_{6}{ }^{2-;} ; \mathrm{SO}_{3}{ }^{2-}, \mathrm{H}_{2}$ ) la desnitrificación se denomina autotrófica (Koenig y col., 2005; Fernández y col., 2006).

\subsubsection{Factores que afectan la desnitrificación}

La presencia y concentración de algunos compuestos y condiciones de cultivo, pueden modificar de manera positiva o negativa las variables de respuesta de los procesos metabólicos. A través de factores como la concentración de oxígeno, fuente de carbono, presencia de intermediarios, $\mathrm{pH}$ y temperatura, el proceso desnitrificante se puede ver afectado positiva o negativamente. La desnitrificación es un proceso respiratorio anaerobio de tipo anóxico mediante microorganismos como Alcaligenes, Paracoccus, Pseudomonas, Thiobacillus y Thiosphaera, donde la mayoría de éstos son heterótrofos, sin embargo, también pueden tener un metabolismo autotrófico con hidrógeno molecular (Cervantes-Carrillo y col., 2000). La concentración de oxígeno ha sido una variable constantemente estudiada en procesos anaerobios, donde las enzimas reductasas se han reportado afectadas por represión en presencia de oxígeno (Knowles, 1982). Durante la última etapa de la desnitrificación la reducción de $\mathrm{N}_{2} \mathrm{O}$ a $\mathrm{N}_{2}$ se lleva a cabo por la enzima óxido nitroso reductasa, esta enzima es severamente inhibida por la presencia de una concentración de oxígeno de $0.64 \mathrm{mg} / \mathrm{L}$ (Ferguson, 1994). La presencia de oxígeno va a tener un efecto negativo en el proceso desnitrificante dependiendo del tipo de microorganismos que estén participando en la reducción del nitrato y en qué etapa de la ruta metabólica. Para microorganismos como Paracoccus denitrificans, Davies y col. (1989) observaron que el efecto de la presencia de concentraciones de oxígeno entre $3.2 \mathrm{a} 4.8 \mathrm{mg}$ $\mathrm{O}_{2} / \mathrm{L}$ disminuyó el porcentaje de producción de nitrógeno molecular en una magnitud de $6 \%$ respecto a las condiciones anaerobias donde se había alcanzado hasta un $94 \%$ de producción de $\mathrm{N}_{2}$. Por otro lado, para Pseudomonas aeruginosa, el efecto de la presencia oxígeno fue el opuesto, donde en 


\section{$\Delta a 140$

presencia de oxígeno observaron hasta $94 \%$ en la producción de $\mathrm{N}_{2}$, y bajo condiciones anaerobias solo el $88 \%$.

En microorganismos como Pseudomonas pseudoalcaligenes, se han estudiado en el proceso desnitrificante por su capacidad de reducir nitrato a $\mathrm{N}_{2} \mathrm{O}$ o $\mathrm{N}_{2}$; así como Bacillus niacini $y$ Staphylococcus para reducir nitrato y nitrito, bajo condiciones donde no hay una acumulación de nitrito. Sin embargo, Martienssen y col. (1998) observaron que estas cepas redujeron un $30 \%$ su capacidad de reducir el nitrato en presencia de una concentración de nitrito de $380 \mathrm{mg} / \mathrm{L}$, concentración a la cual la abundancia de Bacillus se vio favorecida respecto a la cepa de Pseudomonas. Al mismo tiempo, en ausencia de nitrito la reducción de nitrato se mantuvo en un 99 \% favoreciendo así a la población de Bacillus. Por lo cual se considera al nitrito como un intermediario de la desnitrificación que a concentraciones elevadas disminuye el proceso nitrato reductor.

Algunos compuestos orgánicos que también se han reportado como inhibidores del proceso desnitrificante tales como acetileno $\left(10^{-3} \mathrm{~atm}\right)$, compuestos fenólicos, pesticidas $(10-20 \mathrm{mg} / \mathrm{L})$ y compuestos azufrados tal como sulfuro y sulfato (100-500 $\mu \mathrm{g} / \mathrm{L}$ ) (Knowles, 1982). Por su parte, los colorantes en función de sus características químicas y concentración, han sido reportados como compuestos que pueden tener un efecto positivo o negativo sobre el proceso desnitrificante. Mediante Bacillus lucheniformis se ha evaluado de manera cualitativa la capacidad metabólica de decolorar y de desnitrificar, ambos sustratos, colorante azul ácido $74 \mathrm{y}$ nitrato, evaluados de manera independiente (Bricky y col., 2000). Lourenço y col. (2000), reportaron la eliminación del colorante violeta remazol brillante en un reactor de lotes secuenciados bajo condiciones anaerobias en el cual observaron la capacidad del lodo desnitrificante de decolorar hasta 90\%, sin embargo en presencia de 45 y $60 \mathrm{mg}-\mathrm{NO}_{3}-\mathrm{L}$, el proceso decolorante disminuyó hasta $70 \%$ de eficiencia y el proceso desnitrificante se mantuvo con una eficiencia de consumo de nitrato de $75 \%$, mientras que en ausencia del colorante la desnitrificación se llevó a cabo en un $90 \%$. Por otra parte, Ong y col. (2010) evaluaron el tratamiento del colorante naranja ácido a una concentración de 50 y $100 \mathrm{mg} / \mathrm{L}$, el proceso decolorante y desnitrificante fueron disminuidos a estas concentraciones de colorante, debido a que mediante la previa oxidación del colorante detectaron la acumulación de aminas recalcitrantes que afectaron directamente al proceso desnitrificante, proceso que corrigieron mediante el incremento del tiempo de residencia hidráulica.

\subsection{Procesos físico-químicos en el tratamiento de colorantes}

Los procesos para el tratamiento de colorantes son factor de distintos fenómenos que van desde la decoloración, degradación y mineralización total de los colorantes (carbono orgánico hasta $\mathrm{CO}_{2}$ ). Una decoloración puede ser el resultado de la alteración del pH de la solución generando solo la ruptura del grupo cromóforo de la molécula del colorante. Sin embargo, existen métodos más sofisticados como los métodos electroquímicos óxido-reducción por electro-coagulación, electro-oxidación y electro-flotación; dentro de estos métodos la generación de intermediarios puede ser de productos con un nivel de toxicidad alto por lo cual es necesario acoplar estos métodos a otro proceso secundario para evitar efectos nocivos. Métodos físicos como: filtración por membrana, nanofiltración y 


\section{$\Delta a 140$

electrofiltración son comúnmente los procesos secundarios que se utilizan. Dentro de los métodos químicos se encuentran los métodos de coagulación-precipitación, que evidencia la eliminación de sólo aquellos colorantes que no son altamente solubles; intercambio iónico; ozonación, el cual presenta la desventaja de ser un método efectivo sólo a valores de $\mathrm{pH}$ altos; oxidación con aire húmedo (con altas temperaturas y presiones) (Hao y col. 2010; Wu y col., 1998; Kuo y col., 1992); finalmente la adsorción, la cual se ha reportado por ser eficiente en el tratamiento de colorantes tipo azo (Richardson, 1983). El uso de la adsorción para el tratamiento de contaminantes ha incrementado debido a los múltiples materiales a partir de los cuales es posible producir carbón activado, éstos al poseer diversas cargas superficiales en función del material, se caracterizan por la presencia de grupos funcionales como carboxilo, fenólico, carbonilo, lactónico y etérico. Esta diversidad de grupos funcionales hace que la superficie química sea mucho más versátil que otros adsorbentes (Allen y Koumanova, 2005). Por lo tanto, el carbón activado muestra una alta capacidad adsorbente de colorantes ácidos y básicos (Allen y Koumanova, 2005), sin embargo, presenta fenómenos de saturación de los adsorbentes que comúnmente necesitan un tratamiento de regeneración química 0 térmica;

De acuerdo a su estructura química, los colorantes pueden ser eliminados o tratados con mayor eficiencia. Según lo reportado por Richardson y col. (1983), los colorantes tipo azo, ácidos y básicos, son frecuentemente tratados de manera eficiente mediante tratamientos de coagulación con aluminio, ozonación y carbón activado, sin embargo, en los dos primeros casos se requiere de la adición de compuestos ya sea coagulantes como peróxidos y/o compuestos metálicos como hierro o manganeso, y generalmente presentan la desventaja de necesitar un post tratamiento para la eliminación total del colorante o sus subproductos (Robinson y col., 2001; Barrios-Ziolo y col., 2015). Por su parte, el carbón activado es una tecnología frecuentemente utilizada para el tratamiento de colorantes debido a su alta eficiencia de decoloración de una amplia gama de colorantes mediante adsorción, y a pesar de que algunos autores han reportado a esta tecnología desventajosa debido a sus costos (Robinson y col., 2001), actualmente existen diversos tipos de carbón activado provenientes de materiales residuales que permiten que esta tecnología sea económicamente favorable (Otero y col., 2003; Luna y col., 2007).

\subsection{Azul ácido 74 (ab74)}

El colorante azul ácido 74 también conocido como índigo natural, índigo carmín o índigo sulfatado (Fig. 6) tiene una fórmula $\mathrm{C}_{16} \mathrm{H}_{8} \mathrm{~N}_{2} \mathrm{Na}_{2} \mathrm{O}_{8} \mathrm{~S}_{2}$ y peso molecular de $466 \mathrm{~g} / \mathrm{mol}$. Y presenta una longitud máxima de absorción de $608 \mathrm{~nm}$. Es un colorante utilizado en la industria textil de la mezclilla, y en la industria química es utilizado también como indicador de pH (11.6: azul - 14.0: Amarillo) (Quintero y Cardona, 2010). El colorante azul ácido 74 pertenece al grupo de los tintes tina, los cuales en el proceso de teñido permanecen sin fijarse entre el 5 - 20\% (O'Neill y col., 1999). La toxicidad del ab74 es alta pudiendo ocasionar irritación de ojos y piel en el ser humano, así como malformaciones fetales, daños en el desarrollo mental e intoxicación en mujeres embarazadas (Jeffords y col., 1977). 


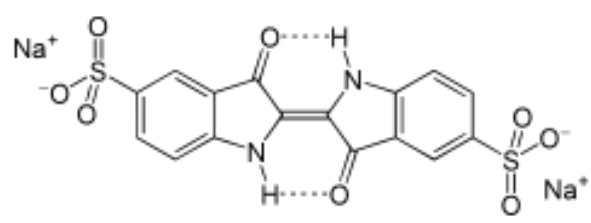

Figura 6. Estructura química del ab74

\subsection{Reactores híbridos}

Recientemente el acoplamiento de distintos procesos físico-químicos y/o biológicos se han propuesto para mejorar el tratamiento de contaminantes de manera simultánea. Los sistemas convencionales se han utilizado comúnmente de manera separada en distintos sistemas e incluso en distintas etapas, debido a la complejidad de los procesos de tratamiento, sin embargo, en este tipo de tratamiento convencional es necesario un tratamiento secundario o terciario para finalizar el proceso. Sin embargo, gracias al estudio de estos sistemas convencionales, se ha contribuido con información de ciencia básica para mejorar estos sistemas.

Frecuentemente se ha estudiado la oxidación simultánea de carbono y nitrógeno, ya que son los principales contaminantes de los ecosistemas. La oxidación de amonio en presencia de compuestos fenólicos ha sido reportada en sistemas continuos y en lote (González-Blanco y col., 2012; TéllezPérez y col., 2013) debido al efecto que estos presentan en los ecosistemas acuáticos y terrestres, así como en la flora y fauna de estos, causando fenómenos de eutrofización y toxicidad. Estos resultados han mostrado evidencia del potencial que puede llegar a tener un sistema biológico debido a la flexibilidad metabólica que los microorganismos presentan. Consecutivamente, otros estudios han evidenciado la capacidad de adaptación de procesos respiratorios en una misma unidad experimental, lo cual, para este trabajo, definimos como un "sistema híbrido" en el cual se puede llevar a cabo más de un proceso físico, químico y/o biológico en una misma unidad experimental. De la Torre y col. (2013), mostraron la capacidad de adaptar un sistema de lodos activados con capacidad de eliminar compuestos azufrados, nitrogenados y fenólicos en un mismo reactor bajo un proceso secuencial nitrificante-desnitrificante. Sin embargo, estos estudios podrían trasladarse a una geometría del sistema en donde se optimicen espacios para potencializar su aplicación.

La adaptación de estos procesos ha generado las bases de los sistemas híbridos en los cuales se pretende mejorar la eficiencia de los procesos físico-químicos y biológicos, con mejores condiciones de operación y menores costos de operación. Para esto, algunos sistemas híbridos combinan procesos biológicos a sistemas físico-químicos, o bien, procesos respiratorios secuenciales aerobiosanaerobios. Lesage y col. (2008) implementaron un sistema híbrido de membrana y carbón activado para el tratamiento de un agua residual, sin embargo, la adición del carbón activado no mejoró la eficiencia del sistema. Ahmad y col. (2010) usaron un sistema híbrido de dos módulos cilíndricos continuos en el cual optimizaron la capacidad de eliminar al $100 \%$ el colorante amarillo ácido en un sistema de bacterias anaerobias y un segundo módulo de filtración. 
190

De manera general, el mejoramiento de los sistemas convencionales se ha intencionado mediante la nueva implementación de sistemas híbridos como los mencionados anteriormente, con el objetivo de mejorar las condiciones y costos de operación. 
2. Justificación

El uso y producción de colorantes se ha incrementado en años recientes, principalmente en la industria textil. Esto se ha hecho más evidente en la actualidad debido a la producción y descarga de sus efluentes textiles a presas, ríos, mares, y suelos, sin la adecuada supervisión de la aplicación de las normas ambientales antes de ser tratados y descargados al ambiente. Los cuales son perturbados de manera inmediata al contacto con los contaminantes de éstos, donde se encuentran altas concentraciones de colorantes, materia orgánica y nitrógeno, principalmente debido a que, en los procesos de tinción en la industria textil, alrededor del $10 \%$ del total de los colorantes son inutilizados y descargados, así como el resto de los químicos utilizados para fijar los tintes a las telas. Uno de los colorantes frecuentemente utilizados en la industria textil es el colorante azul ácido 74 , que se emplea en la industria de la mezclilla. Se sabe que la descarga de estos contaminantes limita el recurso hídrico para la población humana debido a la toxicidad que presentan para la salud pública. Sin embargo, otro de los problemas originados con estas descargas, es a nivel del ecosistema acuático, debido la limitación del paso de la luz a la flora y fauna de estos ecosistemas, ocasionando la limitación o el impedimento de procesos naturales como la fotosíntesis. La limitación del paso de la luz con este tipo de descargas es producida por la presencia de concentraciones de colorantes desde 10 ppm, así como por fenómenos de eutrofización por acumulación de nitrógeno generando también la acidificación de las aguas.

Por lo anterior, es de importancia aportar conocimiento y generación de la mejora de los sistemas de tratamiento actuales que contribuya a la depuración de este tipo de efluentes antes de ser descargados a ecosistemas acuáticos y/o terrestres. Actualmente ya se implementan distintos tratamientos para la eliminación de colorantes por vías físico químicas y biológicas, sin embargo, como en la mayoría de los sistemas, se requiere del acoplamiento de dos o más sistemas para el tratamiento total de estos contaminantes. Además, otro tipo de limitación para la mayoría de los métodos físico-químicos de decoloración, implica la generación de costos debido a los reactivos químicos utilizados para los procesos de oxidación química o floculación-coagulación para aplicar dichos tratamientos. Con lo anterior, es posible que exista información de la eliminación de estos contaminantes de manera individual, sin embargo, debido a la generación simultánea de diversos contaminantes en la industria textil, es relevante que en futuros sistemas se considere la eliminación simultánea de diversos contaminantes en sistemas donde al mismo tiempo se reduzcan espacios operacionales para la disminución de costos.

Por lo cual el presente trabajo de investigación propone contribuir con variables de respuestas metabólicas y cinéticas para interpretar y comunicar el comportamiento de un sistema híbrido de lodos activados en un proceso nitrificante-decolorante-desnitrificante en soportes de poliuretano y carbón activado para la oxidación y adsorción simultánea del amonio y el colorante azul ácido 74 acoplado a un sistema desnitrificante, con la finalidad de oxidar los compuestos carbonados y reducir los compuestos nitrogenados para la generación de compuestos inocuos al ambiente. 
3. Hipótesis

Un reactor híbrido nitrificante-decolorante-desnitrificante puede acoplar la biotransformación del colorante azul ácido 74 a la oxidación y adsorción simultánea de amonio y a la reducción de nitrato vía desnitrificante, generando productos inocuos al ambiente.

\section{Objetivos}

\subsection{Objetivo general}

Evaluar la oxidación y adsorción simultánea de amonio y el colorante azul ácido 74 (ab74) en un reactor híbrido nitrificante-desnitrificante, en un sistema continuo de flujo ascendente.

\subsection{Objetivos particulares}

$\checkmark$ Obtener y caracterizar las fuentes de inóculo: lodos activados, lodos pre-tratados, carbón activado y lacasa comercial.

$\checkmark$ Evaluar la actividad enzimática de lodos activados, lodos pre-tratados, lacasa y comercial mediante la oxidación de ABTS y ab74, en estudios en lote.

$\checkmark$ Evaluar la presencia/ausencia de la actividad de la lacasa mediante un zimograma

$\checkmark$ Determinar la actividad de la enzima lacasa en lodos activados y lodos pre tratados para decolorar el ab74.

$\checkmark$ Evaluar la capacidad del carbón activado para adsorber el ab74, en estudios en lote.

$\checkmark$ Evaluar la capacidad de los lodos activados en presencia del carbón activado para la remoción del ab74 en cultivos lote.

$\checkmark$ Diseñar un reactor híbrido de dos módulos (aerobio-anaerobio)

$\checkmark$ Instalar, operar y evaluar el reactor híbrido aerobio-anaerobio durante la decoloración del ab74 y oxidación simultánea del amonio, presente en un agua sintética en un sistema continuo.

$\checkmark$ Evaluar el efecto de la concentración del ab74, en el reactor híbrido bajo condiciones nitrificante-desnitrificante. 


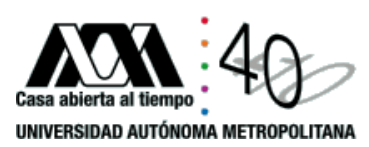

5. Materiales y métodos

\subsection{Fuente de inóculo}

Los lodos activados secundarios (LA) para la obtención de los lodos pre tratados se obtuvieron de la planta de tratamiento de aguas residuales (PTAR) "Reciclagua Ambiental S.A. de C.V." de la Secretaría del Medio Ambiente, la cual opera mediante un proceso de lodos activados con difusión de aire. La planta Reciclagua se encuentra ubicada en el municipio de Lerma, Estado de México y da tratamiento a los efluentes industriales (con una carga variable de DQO entre 2-10 g/L y 80-200 mg $\mathrm{NH}_{4}+/ L$ ) del Corredor Industrial del valle de Toluca y Parque Industrial Lerma.

Como control del proceso biológico, se utilizó una enzima Lacasa comercial grado reactivo (Deni Lite II, Novozymes).

Para llevar a cabo el proceso de adsorción se utilizó carbón activado granular reactivo (Meyer®) previamente lavado con agua desionizada y secado a $100{ }^{\circ} \mathrm{C}$ por $24 \mathrm{~h}$.

\subsubsection{Obtención de los lodos pre tratados (LPT)}

Los lodos pre-tratados (LPT) se obtuvieron mediante la sonicación de la biomasa microbiana proveniente de la PTAR Reciclagua. Ésta fue previamente lavada con solución fisiológica de $\mathrm{NaCl}$ (9 $\mathrm{g} / \mathrm{L})$ por 5 veces, para posteriormente ser sonicada a distintos tiempos. Se sonicaron $50 \mathrm{~mL}$ de biomasa previamente lavada a $0,0.5,2,5$ y 10 minutos, en un sonicador (Sonicor) a $2 \pm 1{ }^{\circ} \mathrm{C}$, con ciclos de $50 / 60 \mathrm{~Hz} 110 / 120 \mathrm{~V}$.

\subsubsection{Caracterización de los inóculos: Microscopía electrónica de barrido}

La caracterización de los inóculos se llevó a cabo mediante microscopía electrónica de barrido (SEM, Scanning Electron Microscopy), se caracterizaron las propiedades superficiales de los inóculos LA y LPT. Se tomaron muestras homogéneas de los LA y LPT para posteriormente obtener las imágenes. Se tomaron pellets de $2 \mathrm{~mm}$ de LA y LPT los cuales fueron fijados y protegidos mediante lavados con glutaraldehído $(3.5 \%)$ y tetraóxido de osmio $(0.1 \mathrm{M})$. Estas muestras fueron lavadas con $\mathrm{Na}_{2} \mathrm{HPO}_{4}$ $\mathrm{NaH}_{2} \mathrm{PO}_{4}$-buffer- $(0.1 \mathrm{M})$, pH 5.8-8.0 y deshidratadas con etanol a concentraciones ascendentes de 10 a $100 \%$. Finalmente, los pellets de las muestras fueron encapsulados y secados a su punto crítico para ser así ser recubiertos con una fina capa de oro para ser observados por SEM (Jeol JSM-5900), de acuerdo a Bozzola y Russel (1991).

\subsection{Actividad de la enzima lacasa en lote}

Se determinó la actividad enzimática de la lacasa comercial mediante la técnica utilizada por Bourbonnais y col. (1995), determinando la oxidación del ABTS (2,2'-azino-bis (3-ethylbenzothiazoline- 


\section{$\Delta 0140$

6-sulphonic acid) mediante un ensayo colorimétrico con una concentración de $0.27 \mathrm{mM}$ del ABTS en una solución amortiguadora de acetato de sodio $0.1 \mathrm{M}$, ajustado a pH 5 y $1 \mathrm{~g} / \mathrm{L}$ de lacasa. La oxidación del ABTS fue monitoreada mediante espectrofotometría a una longitud de onda de $420 \mathrm{~nm}$. La actividad enzimática fue expresada en $1 \mathrm{U}=\mu \mathrm{mol}$ de ABTS/L-min.

Bajo las mismas condiciones se evaluó la actividad de la lacasa presente en los lodos activados con una concentración de $2.6 \mathrm{~g}$ de proteína microbiana/L y en los lodos pre-tratados con $4.75 \mathrm{mg}$ proteína microbiana/L.

\subsubsection{Identificación cualitativa de la enzima lacasa}

Mediante la técnica de electroforesis en gel de acrilamida se detectaron las enzimas lacasas presentes en los inóculos (Lac, LA, y LPT) utilizados en este estudio. El zimograma se basó en la técnica de SDS-PAGE a pH alcalino bajo condiciones no desnaturalizantes. El gel de resolución y compactación fueron preparados a 12 y $5 \%$ de acrilamida, en buffers de $1.5 \mathrm{M}$ Tris $\mathrm{HCl}(\mathrm{pH} 8.8)$ y $0.5 \mathrm{M} \mathrm{Tris-HCl}$ (pH 6.8) respectivamente. La electroforesis se llevó a cabo en un sistema Bio-Rad Mini-PROTEAN system con un voltaje de $150 \mathrm{~V}$ durante 60 minutos (Laemmli, 1970). Para obtener el zimograma, el gel fue teñido para revelar bandas de proteínas con actividad lacasa utilizando ABTS $25 \mathrm{mM}\left(2,2^{\prime}-\right.$ azinebis-(3-ethylbenzothiazoline-6-sulfonate acid) en un buffer $0.1 \mathrm{M}$ de acetato de sodio ( $\mathrm{pH}$ 5).

\subsection{Decoloración del azul ácido 74}

\subsubsection{Lacasa comercial}

Se realizaron cinéticas de consumo de sustrato azul ácido 74 (ab74) a concentraciones de 50, 100, 150, 200 y $250 \mathrm{mg} / \mathrm{L}$, para determinar la concentración a la cual se alcanza la velocidad máxima de consumo de sustrato, de acuerdo al modelo de Michaelis-Menten (Fersht, 1980), y así determinar las condiciones iniciales de reacción de la fase de decoloración enzimática. Este ensayo se realizó con la enzima control $5 \mathrm{~g} / \mathrm{L}$ (lacasa comercial) para posteriormente evaluar los extractos enzimáticos obtenidos de los lodos activados, así como los propios lodos activados.

Las cinéticas de decoloración del ab74 con lacasa comercial se hicieron de igual manera en reactores de $100 \mathrm{~mL}$ de volumen nominal, $75 \mathrm{~mL}$ de volumen de operación, $40 \pm 1^{\circ} \mathrm{C}, 300 \pm 25 \mathrm{rpm}$, pH de 6.45 y una aireación de $0.03 \mathrm{vvm}$. La cinética fue monitoreada durante $2.5 \mathrm{~h}$ de tiempo reacción. Se muestreó por intervalos de 15 y 30 minutos, y cada muestra fue depositada en un baño de hielo a -1 $\pm 0.5^{\circ} \mathrm{C}$ para detener la reacción enzimática. 


\section{$\Delta a 140$ \\ UNIVERSIDAD AUTÓNOMA METROPOLITANA}

5.3.2 Lodos activados

Se evaluó la capacidad metabólica de los lodos activados para decolorar el ab74 a concentraciones de 50 a 250 ppm, ésta fue evaluada en reactores de volumen nominal de $100 \mathrm{~mL}$ con un volumen de operación de $75 \mathrm{~mL}$, una concentración de LA de $4.15 \pm 0.05 \mathrm{~g}$ proteína microbiana/L, a $29 \pm 1{ }^{\circ} \mathrm{C}$, $300 \pm 25 \mathrm{rpm}$, pH de $7.0 \pm 0.5$ y una aireación de $0.03 \mathrm{vvm}$. El agua sintética a decolorar además del ab74 se formuló con una concentración $9 \mathrm{~g} / \mathrm{L}$ de NaCl y $0.2 \mathrm{~mL}$ de elementos traza (Tab. 3) Se tomaron muestras en distintos intervalos de tiempo durante un periodo de $6 \mathrm{~h}$.

Tabla 3. Solución de elementos traza

\begin{tabular}{ll}
\hline & $(\mathrm{g} / \mathrm{L})$ \\
\hline $\mathrm{CaCl}_{2}$ & 0.1 \\
$\mathrm{CuSO}_{4} \cdot 5 \mathrm{H}_{2} \mathrm{O}$ & 0.2 \\
$\mathrm{Na}_{2} \mathrm{MoO}_{4} \cdot 2 \mathrm{H}_{2} \mathrm{O}$ & 0.01 \\
$\mathrm{MgSO}_{4}$ & 0.03 \\
$\mathrm{FeSO}_{4} \cdot 7 \mathrm{H}_{2} \mathrm{O}$ & 0.017 \\
$\mathrm{MnCl}_{2} \cdot 2 \mathrm{H}_{2} \mathrm{O}$ & 0.005 \\
\hline
\end{tabular}

\subsubsection{Lodos pre tratados}

Se evaluó la capacidad metabólica de los lodos pre tratados provenientes de los lodos activados para decolorar el ab74 a concentraciones de 50 a $250 \mathrm{mg} / \mathrm{L}$, bajo las mismas condiciones que se hizo para los lodos activados. La concentración de lodos pre tratados por sonicación fue $4.75 \mathrm{mg}$ de proteína microbiana/L. Se tomaron muestras en distintos intervalos de tiempo durante un periodo de $6 \mathrm{~h}$.

\subsubsection{Control abiótico}

Se realizó una prueba cinética de adsorción del ab74 (durante 24 h) a una concentración de 100 ppm en la biomasa de los lodos activados esterilizada en autoclave por 15 minutos a 15 psi y descartar ese porcentaje en los resultados asociados al metabolismo oxidativo del ab74. Este estudio se realizó a $29 \pm 1^{\circ} \mathrm{C}, 300 \pm 25 \mathrm{rpm}, \mathrm{pH}$ de $7.0 \pm 0.5$ y una aireación de $0.03 \mathrm{vvm}$. La concentración de biomasa en términos de proteína microbiana fue la misma, de $4.15 \pm 0.05 \mathrm{~g}$ proteína microbiana/L.

\subsubsection{Carbón activado}

Se evaluaron en lote los parámetros cinéticos de remoción del ab74 por adsorción en carbón activado granular con una concentración de $2.6 \mathrm{~g}$ carbón activado/L. Se evaluó una concentración de 100 mg/L 


\section{$\Delta a 140$

de ab74 en reactores de volumen nominal de $100 \mathrm{~mL}$ y $75 \mathrm{~mL}$ de volumen de operación a $25 \pm 1{ }^{\circ} \mathrm{C}$, $250 \pm 25 \mathrm{rpm}$ y $0.03 \mathrm{vvm}$ de aireación en un tiempo de reacción de $10 \mathrm{~h}$.

\subsubsection{Adsorción-desorción del ab74 en CA}

En matraces de $250 \mathrm{~mL}$ a $300 \pm 25 \mathrm{rpm}$, pH de $7.0 \pm 0.4$ y una aireación de 0.03 vvm se evaluó el consumo de ab74 mediante adsorción en carbón activado. En una primera etapa (etapa I) se puso en agitación una solución con $30 \mathrm{mg}$ ab74/L y $2.5 \mathrm{~g} \mathrm{CA} / \mathrm{L}$ hasta observar el consumo de ab74; en una etapa II se volvió a alimentar el matraz con $30 \mathrm{mg}$ ab74/L hasta observar su consumo y/o saturación mediante la adsorción en el CA; posteriormente en una etapa III se lavó el soporte de carbón activado y se puso en contacto con una suspensión de lodos activados ( $2.5 \mathrm{~g}$ SSV/L) durante $72 \mathrm{~h}$ para observar la desorción o regeneración in situ del CA mediante LA. Para corroborar lo anterior, en una etapa IV, se separaron los lodos activados del CA y se alimentó un nuevo lote con $30 \mathrm{mg}$ ab74/L y el CA (regenerado) hasta observar el consumo del ab74 en el medio.

\subsubsection{Carbón activado y lodos activados}

En reactores de volumen nominal de $100 \mathrm{~mL}$ con un volumen de operación de $75 \mathrm{~mL}$, a $29 \pm 1{ }^{\circ} \mathrm{C}$, $300 \pm 25 \mathrm{rpm}$, pH de $7.0 \pm 0.5$ y una aireación de $0.03 \mathrm{vvm}$; se evaluó en lote la remoción del ab74 por adsorción con carbón activado y oxidación mediante lodos activados con una concentración de SSV de $2.6 \mathrm{~g} / \mathrm{L}$ y $2.5 \mathrm{~g} / \mathrm{L}$ de carbón activado. Se evaluó una concentración inicial de $100 \mathrm{mg} / \mathrm{L}$ de ab74.

\subsection{Lodos activados: Inhibición de lacasas}

En reactores de volumen nominal de $100 \mathrm{~mL}$ con un volumen de operación de $75 \mathrm{~mL}$, a $30 \pm 1{ }^{\circ} \mathrm{C}$, $300 \pm 25 \mathrm{rpm}$, pH de $7.0 \pm 0.4$ y una aireación de $0.03 \mathrm{vvm}$; se evaluó en lote la decoloración del ab74 (100 mg/L) por vía biológica mediante lodos activados con una concentración de SSV de $2.6 \mathrm{~g} / \mathrm{L}$ en presencia de una concentración de $\mathrm{HgCl}_{2} 50 \mathrm{mM}$ (Baldrian y Gabriel, 2002) y $100 \mathrm{mg} / \mathrm{L}$ de ab74. Esto para determinar de manera indirecta la contribución de lacasas presentes en lodos activados, mediante fi (factor de inhibición de lacasas), este factor de inhibición se refiere a la relación del porcentaje de eficiencia de decoloración en presencia del inhibidor respecto a la eficiencia de decoloración en ausencia del inhibidor.

\subsection{Reactor híbrido de flujo ascendente (RHFA)}

Se operó un reactor híbrido de flujo ascendente continuo, el reactor fue construido de acrílico con un volumen total de $1.6 \mathrm{~L}$, una altura de $28.5 \mathrm{~cm}$ para el módulo 1 y $29 \mathrm{~cm}$ del módulo 2, diámetro interior de $6 \mathrm{~cm}$ y diámetro exterior de $7 \mathrm{~cm}$. El reactor tuvo una alimentación de la fuente nitrogenada y 
carbonada (C-ab74 y N-NH${ }_{4}^{+}$) por la parte inferior del módulo 1 teniendo 3 salidas, correspondientes al efluente nitrificante, efluente desnitrificante y la salida de los gases producidos $\left(\mathrm{N}_{2}\right.$ y CO 2$)$, como se muestra en la Figura 7 y 8.

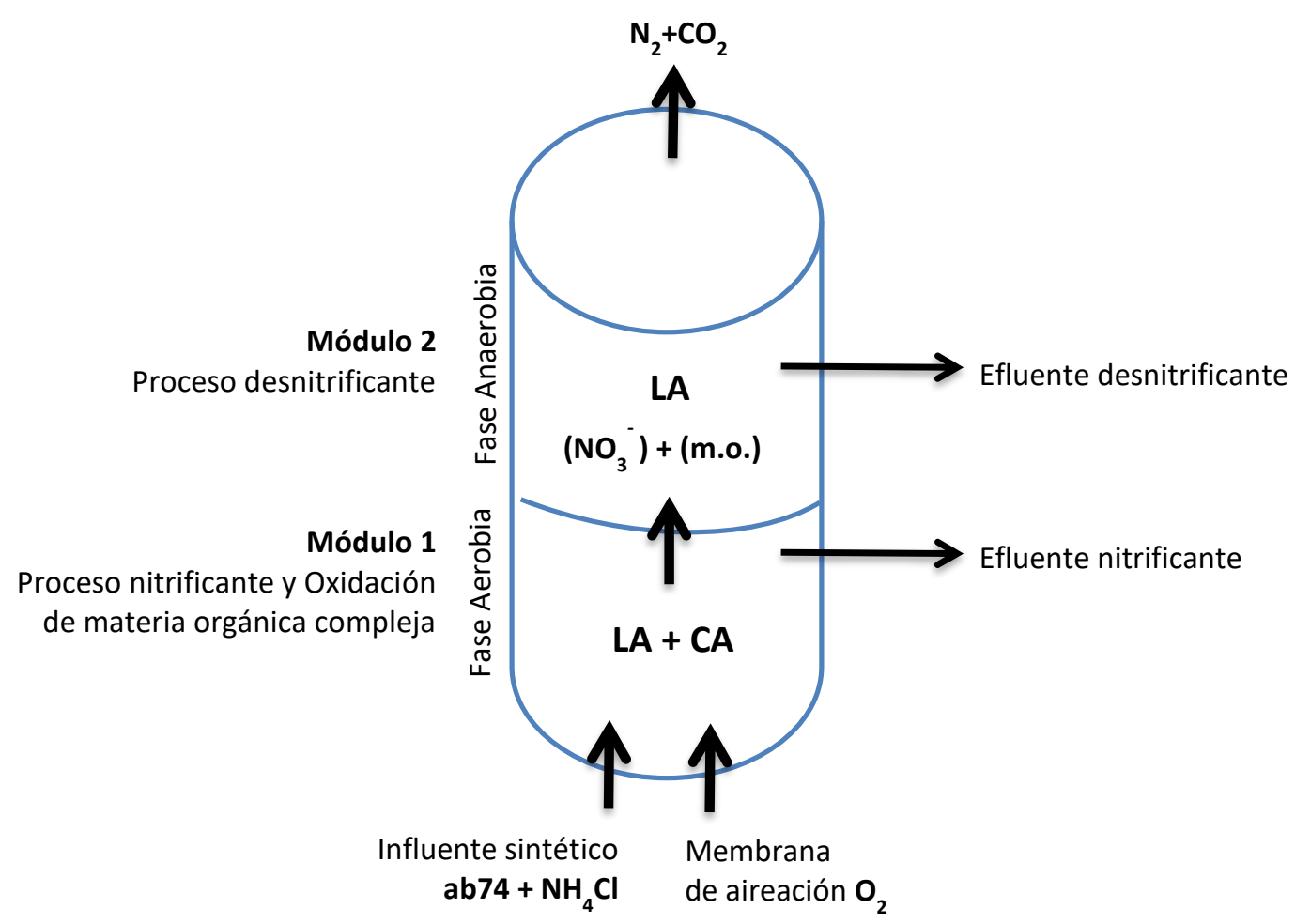

Figura 7. Diagrama del reactor híbrido de flujo ascendente

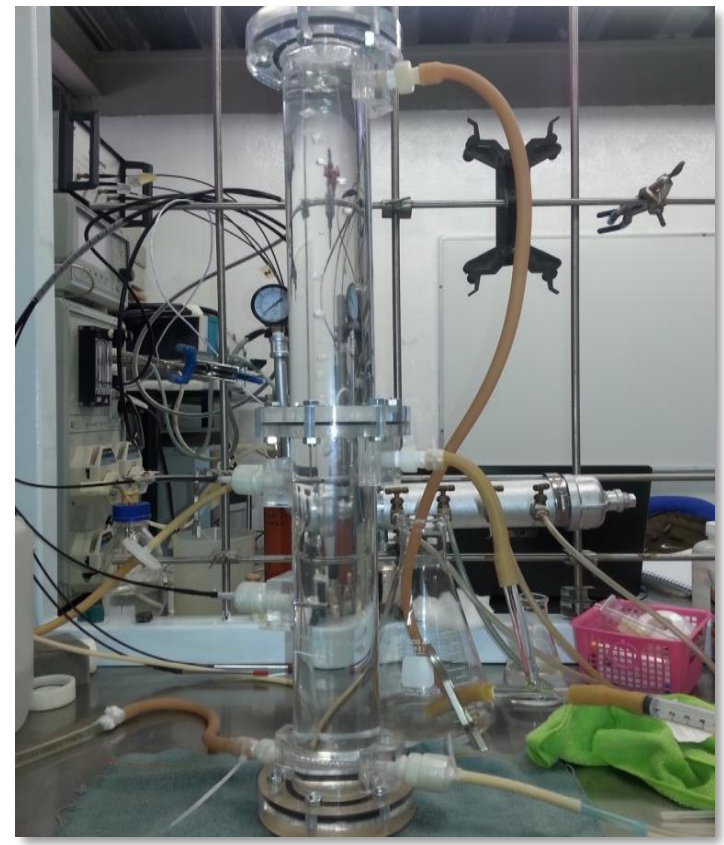

Figura 8. Reactor híbrido de flujo ascendente 


\subsubsection{Módulo nitrificante-decolorante (m1)}

Se operó el primer módulo (m1) del RHFA durante 30 días bajo condiciones nitrificantes con un lodo previamente expuesto al colorante ab74. El lodo fue tomado de la planta de tratamiento de aguas residuales en operación desde hace 20 años aproximadamente (Reciclagua, Lerma, Edo. de México). El reactor se operó con una concentración inicial de inóculo de $3.2 \pm 0.2 \mathrm{~g}$ SSV/L y un TRH de 1 día. Se alimentó con una concentración inicial de $12 \mathrm{mg} \mathrm{C}$-ab74/L y $100 \mathrm{mg} \mathrm{N}-\mathrm{NH}_{4}+/ \mathrm{L}$. El reactor fue empacado con $3.2 \mathrm{~g}$ (equivalente al $20 \%$ del volumen del módulo 1) de poliuretano con carbón activado como soporte (LEVAPOR) (Fig. 9a) para la formación de la biopelícula de los lodos activados, como lo sugiere la metodología de LEVAPOR (2017). En la siguiente Tabla (Tab. 4) se incluyen las características de los soportes de espuma de poliuretano (PUF/PolyUrethane Foam).
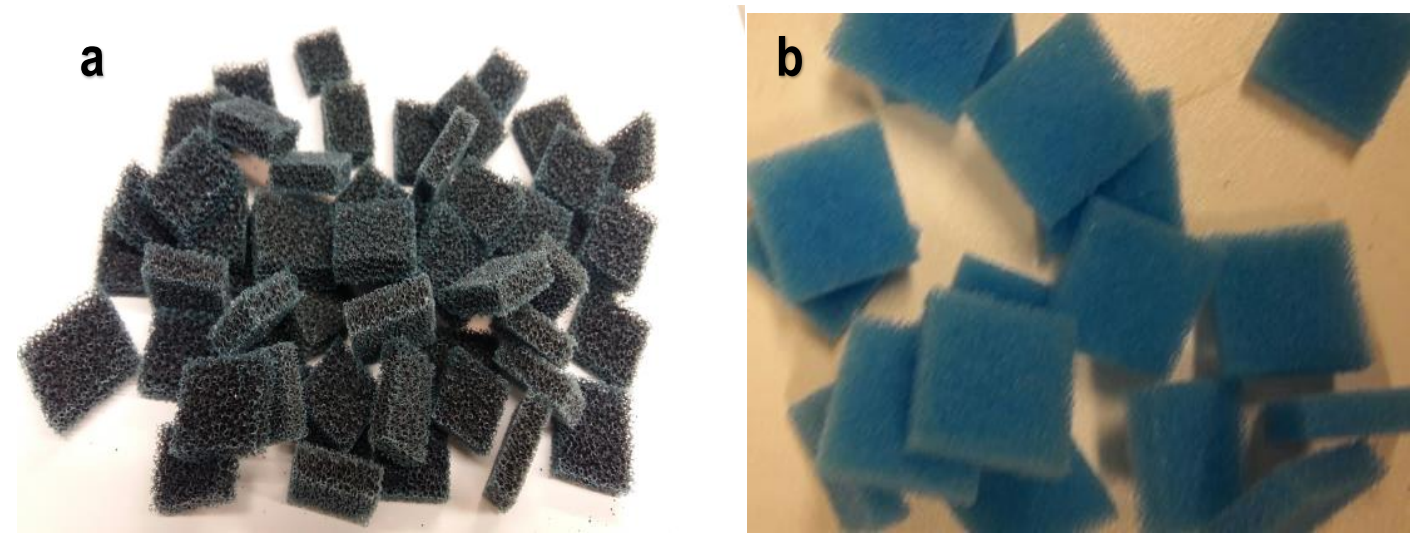

Figura 9. Soportes de poliuretano (a): sin carbón activado y (b): con carbón activado 
Tabla 4. Propiedades del soporte LEVAPOR

\begin{tabular}{|l|c|}
\hline \multicolumn{1}{|c|}{ Propiedades } & LEVAPOR \\
\hline Superficie total $\left(\mathrm{m}^{2} / \mathrm{m}^{3}\right)$ & Superior a 20,000 \\
Capacidad adsorbente & Muy alta \\
Grado de llenado requerido del reactor & 12 to $15 \%$ \\
porosidad & 75 to $90 \%$ \\
humedad & Inmediata (1- 3 días) \\
absorción de agua & Superior a $250 \%$ \\
carga iónica & + a - \\
colonización microbiana & 60 a 90 min. \\
aireación & Finas burbujas \\
energía adicional para la fluidización & No requerida \\
eliminación de lodo en exceso & Por fluidización \\
\hline
\end{tabular}

\subsubsection{Módulo nitrificante-decolorante-desnitrificante $(\mathrm{m} 1+\mathrm{m} 2)$}

En una segunda etapa se instaló el segundo módulo anaerobio para la reducción de los compuestos oxidados del nitrógeno y la decoloración total del ab74. El segundo módulo (m2), se empacó al $100 \%$ con $14.3 \mathrm{~g}$ de soporte de poliuretano sin carbón activado (Fig. 9b). Esto con el objetivo de mejorar la formación de biopelícula en el soporte, así como lograr los espacios anaerobios dentro y entre los soportes y favorecer el proceso desnitrificante. 


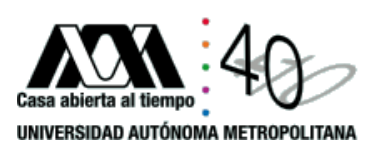

6. Métodos analíticos

\subsection{Electrodo selectivo de amoniaco: determinación de amonio}

El nitrógeno de amonio se determinó utilizando un electrodo selectivo de amoniaco. La muestra se alcalinizó con $\mathrm{NaOH} 10 \mathrm{~N}$ en una proporción 0.5:50 (v:v), bajo agitación constante. Transcurridos 3 minutos se adquirió una lectura estable. De esta manera se construyó una curva de calibración y posteriormente una vez medidos los potenciales de las muestras de los influentes y efluentes, se analizaron los valores.

\subsection{Espectrofotometría}

\subsubsection{Determinación del azul ácido 74 (ab74)}

Se tomaron $2 \mathrm{~mL}$ de muestra previamente filtradas utilizando filtros Watman número 40 de $8 \mu \mathrm{m}$ de porosidad, para cada cultivo en lote y en continuo para cuantificar la presencia del ab74 mediante espectrofotometría a una longitud de onda a $608 \mathrm{~nm}$, mediante una curva patrón.

\subsubsection{Método de reducción de cadmio: determinación de nitrato}

Se muestreó el reactor en el influente, módulo aerobio $(\mathrm{m} 1)$ y reactor híbrido $(\mathrm{m} 1+\mathrm{m} 2)$. Las muestras fueron filtradas con membrana de nylon de $0.45 \mu \mathrm{m}$ de porosidad. Se tomaron $25 \mathrm{~mL}$ de muestra y se adicionó el polvo reactivo nitraVer5 para cuantificar el nitrato presente en las muestras a una longitud de onda de $500 \mathrm{~nm}$, según el método 8039 para agua, aguas residuales y agua de mar del manual de análisis de agua de Hach (Water Analysis Manual, 2000).

\subsubsection{Método de diazotización: determinación de nitrito}

De las muestras previamente filtradas provenientes del reactor se tomaron $10 \mathrm{~mL}$ para adicionarle una bolsa de polvo reactivo nitriver3, esperar 20 minutos de reacción y se cuantificó el nitrito a $507 \mathrm{~nm}$, según el método 8507 para agua, aguas residuales y agua de mar del manual de análisis de agua de Hach (Water Analysis Manual, 2000).

\subsubsection{Método Lowry: Determinación de proteína microbiana}

Se cuantificó la proteína microbiana mediante espectrofotometría por la técnica propuesta por Lowry y col. (1951), tomando por triplicado una muestra de $1 \mathrm{~mL}$ de biomasa microbiana previamente lavada y homogenizada, a la cual se le añadió $0.1 \mathrm{~mL}$ de $\mathrm{NaOH} 10 \mathrm{~N}$ y posteriormente fueron calentados a $90{ }^{\circ} \mathrm{C}$ por 20 minutos. Se prepararon tres soluciones: $\mathrm{A}\left(\mathrm{Na}_{2} \mathrm{CO}_{3} 0.19 \mathrm{M}\right.$ en $\left.\mathrm{NaOH} 0.1 \mathrm{~N}\right)$, solución $\mathrm{B}$ 


\section{$\Delta 0140$}

(CuSO 4 al $1 \%$ ) y solución $\mathrm{C}$ (tartrato de sodio y potasio al $2 \%$ ). Se añadieron $5 \mathrm{~mL}$ de una mezcla de $1 \mathrm{~mL}$ de solución $B$ y $1 \mathrm{~mL}$ de solución $C$ aforados a $50 \mathrm{~mL}$ de la solución $A$. Posterior a esto, se dejaron reposar por 30 minutos en la oscuridad para después añadir $1 \mathrm{~mL}$ de reactivo de FolinCiocalteu y se dejaron reposar nuevamente en la oscuridad por 1 hora. Se homogenizaron en vórtex para posteriormente medir por espectrofotometría a $750 \mathrm{~nm}$.

\subsubsection{Determinación de carbono orgánico total}

Se tomó una muestra filtrada $(0.25 \mu \mathrm{m})$ de $10 \mathrm{~mL}$ del reactor: influente, módulo aerobio $(\mathrm{m} 1)$ y del reactor híbrido $(\mathrm{m} 1+\mathrm{m} 2)$, se adicionó $0.4 \mathrm{~mL}$ de solución amortiguadora a pH 2.0 para acidificar las muestras. A cada tubo de digestión ácida (kit COT Hach) se le adicionó un sobre de polvo de persulfato y, $1 \mathrm{~mL}$ de muestra acidificada y $1 \mathrm{~mL}$ del blanco (agua desionizada), posteriormente se adicionaron las ámpulas indicadoras previamente lavadas con agua destilada. Los tubos de digestión fueron calentados a $103-105{ }^{\circ} \mathrm{C}$ por 120 minutos. Una vez enfriados los tubos fueron leídos por espectrofotometría según el método 10173 para aguas residuales y aguas industriales del manual de Hach (Water Analysis Manual, 2000).

\subsection{Determinación de sólidos suspendidos volátiles (SSV)}

La concentración de SSV de los lodos activados se determinó por el método APHA/AWWA/WEF, (2005). Se pusieron a peso constante crisoles a $100^{\circ} \mathrm{C}$ al menos por 4 horas. Se tomó una muestra homogénea de $5 \mathrm{~mL}$ (por triplicado), se evaporó el líquido de la muestra en el crisol en una parrilla a baja temperatura, para evitar ebullición y pérdidas. Las muestras con líquidos evaporados se secaron en una estufa a $105^{\circ} \mathrm{C}$ por al menos una hora, y posteriormente se colocaron en un desecador por 15 minutos. Se pesaron en una balanza analítica y se obtuvo el peso de sólidos suspendidos totales (SST). Posteriormente se colocaron los crisoles con la muestra seca por 45 minutos en una mufla a $550{ }^{\circ} \mathrm{C}$ y fueron desecados por 15 minutos, para posteriormente obtener el peso de sólidos suspendidos fijos (SSF). Con los pesos anteriores se calculó la concentración de SSV de la siguiente manera, donde A es el peso constante del crisol:

$$
\frac{g S S V}{L}=\frac{(S S T-A)-(S S F-A)}{\text { Volumen de la muestra }}
$$

\subsection{Variables de respuesta}

Para poder realizar el análisis de resultados y evaluar los procesos en lote y en continuo, se determinaron variables de respuesta metabólicas (rendimiento de formación de los productos) y cinéticas (velocidades específicas de consumo). Asimismo, las observaciones cinéticas enzimáticas se describieron con el modelo de Michaelis-Menten mediante la siguiente ecuación: 
$q=\frac{V_{\max } S}{K_{m}+S}$

Donde: $q$ es la tasa específica de decoloración; $V_{\max }$ es la velocidad máxima de consumo de sustrato en $\mathrm{mg} / \mathrm{U} \mathrm{h} ; K_{m}$ es la afinidad de la enzima por el sustrato en $\mathrm{mg} / \mathrm{L}$; y $S$ es la concentración de sustrato en $\mathrm{mg} / \mathrm{L}$.

Eficiencia total de decoloración:

$E_{\%}=\frac{C r}{C i} * 100$

Eficiencia de decoloración de las lacasas:

$E_{L A \%}=\left(E_{\%}\right)-\left(\left(\frac{C r}{C i}\right) *(f i) * 100\right)$

Tasa específica de decoloración:

$q=\left(\frac{C r}{U * t}\right)$

Eficiencia de consumo de amonio:

$E_{\%}=\frac{\left(N-N H_{4 \text { influente }}\right)-\left(N-N H_{4 \text { efluente }}\right)}{N-N H_{4} \text { influente }} * 100$

Eficiencia de consumo de nitrito:

$E_{\%}=\frac{\left(N-N O_{2 \text { influente }}\right)-\left(N-N O_{2 \text { efluente }}\right)}{N-N O_{2} \text { influente }} * 100$

Eficiencia de consumo de nitrato:

$E_{\%}=\frac{\left(N-N O_{3 \text { influente }}\right)-\left(N-N O_{3 \text { efluente }}\right)}{N-N O_{3} \text { influente }} * 100$ 
Rendimiento de formación de nitrito:

$$
Y=\frac{\left(N-N O_{2} \text { efluente }\right)-\left(N-N O_{2} \text { influente }\right)}{\left(N-N H_{4} \text { influente }\right)-\left(N-N H_{4} \text { efluente }\right)}
$$

Rendimiento de formación de nitrato:

$$
Y=\frac{\left(N-N O_{3 \text { efluente }}\right)-\left(N-N O_{3} \text { influente }\right)}{\left(N-N H_{4 \text { influente }}\right)-\left(N-N H_{4 \text { efluente }}\right)}
$$

Donde $\mathrm{Cr}$, es la concentración del ab74 en un tiempo específico de reacción o en el efluente; Ci, es la concentración inicial o en el influente de ab74 (mg/L); fi, es el factor de inhibición que aplica a la tasa de decoloración especifica en presencia del inhibidor de lacasa $\left(\mathrm{HgCl}_{2}\right)$ respecto a la eficiencia de decoloración en ausencia del inhibidor ( $\left.E_{\% \text { inhibidor }} / E_{\%}\right)$; $q$ es la tasa específica de decoloración que fue normalizada por unidad de actividad enzimática para comparar las tasas de decoloración por lacasas contenidas en LA, AS y LPT, y t es el tiempo de reacción (h). 
7. Resultados

Los resultados son presentados en dos etapas experimentales:

-Etapa 1. Estudio biocinético y zimográfico de la decoloración del azul ácido 74 en lote, mediante: lacasa comercial, lodos activados, lodos pre-tratados y carbón activado.

-Etapa 2. Oxidación y adsorción simultánea de amonio y azul ácido 74 en un reactor híbrido de flujo ascendente, mediante: Lodos activados soportados en PUF con carbón activado (Fase aerobiadecolorante-nitrificante). Y lodos activados soportados en PUF (Fase anaerobia-desnitrificante).

\subsection{Resultados Etapa 1}

Primeramente, se presenta una sección de la caracterización de los lodos activados y los lodos pre tratados, mediante microscopía electrónica de barrido, antes y después del proceso de sonicación. La siguiente sección presenta un análisis y discusión de la actividad de lacasas presentes en LA y LPT, en el cual, se muestra un zimograma donde las bandas reveladas indican la oxidación de ABTS por la actividad lacasa presente. Posteriormente, se discute el comportamiento de la decoloración del ab74 mediante los diferentes tratamientos (Lac, LA, LTP, CA y CA+LA), así como el efecto del $\mathrm{HgCl}_{2} \mathrm{Como}$ inhibidor de lacasa para todos los tratamientos.

\subsubsection{Obtención de los lodos pre tratados (LPT)}

Una vez sonicadas las muestras de los lodos activados a diferentes tiempos se observó la liberación de proteína microbiana, como se observa en la Fig. 10. Al sonicar por un periodo de 10 minutos, se obtuvo un incremento del $14 \%$ de proteína liberada respecto a la biomasa sin sonicar. Este resultado sugiere que mediante la técnica de sonicación se libera proteína microbiana la cual podría ser proteína con actividad catalítica, o bien de tipo estructural. Sin embargo, no se descarta la posibilidad de que se encuentren liberadas enzimas de tipo lacasas u otro tipo de enzimas capaces de oxidar al ab74, lo cual podría ocurrir, en función del tipo de células presentes en los lodos activados. Foladori y col. (2007) observaron que en suspensiones de cepas puras o cultivos axénicos (1010 bacterias/L), el 


\section{A91 40

efecto de la sonicación resultó insuficiente para la disgregación o modificación de las cepas de $E$ coli y E. Fecalis, ya que esta técnica debe considerar la concentración celular, composición de pared celular bacteriana, tiempo de sonicación, temperatura, etc., por lo que dichos autores sugieren que para que ocurra un daño celular en lodos activados, la frecuencia de sonicación necesita ser mayor a $20 \mathrm{kHz}$, incrementar el tiempo de sonicación, e incluso combinar la sonicación con UV convencional (Blume y col., 2004). De acuerdo a Covarrubias y col. (2015), el proceso de sonicación mejoró el contacto enzima-sustrato, en ese estudio el consumo de sustrato se incrementó 1.6 veces respecto a las células completas utilizando una frecuencia de sonicación de $50 / 60 \mathrm{~Hz}$; sin embargo, no es claro de qué manera las propiedades cinéticas fueron afectadas.

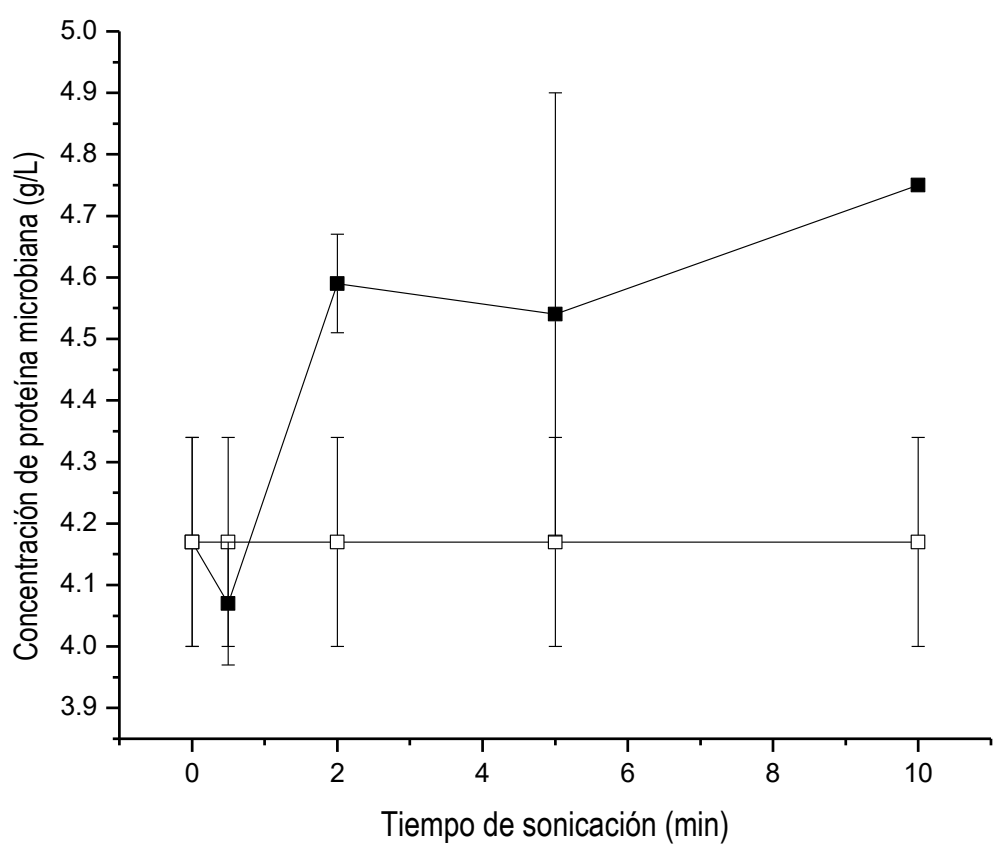

Figura 10. Obtención de los lodos pre tratados. (๘) Biomasa sonicada, () Biomasa sin sonicar.

\subsubsection{Caracterización de los inóculos}

Debido a la morfología bacteriana que se observó en las imágenes de SEM, se evidenció la presencia de estreptobacilos en ambas muestras LA (Fig. 11a) y LPT (Fig. 11b). Yu y col. (2001) mostraron la presencia de cepas bacilares de Pseudomonas en lodos activados con capacidad de remover el colorante azul ácido 74 con eficiencias cercanas al $80 \%$. Jadhav y col. (2010), observaron la capacidad 


\section{$\Delta a 140$ \\ UNIVERSIDAD AUTÓNOMA METROPOLITANA}

de cepas de pseudomonas para remover el colorante reactivo naranja con eficiencias cercanas al 100\%. También Ayed y col. (2012) mostraron la capacidad metabólica de cepas de pseudomonas cepacia y Bacillus sp. para decolorar un efluente textil, así mismo, detectaron enzimas con actividad lacasa en estas dos cepas. Además, la Figura 9b sugiere la presencia de una mayor área superficial en LPT respecto a LA. Bajo una perspectiva ingenieril del reactor, esta mayor área superficial podría incrementar la conversión del ab74. De acuerdo a lo reportado por Covarrubias y col. (2015), la sonicación de lodos activados mejoró el contacto enzima sustrato con células sonicadas.
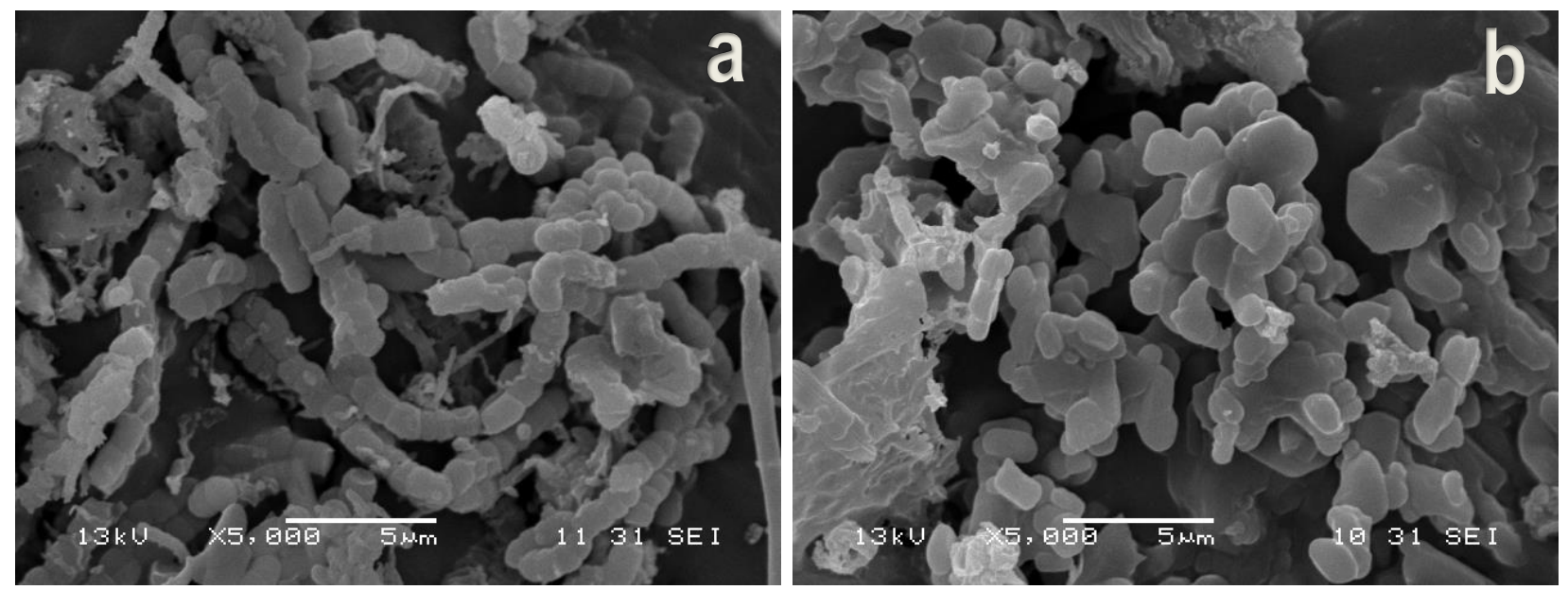

Figura 11. Micrografía electrónica de barrido de LA (a) y LPT (b). LA: lodos activados sin sonicar, LTP lodos pre tratados con sonicación $10 \mathrm{~min}$

\subsubsection{Actividad de la enzima Lacasa en Lac, LA y LPT, en cultivos lote}

La actividad enzimática de la lacasa se evaluó en lote mediante la oxidación del ABTS bajo las condiciones de operación que se mencionaron anteriormente, las actividades específicas de lacasa fueron de $0.9,1.53 \times 10^{-5}, 2.89 \times 10^{-6} \mathrm{U} / \mathrm{mg}$-proteína para Lac, LA y LPT, respectivamente. La actividad específica de la lacasa comercial fue mayor que la actividad reportada para otras lacasas comerciales; por ejemplo, las actividades lacasa reportadas en Pseudomonas cepacia y Bacillus sp. fueron de 7.11 $\times 10^{-10}$ y $8.13 \times 10^{-10} \mathrm{U} / \mathrm{mg}$-proteína, respectivamente (Ayed y col., 2012). La diferencia entre la actividad expresada en lacasas comerciales y lacasas estudiadas de lodos activados podría estar 
A21:40

asociado a la concentración de enzimas dentro de las células, así como sus propiedades catalíticas. Así como los mediadores incluidos en algunas enzimas comerciales que mejoran su actividad (Munteanu y col., 2007).

\subsubsection{Presencia y actividad de la enzima lacasa}

\subsubsection{Zimograma}

La Figura 12 muestra el zimograma obtenido con Lac, LA y LPT. Se observó en el carril de la muestra de proteínas de lacasa comercial (Lac), una banda de peso molecular cercano a 75 kDa. Sin embargo, en los carriles de lodos activados y lodos pre tratados se observaron dos bandas alrededor de 150 $\mathrm{kDa}$, las cuales sugirieron la presencia de proteínas lacasa. Las bandas expresadas en lodos activados y lodos pre tratados, mostraron un peso molecular distinto al de la lacasa comercial. En la literatura (Leigh, 1997) se tienen estudios de identificación de proteínas con actividad lacasa, con un peso molecular similar al observado para LA y LPT en este estudio. Se ha reportado que la enzima lacasa puede variar su peso molecular en función del microorganismo que la produce (Arana-Cuenca y col., 2004). Comúnmente las enzimas con actividad lacasa se reportan de bajo peso molecular para bacterias, tal es el caso de la lacasa proveniente de Bacillus subtillis con un peso molecular de 52.7 kDa (Phelan y col., 2013); sin embargo, existe el caso opuesto, Streptomyces griseus que expresa lacasas con un peso molecular de 209 kDa (Leigh, 1997). La enzima lacasa puede expresar distintas características como su peso molecular, punto isoeléctrico, actividad, parámetros cinéticos enzimáticos ( $\mathrm{K}_{m} \mathrm{y} \mathrm{V}_{\max }$ ), etc., lo cual puede estar influenciado por las condiciones ambientales, como pH, temperatura, inductores, composición del medio de cultivo, entre otras (Giardina y col., 1999; Téllez-Téllez y col., 2008). 


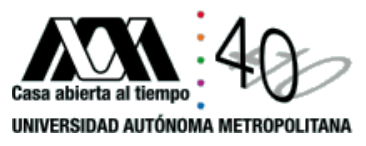

MPM Lac LA LPT Lac LA LPT

$250 \mathrm{kDa}$

$150 \mathrm{kDa}$

$100 \mathrm{kDa}$

75 kDa

50 kDa

37 kDa

25 kDa

Figura 12. Zimograma: actividad lacasa de lacasa comercial (Lac), lodos activados (LA) y lodos pre tratados (LPT)

\subsubsection{Decoloración del ab74 en lote}

\subsubsection{Decoloración del ab74 con Lac, LA y LPT}

En la Figura 13 se muestran los perfiles de decoloración del ab74 en función del tiempo de Lac, LA y LPT, a diferentes concentraciones iniciales de ab74 (50-250 mg/L). Lac, LA y LPT mostraron capacidad metabólica de remover el ab74 de una solución acuosa, LA y LPT mostraron la mejor eficiencia de decoloración de $23.8 \%$ y $12.2 \%$ en presencia de $50 \mathrm{mg} / \mathrm{L}$ de ab74 en un tiempo de $6 \mathrm{~h}$. A las condiciones evaluadas Lac mostró los mejores resultados de decoloración con $50 \%$ de eficiencia decolorante en $6 \mathrm{~h}$ de reacción en presencia de $250 \mathrm{mg} / \mathrm{L}$ de ab74 (Tabla. 5). En todas las concentraciones evaluadas Lac mostró una mejor eficiencia de 20 y $40 \%$ mayor que LA y LPT respectivamente, asociado a dos propiedades reportados en la literatura, pureza de la enzima y su contacto directo enzima-ab74; así que como en algunos casos las lacasas comerciales de Novozymes incluyen un sistema mediador de lacasas que mejorara la actividad enzimática (Tavares y col., 2009). Por otra parte, aunque los LPT parecían tener un cambio cualitativo en su morfología bacteriana (Fig.11b) respecto a LA, tanto LA como LPT presentan perfiles de decoloración similares (Fig. 13b y 13c) que aparentemente se vieron afectados por la concentración inicial de ab74. En este sentido, el 
101: 40

tratamiento de LPT mediante sonicación $(110 / 120 \mathrm{~Hz}, 10 \mathrm{~min})$ no fue capaz de favorecer la conversión del color del ab74. Puvaneswari y col. (2006) observaron como células lisadas mostraron la liberación de cofactores como FAD, en un ambiente extracelular que fue reducido enzimáticamente por NADH y $\mathrm{FADH}_{2}$, incrementando así la decoloración de un colorante tipo azo. Para este trabajo, la eficiencia de decoloración (E\%) para todos los inóculos se presenta en la Tabla 5. Estas variables de respuesta fueron diferentes para cada inóculo evaluado. LA y LPT mostraron eficiencias de decoloración de 2.2 a $23.8 \%$ y de 2.6 a $18.4 \%$, respectivamente. Hasta el momento, un incremento de la concentración inicial del ab74 afectó negativamente la eficiencia de decoloración. Las membranas de LA y LPT son una barrera que protege a las células, las cuales se conforman de lípidos y proteínas y, por tanto, están implicados en la señalización, la estabilidad celular, y las interacciones de proteína (Rannikko y col., 2014). Por su parte, la capacidad celular intrínseca de LA y LPT se relacionó con la osmolaridad externa y condiciones de estrés producidas entre las células y su medio ambiente (Machado y col., 2004). En este trabajo, el tratamiento de sonicación no mostró una mejora significativa en la tasa de decoloración entre los lodos pre tratados (LPT) y los lodos activados (LA) con $13.97 \pm 0.16$ y $13.57 \pm$ $0.18 \mathrm{mg}$ ab74/U-h, respectivamente.

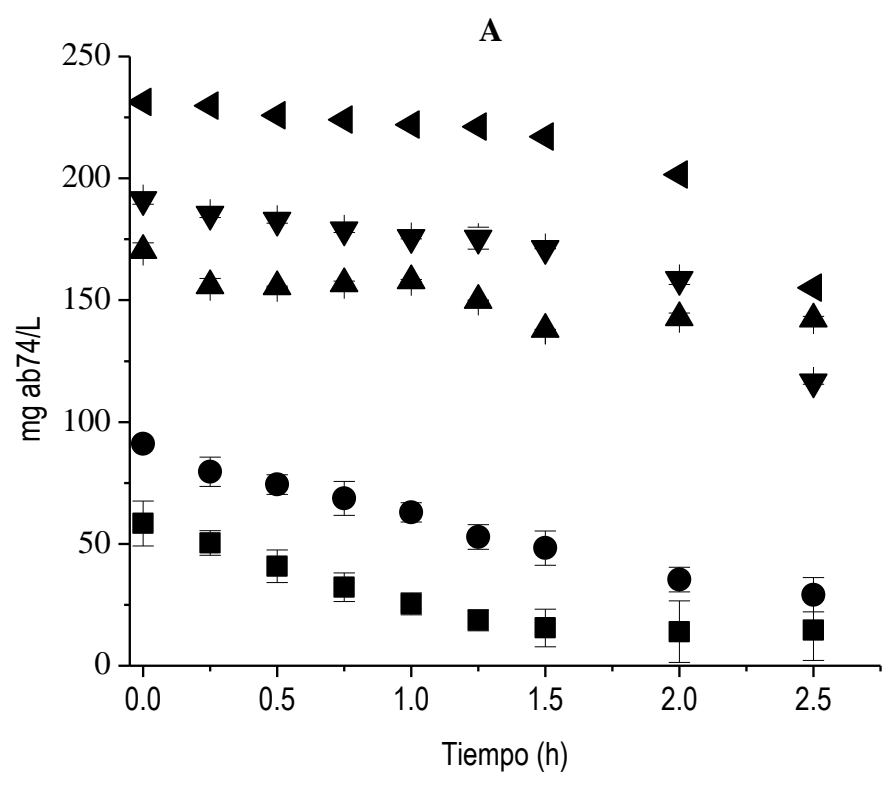



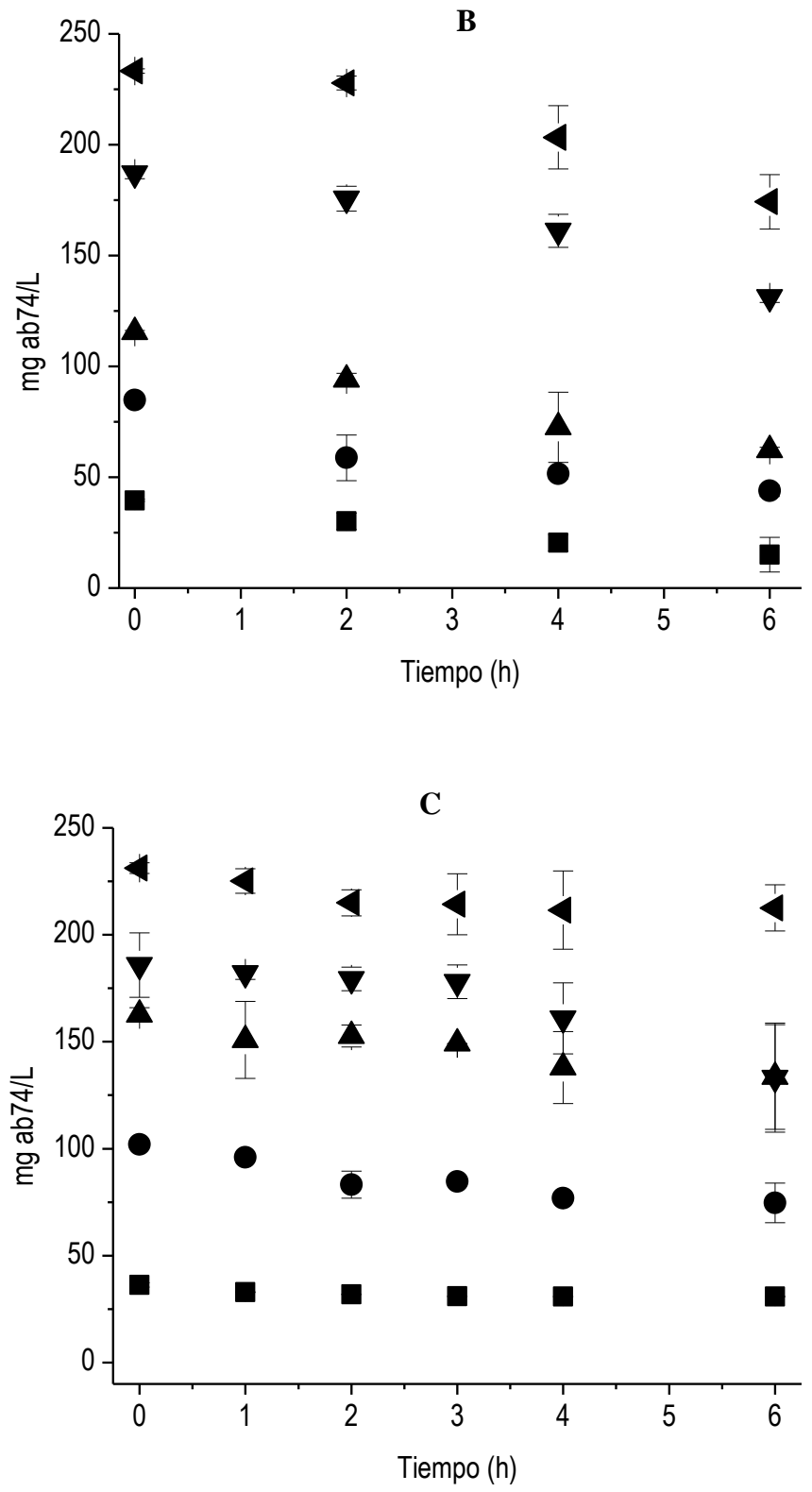

Figura 13. Decoloración del ab74

A: Lacasa comercial (Lac); B Lodos activados (LA): C: Lodos pre tratados (LPT)

(•) $50 \mathrm{mg} / \mathrm{L} ;(\bullet) 100 \mathrm{mg} / \mathrm{L} ;(\mathbf{\Delta}) 150 \mathrm{mg} / \mathrm{L} ;(\boldsymbol{\nabla}) 200 \mathrm{mg} / \mathrm{L} ;$ ( \) $250 \mathrm{mg} / \mathrm{L}$ 
Tabla 5. Eficiencias (\%) de decoloración del ab74 mediante Lac, LA y LPT, en cultivos en lote

\begin{tabular}{|c|c|c|c|}
\hline $\mathrm{ab74}(\mathrm{mg} / \mathrm{L})$ & Lacasa comercial (Lac) & Lodos activados $(\mathrm{LA})$ & Lodos pre tratados (LPT) \\
\hline 50 & $57.6 \pm 12.4$ & $23.8 \pm 8.4$ & $12.2 \pm 2.5$ \\
\hline 100 & $42.6 \pm 7.0$ & $22.1 \pm 2.5$ & $18.4 \pm 6.1$ \\
\hline 150 & $19.0 \pm 2.0$ & $18.6 \pm 2.1$ & $6.1 \pm 1.3$ \\
\hline 200 & $40.1 \pm 11.7$ & $6.1 \pm 4.2$ & $9.1 \pm 2.3$ \\
\hline 250 & $38.9 \pm 7.2$ & $2.3 \pm 0.9$ & $2.6 \pm 1.4$ \\
\hline
\end{tabular}

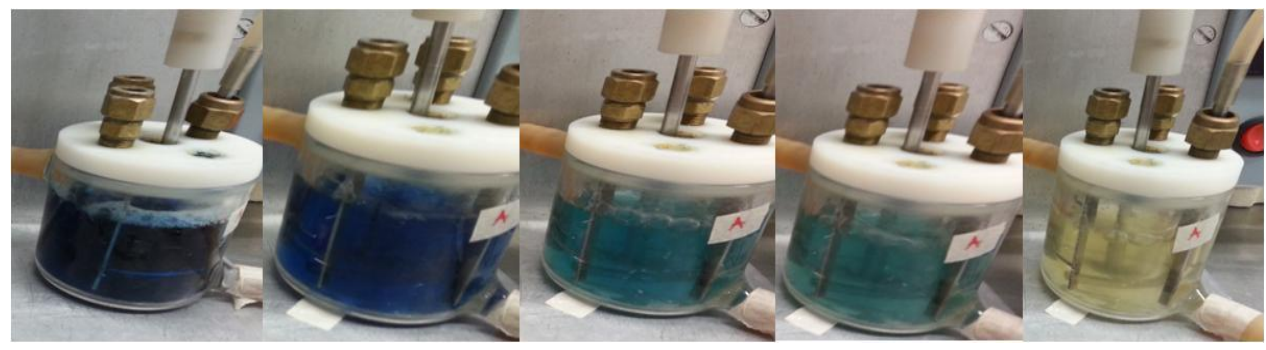

Figura 14. Decoloración del ab74 mediante Lacasa comercial (Lac) en lote

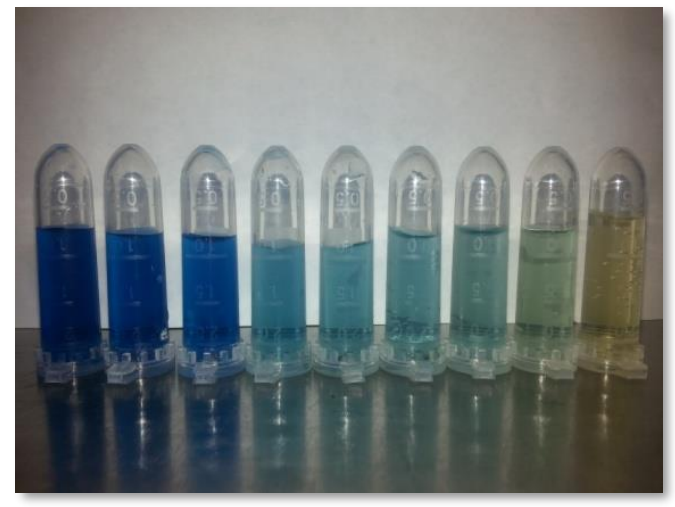

Figura 15. Decoloración del ab74 mediante lodos activados 


\subsubsection{Control abiótico}

Los experimentos de control abiótico que evaluaron la disminución de la concentración del ab74 por la biomasa de LA y LPT (Fig. 16) dieron lugar a una eficiencia de decoloración de $2.8 \pm 0.1 \%$, que se relacionó totalmente con la adsorción del ab74 a través de la membrana de estos lodos. En otros estudios se ha informado de que una cantidad mínima de colorante se adsorbe en la superficie celular, aunque principalmente se lleva a cabo la degradación biológica (Chen y col., 1999).

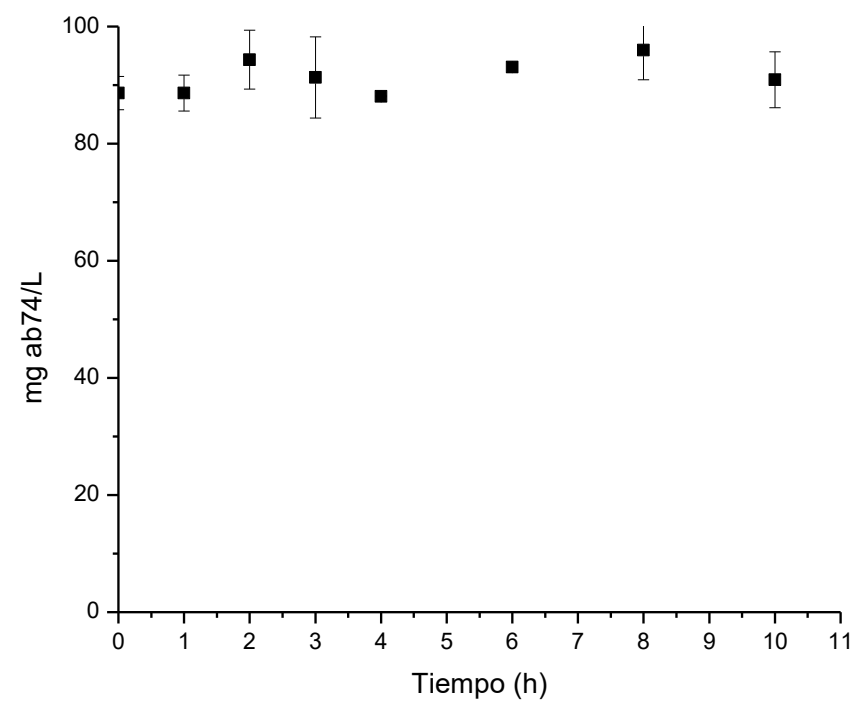

Figura 16. Cinética abiótica de adsorción del ab74 en LA

\subsubsection{Contribución de lacasas presentes en LA y LPT para la decoloración del ab74}

La Tabla 6 presenta la eficiencia de decoloración del ab74 debido a las enzimas lacasa contenidas en LA y LPT. Estas variables de respuesta se analizaron mediante análisis de varianza (ANOVA) con la prueba de comparación de Tukey. Se identificó estadísticamente que la eficiencia decoloración del ab74 de LA y LPT fueron significativamente diferentes en las condiciones de operación estudiadas ( $P$ $<0.001)$. Con el fin de observar el papel de la lacasa de los lodos en el proceso de decoloración del 
Ald 40

ab74, se añadió $\mathrm{HgCl}_{2}$ como un inhibidor de la actividad de la lacasa. El $\mathrm{HgCl}_{2}$, afectó negativamente a la eficiencia y tasas específicas de decoloración del ab74 de Lac, LA y LPT. Primeramente, el $\mathrm{HgCl}_{2}$ inhibió totalmente la actividad enzimática de Lac, obteniendo una nula decoloración del ab74. Este resultado fue asociado a la evidente actividad lacasa presente en LA y LPT ya que la eficiencia decoloración disminuyó un 23.2 y 19.09\% para LA y LPT, respectivamente, y las tasas específicas de decoloración disminuyeron el 23.8 y el $20.2 \%$ para LA y LPT, respectivamente. Sin embargo, aunque se evidenció la participación de las enzimas lacasa, es posible que exista la presencia de otro tipo de enzimas que contribuyeron durante el proceso de decoloración del ab74, por lo que son necesarios futuros estudios para identificarlas. De hecho, monooxigenasas, peroxidasas y dioxigenasas, han sido reportadas como enzimas identificadas en lodos activados en procesos de decoloración (Kandelbauer y col., 2013; Méndez-Hernández y col., 2013).

Tabla 6. Eficiencias de decoloración por lacasas contenidas en LA y LPT

\begin{tabular}{|c|c|c|}
\hline $\mathrm{ab74}(\mathrm{mg} / \mathrm{L})$ & LA & LPT \\
\hline 50 & $5.7 \pm 0.4$ & $2.9 \pm 0.98$ \\
\hline 100 & $5.3 \pm 0.5$ & $4.4 \pm 0.38$ \\
\hline 150 & $4.4 \pm 0.5$ & $1.5 \pm 0.51$ \\
\hline 200 & $1.5 \pm 0.9$ & $2.2 \pm 0.9$ \\
\hline 250 & $0.5 \pm 0.2$ & $0.6 \pm 0.5$ \\
\hline
\end{tabular}

Por otra parte, es importante mencionar que la eficiencia de decoloración depende de diversos factores como la concentración inicial del inóculo, tipo de sustrato, tiempo de reacción, condiciones de operación, medio de cultivo, tipo de microorganismos, etc. La Tabla 6 muestra la eficiencia de decoloración atribuida a las enzimas de tipo lacasa presentes en LA y LPT. Con esta variable de respuesta atribuida únicamente a lacasa, se observó que la eficiencia de decoloración en cultivos que evaluaron desde 50 a $250 \mathrm{mg}$ ab74/L fue de 0.5 a $5.7 \%$ en LA y de 0.6 a $2.9 \%$ en LPT. Con lo anterior, se pudo cuantificar que la contribución de enzima lacasa presente en lodos activados y en los lodos pre tratados fue de alrededor de $20 \%$ durante el proceso de decoloración y bajo las condiciones de operación evaluadas. Al mismo tiempo, como se observa en la Tabla 7, la tasa específica de decoloración (mg ab74/g h) a $100 \mathrm{mg}$ ab74/L para LA fue 6.6 veces mejor que 
Pseudomonas GM3 y que un consorcio de distintas cepas de Pseudomonas reportado por Yu y col. (2001).

Tabla 7. Eficiencias y tasas específicas de decoloración inhibidas por $\mathrm{HgCl}_{2}$

\begin{tabular}{|c|c|c|c|c|}
\hline Inóculo & $\begin{array}{c}\text { Eficiencia (\%) } \\
\text { en ausencia de } \\
\mathrm{HgCl}_{2}\end{array}$ & $\begin{array}{c}\text { Eficiencia (\%) } \\
\text { en presencia de } \\
\mathrm{HgCl}_{2}\end{array}$ & $\begin{array}{c}\text { Tasa específica de } \\
\text { decoloración en } \\
\text { ausencia de } \mathrm{HgCl}_{2}\end{array}$ & $\begin{array}{c}\text { Tasa específica de } \\
\text { decoloración en } \\
\text { presencia de } \mathrm{HgCl}_{2}\end{array}$ \\
\hline Lac & $38.3 \pm 2.7$ & 0 & $0.279 \pm 0.02$ & $0.039 \pm 0.006$ \\
\hline LA & $74.0 \pm 13.4$ & $56.8 \pm 2.9$ & $0.159 \pm 0.001$ & $0.125 \pm 0.009$ \\
\hline LPT & $84.3 \pm 5.2$ & $68.2 \pm 1.9$ & $0.122 \pm 0.003$ & $0.094 \pm 0.005$ \\
\hline
\end{tabular}

***tasas específicas de decoloración (mg ab74/g h)

\subsubsection{Parámetros cinéticos de la decoloración del ab74 por Lac, LA y LPT}

La Figura 17 presenta el ajuste de las tasas de decoloración del ab74 como una función de la concentración inicial del ab74. El ajuste de los datos experimentales al modelo cinético permitió obtener los parámetros cinéticos que se presentan en la Tabla 8. Las tasas específicas de decoloración basadas en $U$ ( $\mu$ mol de ABTS oxidado/L min) fueron más grandes para LA y LPT que para Lac. Sin embargo, a pesar de las enzimas lacasa de LA y LPT presentaron menores valores de U que Lac durante la oxidación de ABTS, estas enzimas contribuyeron en aproximadamente un $20 \%$ para decolorar el ab74. LA y LPT no mostraron una diferencia significativa en $V_{\max }$, es decir, que el tratamiento de sonicación para la obtención de los LPT no tuvo un efecto significativo en la mejora de los parámetros cinéticos respecto a los LA. 


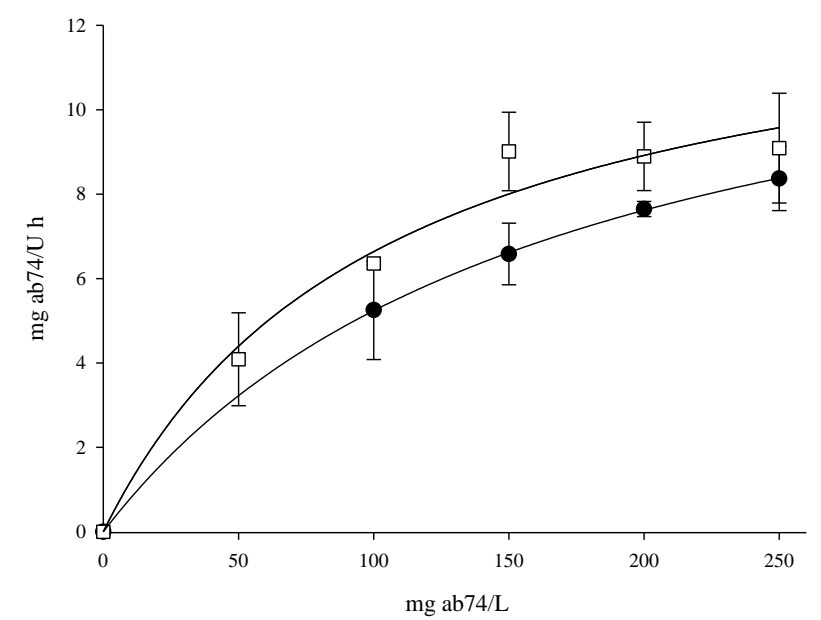

Figura 17. Cinéticas tipo Michaelis-Menten para la decoloración de ab74: $(\bullet)$ Lodos activados, $(\mathrm{LA}),(\mathbf{\Delta})$ Lodos pre tratados (LPT). Modelo ajustado: (-). $R^{2}=0.9785(\mathrm{LA}), R^{2}=0.9999(\mathrm{LPT})$

Tabla 8. Parámetros cinéticos del modelo de Michaelis-Menten de Lac, LA y LPT

\begin{tabular}{|c|c|c|}
\hline Inóculo & $K_{m}(\mathrm{mg} / \mathrm{L})$ & $V_{\max }(\mathrm{mg} \mathrm{ICd} / \mathrm{Uh})$ \\
\hline Lac & $20.5 \pm 3.0$ & $0.23 \pm 0.005$ \\
\hline LA & $104.4 \pm 34.5$ & $13.57 \pm 1.8$ \\
\hline LPT & $166.7 \pm 4.4$ & $13.97 \pm 0.16$ \\
\hline
\end{tabular}

La mejor afinidad entre el inóculo y el ab74 fue para Lac con un valor de $20.5 \mathrm{mg} / \mathrm{L}$, siendo aproximadamente 6 veces mejor que la $\mathrm{K}_{m}$ de los LA y LPT. Por otra parte, los valores de $\mathrm{V}_{\max }$ de LA y LPT fueron 60 veces más rápidos que los obtenidos con Lac. Son pocos los trabajos en los que se reportan variables cinéticas enzimáticas en procesos de decoloración. Cristóvão y col. (2008) reportaron los parámetros cinéticos de decoloración de diversos colorantes textiles, mediante una lacasa comercial donde el valor máximo de LA y LPT evaluados en este trabajo, fueron significativamente superiores a los valores de $\mathrm{V}_{\max }$ que obtuvieron estos autores durante el proceso de decoloración del amarillo reactivo 15, rojo reactivo y negro reactivo 5. Estos resultados experimentales sugieren que LA y LPT son inóculos con características cinéticas prometedoras en el proceso de decoloración del ab74, incluso este tipo de lacasas pueden presentar otras capacidades metabólicas además de la decoloración como la mineralización de moléculas derivadas de la catálisis 
$\Delta a 140$

de la lacasa (Méndez-Hérnandez y col., 2013). Davison y col. (1999) reportó resultados de la evaluación de un lodo activado bajo condiciones de estrés para evaluar su capacidad de eliminar más de una fuente de carbono en el mismo experimento debido a la transferencia de genes que ocurre dentro de los lodos activados como un mecanismo de adaptación. Así que, muchas bacterias aisladas de lodos activados pueden presentar una versatilidad metabólica para decolorar o eliminar diferentes tipos de sustratos. Como Alishewanella que es una bacteria gram negativa aislada de suelo contaminado con colorantes (Kolekar y col., 2013) que al mismo tiempo tiene la capacidad de hidrolizar caseína, formar biopelículas y decolorar (Jung y col., 2012). Cultivos mixtos o bacterias aisladas de lodos activados pueden presentar muchas ventajas metabólicas para aplicarse en procesos biotecnológicos como el tratamiento de diversos colorantes.

\subsubsection{Decoloración con Carbón Activado}

Se realizó una comparación biocinética en lote para evaluar la decoloración del ab74 a una concentración de $100 \mathrm{mg}$ ab74/L. La Figura 18 muestra el perfil de consumo del ab74 respecto al tiempo para cada tratamiento evaluado, es decir, para LA, carbón activado (CA) y la combinación de LA con $C A(L A+C A)$, y la Figura 19 muestra la comparación cinética y de eficiencia mediante las velocidades específicas y eficiencia de cada tratamiento en la decoloración del ab74. La eficiencia y velocidades específicas de decoloración fueron evaluadas estadísticamente y mediante un análisis de varianza y la prueba de comparación de Tukey. La mejor eficiencia de decoloración fue la obtenida mediante el tratamiento sinérgico de CA+LA, con una tasa de decoloración de $5.9 \pm 0.4 \mathrm{mg}$ ab74/h$g_{\text {tratamiento }}$ y una eficiencia de decoloración de $76.6 \pm 11.8 \%$. Este resultado también puede estar asociado a las propiedades fisicoquímicas como porosidad y área superficial del adsorbente, en este caso el carbon activado (Navarro y Vargas, 2010). Al mismo tiempo, los resultados de la decoloración, sugieren que, aunque la enzima lacasa es un método atractivo para la decoloración, el costo para su implementación a nivel industrial es menos factible que el resto de los tratamientos evaluados. Por otra parte, el tratamiento de $C A+L A$, mostró una eficiencia de 1.9 y 2.5 veces mejor que $C A$ y $L A$, indicando ser un interesante método de decoloración para ser implementado a nivel industrial. La mejora de $C A+L A$, respecto a los lodos activados podría estar asociada a que en el método biológico requiere de un mecanismo de transporte de sustrato que necesita la acción de proteínas integrales 
191: 40

que permitan la captación del sustrato a través de la membrana (Jiménez y col., 2006) lo cual pudiera estar limitando su velocidad respecto a los otros tratamientos.

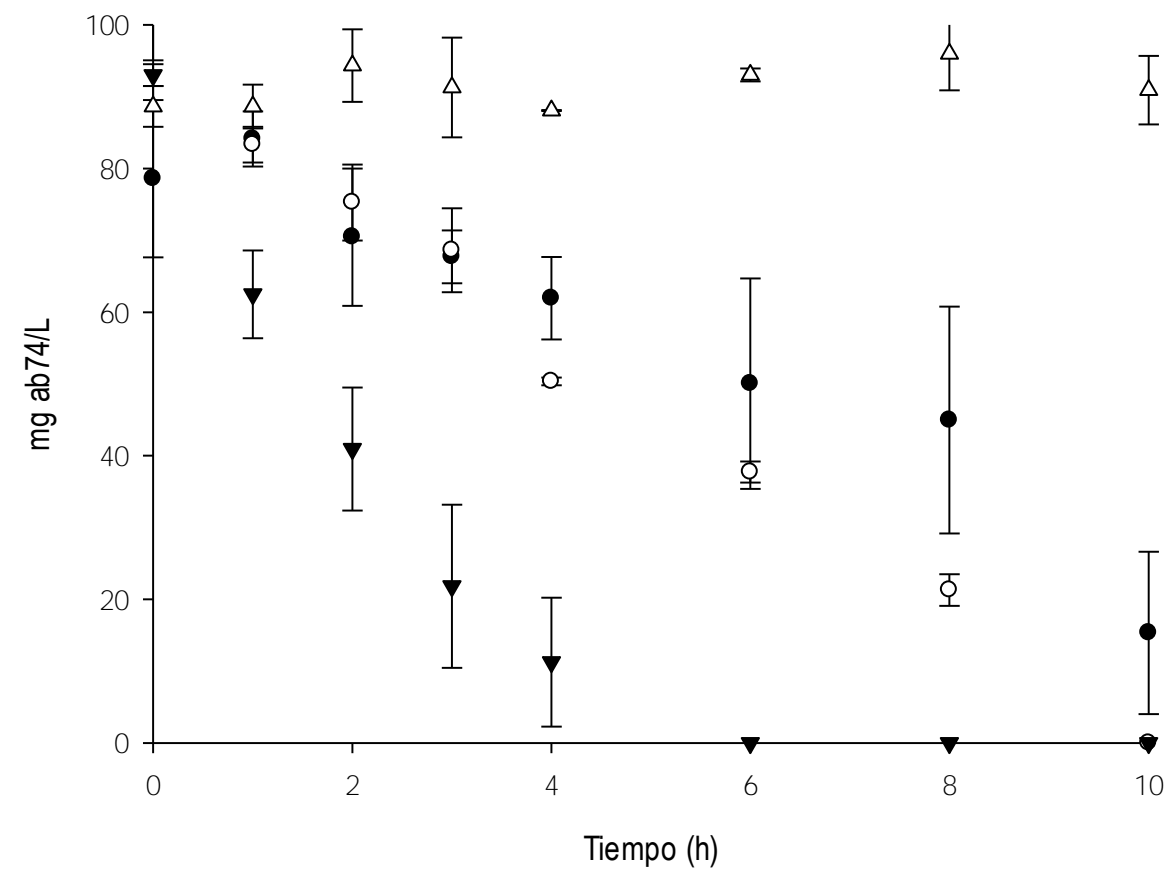

Figura 18. Eliminación física y biológica del ab74. (•) LA, ( ) CA, ( $\mathbf{\nabla}) \mathrm{CA}+\mathrm{LA},(\Delta)$ control abiótico

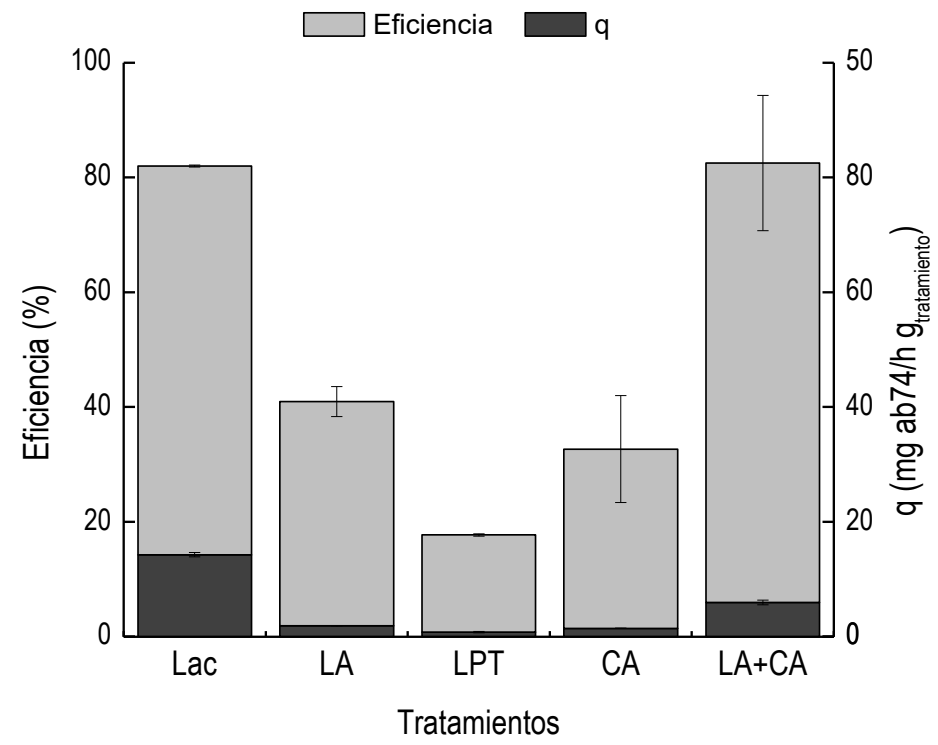

Figura 19. Eficiencia y velocidades específicas de decoloración para los tratamientos evaluados 


\section{$\Delta 0$ 140}

Sin embargo, antes de implementar el tratamiento $C A+L A$, fue importante realizar la evaluación de la capacidad de saturación y regeneración del carbón activado, ya que en procesos de decoloración se ha considerado el proceso de saturación como un cuello de botella o una limitante en procesos de adsorción (Lakshmi y col., 2009). Los resultados obtenidos se muestran mediante la Figura 20. Se evaluó la capacidad máxima de adsorción del CA con el colorante ab74 y su posterior regeneración mediante lodos activados. El experimento consideró distintas etapas (I-IV). La primera y segunda etapa fueron operadas con el objetivo saturar el carbón activado. Para lograr esto, se puso en contacto el carbón activado con una solución de $30 \mathrm{mg}$ ab74/L conteniendo únicamente la espuma de poliuretano con carbón activado, hasta observar el consumo del colorante. En la primera etapa (I), el carbón activado tuvo la capacidad de adsorber todo el colorante con una eficiencia de $100 \pm 2.7 \%$, en la segunda etapa (II) mostró la capacidad de adsorber un segundo lote de ab74 a $30 \mathrm{mg} / \mathrm{L}$ con eficiencia de $74.1 \pm 10.2 \%$. Basados en los datos experimentales, en la segunda etapa, durante el intervalo de tiempo de 75-125 h no se observó una variación en la concentración de ab74 manteniéndose alrededor de $7.5 \mathrm{mg}$ ab74/L, y fue en este punto donde se consideró la saturación del carbón activado. En la tercera etapa (III) se condujo a la regeneración del carbón activado (125 h a $200 \mathrm{~h}$ ), mediante la adición de los lodos activados (2.5 g SSV/L), sin la adición de ab74. Durante esta etapa (III), la concentración del colorante fue cero debido a la decoloración de los lodos activados, con lo que se asumió que los lodos activados mostraron la capacidad de regenerar el carbón activado de manera in situ sin liberar coloración en el medio. Para corroborar este supuesto, se evaluó una etapa IV en la cual se removieron los lodos activados del carbón activado y se alimentó otro lote de ab74 con una concentración inicial de $30 \mathrm{mg} / \mathrm{L}$ observándose una eficiencia de decoloración de $100 \pm 3.5$ \%. Como se observa en la Figura 20, el carbón activado recuperó su capacidad adsorbente mediante la actividad de los lodos activados. Este comportamiento sinérgico encontrado, aparenta ser un método atractivo para ser implementado a nivel industrial ya que la actividad biológica decolorante puede ser incrementada mediante el uso simultáneo de carbón activado y al mismo tiempo se puede llevar acabo la regeneración in situ del adsorbente. 


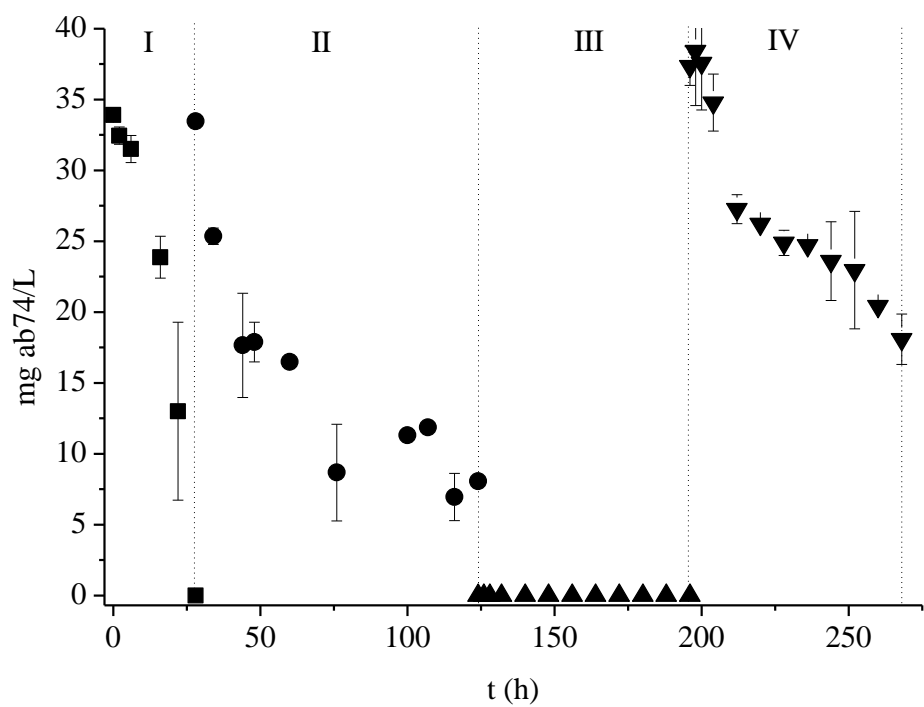

Figura 20. Perfil de decoloración de ab74 usando carbón activado (CA).

(I) Adsorción de ab74 en CA; (II) Saturación de CA mediante ab74; (III) Regeneración de CA mediante LA; (IV) Segundo adsorción de an74 en CA

\subsection{Resultados Etapa 2}

A continuación, se presenta la segunda etapa de resultados, que describe el traslado de los experimentos evaluados en lote en matraces de $250 \mathrm{~mL}$ a un reactor híbrido continuo de flujo ascendente de 1.6 L. Es decir, la evaluación de la decoloración del ab74 en presencia de nitrógeno amoniacal, mediante la acción sinérgica del carbón activado acoplado al sistema de lodos activados. En esta segunda sección se presentan los resultados de la oxidación y adsorción simultánea del ab74 y amonio en un reactor híbrido nitrificante-decolorante-desnitrificante de flujo ascendente, así como las variables de respuesta cinética y metabólicas en un sistema continuo (reactor hibrido) y en lote.

\subsubsection{Cinéticas amonio oxidantes y decolorantes en lote}

Con el objetivo de obtener los parámetros cinéticos de la oxidación y adsorción simultánea del amonio y ab74, se complementaron las comparaciones biocinéticas de decoloración mediante la adición de un segundo sustrato, nitrógeno de amonio $\left(\mathrm{NH}_{4}{ }^{+}\right)$, así como para comprender la relación sinérgica del carbón activado soportado en espuma de poliuretano y los lodos activados dentro del reactor híbrido 
$\Delta 0140$

en la oxidación y adsorción simultánea del $\mathrm{NH}_{4}{ }^{+}$y ab74. Las Figuras 21 y 22, describen el consumo simultáneo de $\mathrm{N}-\mathrm{NH}_{4}{ }^{+}$y ab74.

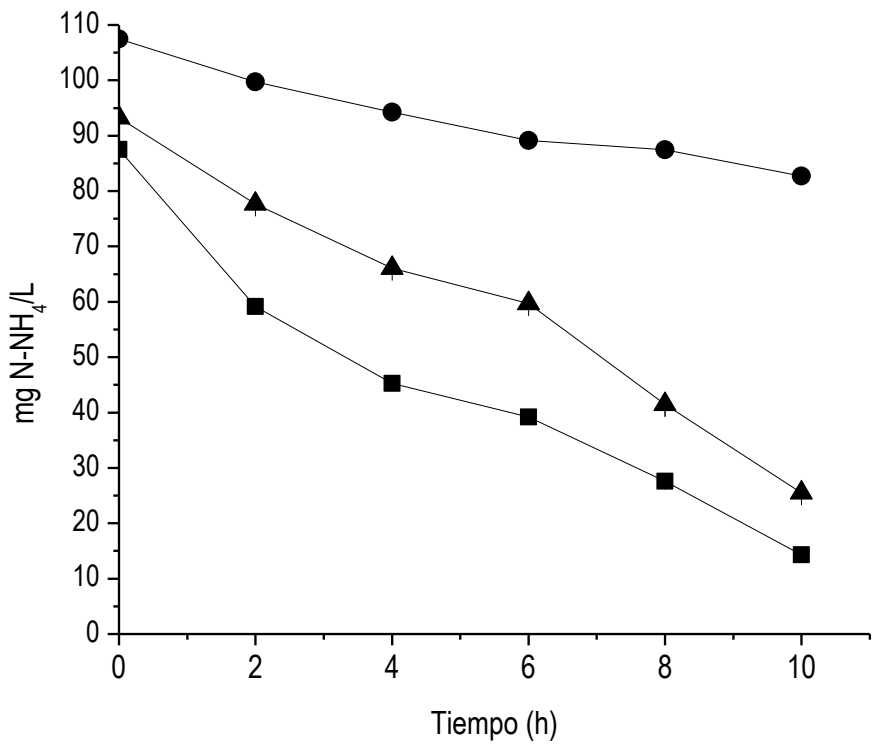

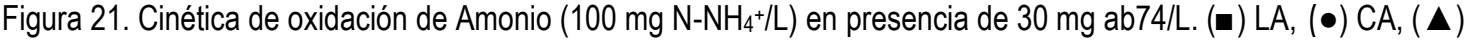
$C A+L A$

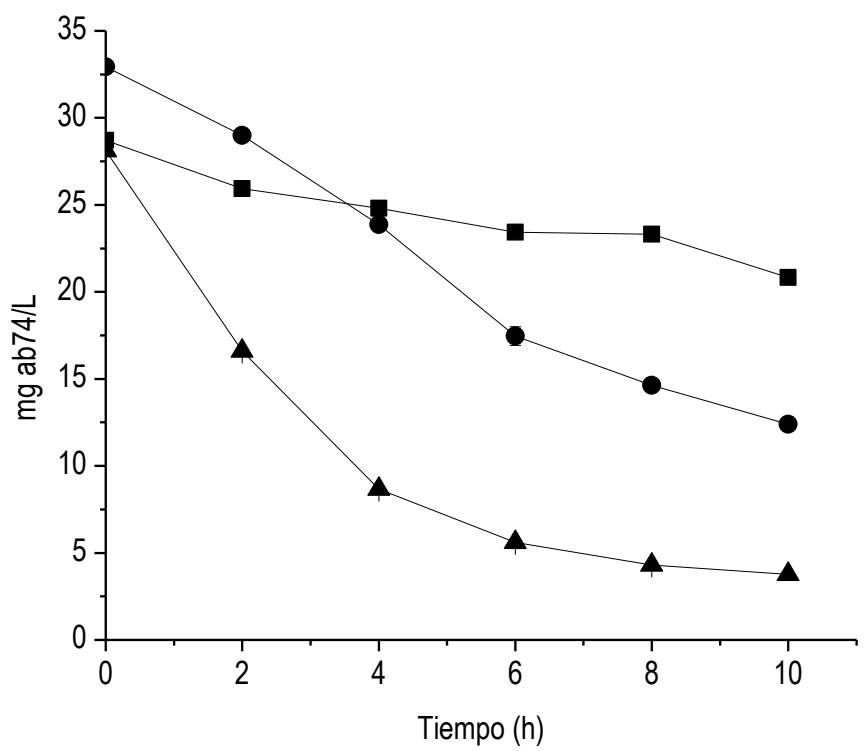

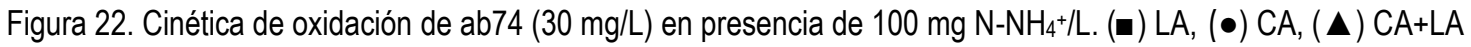


Como puede apreciarse, cuando se encuentran ambos sustratos presentes en una misma unidad experimental, la velocidad de consumo de amonio se favorece con el tratamiento de lodos activados (LA), sin embargo, la velocidad de decoloración no se ve favorecida mediante este tratamiento, el ab74 se decolora con una mejor velocidad específica de $1.50 \pm 0.01 \mathrm{mg}$ ab74/ $\mathrm{g} \mathrm{h}$ con el tratamiento de carbón activado y lodos activados (CA+LA) (Fig. 26), es decir, la decoloración tuvo una mejora de 1.8 veces cuando se evaluó la oxidación y adsorción simultánea de ambos sustratos $\left(\mathrm{NH}_{4}{ }^{+}+\mathrm{ab} 74\right)$ que cuando se evaluaron de manera independiente (Fig. 25).

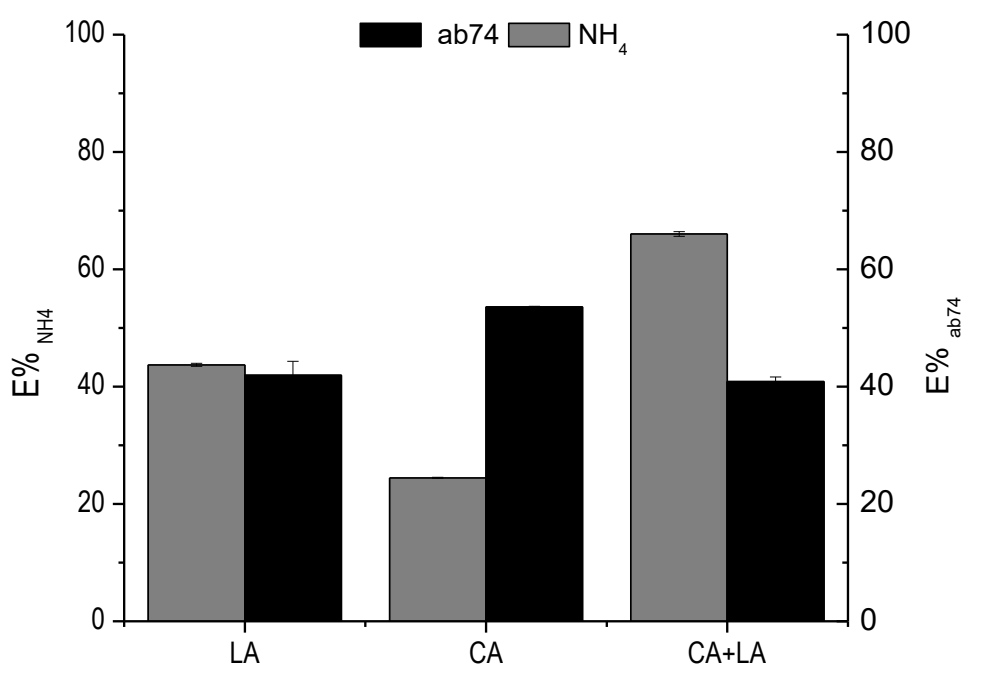

Figura 23. Eficiencia de oxidación independiente de $\mathrm{NH}_{4}+\left(100 \mathrm{mg} \mathrm{N}-\mathrm{NH}_{4} / \mathrm{L}\right)$ y ab74(30 mg/L) mediante LA, CA y CA+LA 


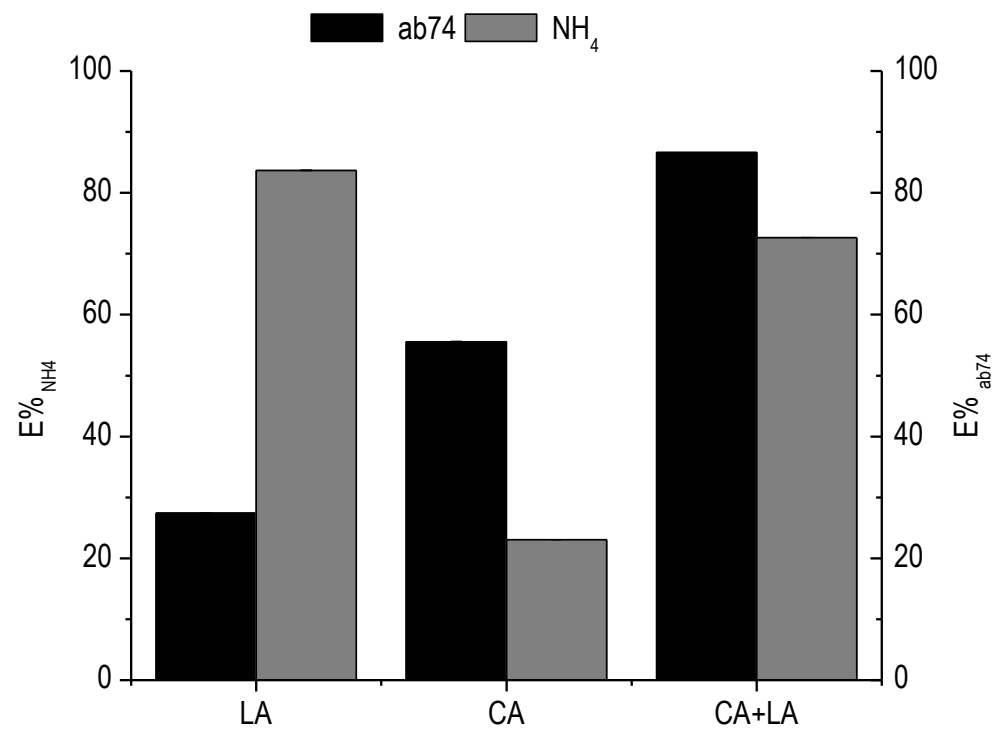

Figura 24. Eficiencia de oxidación simultánea de $\mathrm{NH}_{4}{ }^{+}\left(100 \mathrm{mg} \mathrm{N}-\mathrm{NH}_{4} / \mathrm{L}\right)+$ ab74 $(30 \mathrm{mg} / \mathrm{L})$ mediante LA, CA y CA+LA

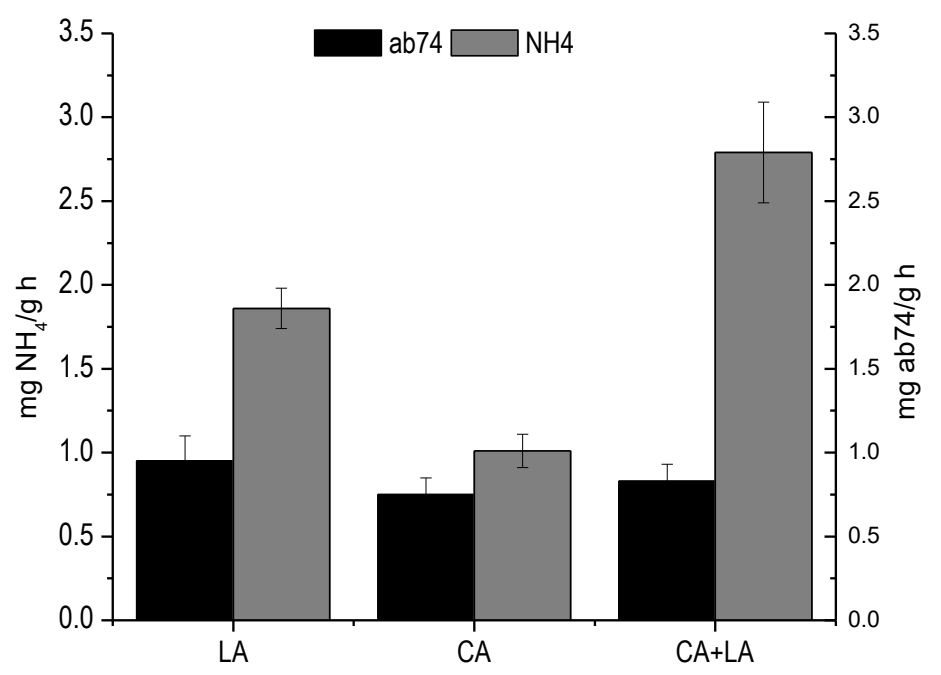

Figura 25. Velocidades especificas de oxidación independiente de $\mathrm{NH}_{4}+\left(100 \mathrm{mg} \mathrm{N}-\mathrm{NH}_{4} / \mathrm{L}\right)$ y ab74(30 mg/L) mediante LA, $C A$ y $C A+L A$ 


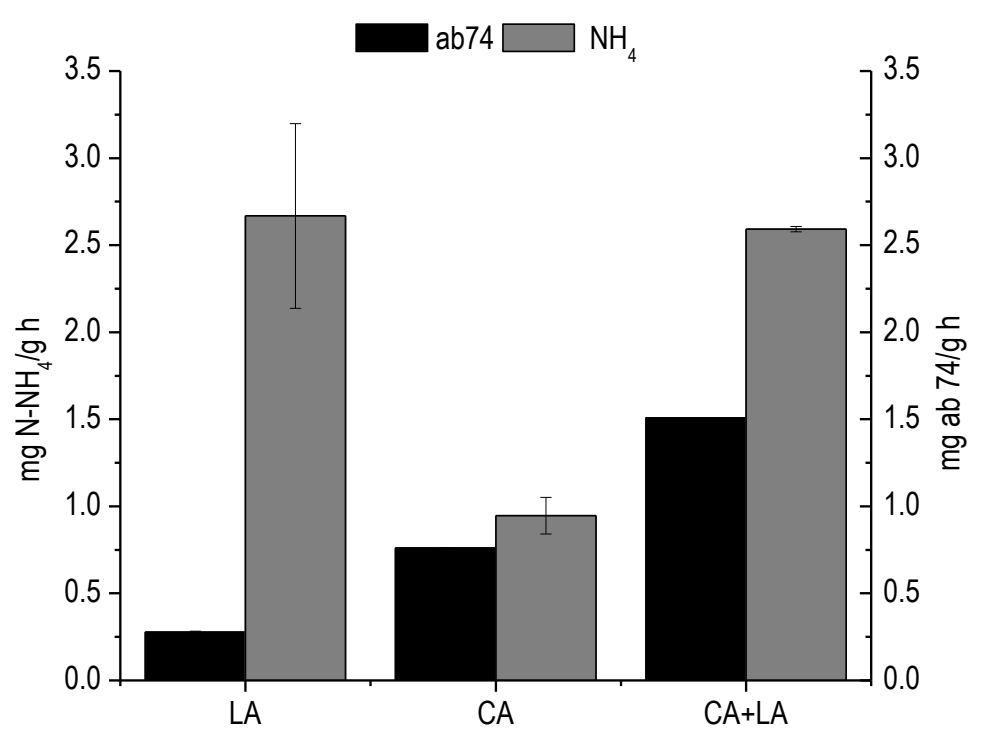

Figura 26. Velocidades específicas de oxidación simultánea de $\mathrm{NH}_{4}+\left(100 \mathrm{mg} \mathrm{N}-\mathrm{NH}_{4} / \mathrm{L}\right)+a b 74(30 \mathrm{mg} / \mathrm{L})$ mediante LA, CA y $C A+L A$

Para el análisis de resultados de todos los tratamientos evaluados en la oxidación y adsorción simultánea de $\mathrm{NH}_{4}{ }^{+}$y ab74 se realizó un análisis estadístico de las variables de respuesta metabólicas y cinéticas, en las que se observó que hubo diferencia significativa la velocidad específica de decoloración y eficiencia de consumo de $\mathrm{NH}_{4}+$ y ab74 entre todos los tratamientos, excepto entre los tratamientos de $C A$ y $C A+L A$, en los cuales, mediante un ANOVA y la prueba de comparación múltiple de Tukey no se observó una diferencia estadísticamente significativa $(P<0.05)$ entre las velocidades de consumo de amonio. Sin embargo, el tratamiento con mejores variables de respuesta, para la eliminación simultánea de $\mathrm{NH}_{4}{ }^{+}$y ab74 fue CA+LA. Por otra parte, al comparar los tres tratamientos, se evidenció la contribución de cada tratamiento para cada sustrato, es decir, que cuando ambos sustratos se encuentran presentes, el consumo de amonio predominó por la vía biológica mediante LA, y el proceso de decoloración de ab74 predominó por la vía físico química mediante CA (Fig. 24 y 26). Es de conocimiento que al ser el nitrógeno amoniacal un contaminante muy importante, se han implementado diversos métodos para su tratamiento y/o eliminación, métodos fisicoquímicos (arrastre de amoniaco "stripping", cloración, intercambio iónico, etc.) y biológicos (procesos respiratorios microbianos). Sin embargo, los tratamientos biológicos se han utilizado sobre los tratamientos fisicoquímicos debido a la afinidad de los microorganismos por el amonio como sustrato, la alta eficiencia de consumo, bajos costos y flexibilidad de operación (Tchobanoglous y Burton, 1991; Cervantes-Carrillo y col., 2000). Como se describe mediante la eficiencia de consumo en la Figura 24, los resultados mostraron la capacidad metabólica de los lodos activados (LA) para nitrificar con una eficiencia de $83.68 \pm 0.1 \%$ y decolorar el ab74 $23.03 \pm 0.3 \%$. No obstante, el tratamiento de CA 


\section{$\Delta a 140$

favoreció la decoloración incrementando la eficiencia hasta $55.56 \pm 0.8 \%$. Sin embargo, la participación en conjunto de estos tratamientos (CA+LA) mejoró la eficiencia de consumo de ambos sustratos a $72.62 \pm 0.4 \%$ y $86.61 \pm 0.5 \%$ para amonio y ab74 respectivamente (Fig. 24). Cuando se trató la eliminación simultánea de ab74 y $\mathrm{NH}_{4}{ }^{+}$mediante $\mathrm{CA}+\mathrm{LA}$, se evidenció que el consumo de amonio de $72.62 \pm 0.4 \%$ se eliminó vía nitrificante con un rendimiento en la producción de nitrito y nitrato de $0.02 \pm 0.001$ y $0.36 \pm 0.001$, respectivamente, es decir que alrededor del $38 \%$ se eliminó vía biológica y $34 \%$ vía fisicoquímica con $\mathrm{CA}$.

Como se mencionó anteriormente, la adición del carbón activado mejoró la eliminación de estos compuestos debido a sus propiedades físico químicas de porosidad y área superficial que le permiten incrementar los fenómenos de adsorción (Navarro y Vargas, 2010), y por lo tanto incrementar la eficiencia de consumo de ab74 y $\mathrm{NH}_{4}{ }^{+}$en distintas proporciones. Por lo cual, cuando el tratamiento fue sinérgico entre LA y CA, el tratamiento para la eliminación de $\mathrm{NH}_{4}{ }^{+}$y ab74 se mejoró cinética y metabólicamente.

Por otra parte, la eliminación de ambos sustratos, ab74 y $\mathrm{NH}_{4}{ }^{+}$se evaluó de manera individual como estudios control, es decir la eliminación de amonio en ausencia de ab74 y la eliminación de ab74 en ausencia de $\mathrm{NH}_{4}{ }^{+}$. Los resultados de eficiencia y velocidad específica de consumo se compararon en el mejor tratamiento, CA+LA. Como se describe en la Tabla 9 y 10 , se obtuvo una mejora en la variable de respuesta metabólica, incrementando la eficiencia de consumo de amonio $6.6 \%$ cuando el cultivo se encontró en presencia del colorante ab74 y al mismo tiempo la eficiencia de consumo de ab74 se mejoró $45.7 \%$ en presencia de amonio. Por otra parte, la respuesta cinética nitrificante, también se vio mejorada en presencia del ab74, incrementando la velocidad específica de consumo de amonio 1.8 veces cuando se encuentra en presencia de ab74 respecto al cultivo donde solo se utiliza al amonio como sustrato. Estos resultados sugieren que el ab74 podría estar actuando como un co-sustrato en el proceso nitrificante y el amonio en el proceso decolorante. Algunos autores han definido a un cosustrato como un sustrato adicional que mejora las variables de respuesta del cultivo, y que al mismo tiempo puede utilizarse como un donador de electrones que mejora las reacciones oxido-reducción (Morales-Guzmán y col. 2009; Martínez-Gutiérrez, 2013). Morales-Guzmán y col. (2009), evaluaron el tratamiento de colorante azo rojo directo 23 , mediante la adición de acetato como co-sustrato, en el cual observaron el $83 \%$ de decoloración en presencia del co-sustrato, mientras que en ausencia de éste solo fue del $63 \%$. Por su parte, Martínez-Gutiérrez y col. (2013) en un proceso desnitrificante con lodos activados evaluaron el consumo del 2-clorofenol y la influencia del acetato y fenol como cosustratos, mejorando la eficiencia de consumo hasta el $100 \%$ y la velocidad específica de consumo se incrementó entre 2 y 9 veces.

Con lo anterior, las cinéticas de consumo en lote permitieron obtener información sobre la influencia del amonio y/o ab74 en el proceso decolorante y nitrificante dentro del reactor híbrido de flujo ascendente. 
Tabla 9. Eficiencia de consumo de amonio y ab74 en lote mediante $C A+L A$

\begin{tabular}{|c|c|c|}
\hline Sustrato & E\% ab74 & E\% NH4 \\
\hline $\mathrm{NH}_{4}{ }^{+}$ & Ausente & $66.02 \pm 0.1$ \\
\hline $\mathrm{ab74}$ & $40.87 \pm 0.1$ & Ausente \\
\hline $\mathrm{NH}_{4}{ }^{+}+\mathrm{ab74}$ & $86.61 \pm 0.1$ & $72.65 \pm 0.1$ \\
\hline
\end{tabular}

Tabla 10. Velocidad específica de consumo de amonio y ab74 en lote mediante $C A+L A$

\begin{tabular}{|c|c|c|}
\hline Sustrato & $\mathrm{q}_{\text {ab74 }}$ & $\mathrm{q}_{\mathrm{NH} 4}$ \\
\hline $\mathrm{NH}_{4}{ }^{+}$ & Ausente & $2.8 \pm 0.03$ \\
\hline $\mathrm{ab74}$ & $0.83 \pm 0.01$ & Ausente \\
\hline $\mathrm{NH}_{4}{ }^{+}+\mathrm{ab} 74$ & $1.51 \pm 0.01$ & $2.6 \pm 0.02$ \\
\hline
\end{tabular}

\subsubsection{Reactor híbrido}

\subsubsection{Módulo nitrificante-decolorante (m1)}

El sistema híbrido se operó inicialmente con el módulo aerobio bajo condiciones nitrificantes para la oxidación y adsorción simultánea del amonio y el colorante azul ácido 74 durante 22 días con el objetivo de adaptar al sistema biológico de lodos activados al nuevo sustrato, nitrógeno amoniacal, en presencia del ab74, así como para evidenciar la capacidad nitrificante de los lodos. El módulo nitrificante se arrancó con un lodo previamente expuesto al ab74 (Fig. 27), en el cual se monitoreó el comportamiento de los compuestos nitrogenados en el influente $\left(\mathrm{N}_{-}-\mathrm{NH}_{4}{ }^{+}\right)$y ab74; y en el efluente $(\mathrm{N}$ $\mathrm{NO}_{2-}, \mathrm{N}^{-\mathrm{NO}_{3}}{ }^{-}$) así como la DQO. Con este perfil, se observó que se pudieron reproducir los estudios previos en lote en un sistema continuo, mediante la acción sinérgica del carbón activado y los lodos activados para nitrificar (Fig. 27) y decolorar el ab74 (Fig. 28), obteniendo una eficiencia de consumo de $99.5 \pm 8.3 \%$ y $57.8 \pm 28.4 \%$ para amonio y ab74 respectivamente en el módulo 1 , con estos resultados se evidenció la capacidad del módulo 1 (nitrificante-decolorante) para oxidar y adsorber el nitrógeno de amonio y el ab74 de manera simultánea. Los rendimientos para el proceso nitrificante fueron $Y_{\mathrm{NO2} / \mathrm{NH} 4}=0.5 \pm 0.3$ y $\mathrm{Y}_{\mathrm{NO} / \mathrm{NH} 4}=0.4 \pm 0.3$. Lo que sugiere una nitrificación parcial con capacidad decolorante, que permitirá acoplar al módulo 1 nitrificante a un proceso anaerobio para la reducción de $\mathrm{NO}_{2}-\mathrm{y} / \mathrm{NO}_{3}$ - hasta nitrógeno molecular como compuesto inocuo al ambiente en un segundo módulo desnitrificante, como se ha propuesto en recientes procesos simultáneos del ciclo del nitrógeno (Silva y col., 2011; Téllez-Pérez y col., 2013). Estos autores han mostrado el comportamiento del proceso nitrificante de lodos activados en presencia de compuestos aromáticos, en el cual han reportado eficiencias de consumo de amonio cercanas al $100 \%$ incluso en presencia de hasta 200 $\mathrm{mg} \mathrm{C/L}$, sin embargo al incrementar la concentración de carbono a $400 \mathrm{mg} \mathrm{C/L}$, observaron una disminución en el rendimiento de la producción de nitrato a $Y_{\mathrm{NO} 3}=0.78 \pm 0.05$, sin embargo reiteran que la configuración del reactor (reactor de lotes secuenciados) así como los ciclos de operación 
pueden mejorar la eliminación simultánea de compuestos recalcitrantes como los evaluados. Este reporte propone que, disminuir el rendimiento nitrificante, al ser un proceso de nitrificación parcial, puede acoplarse a un segundo sistema para reducir estos compuestos a nitrógeno molecular. Tal como fue el caso del presente estudio, como se muestra en los resultados del reactor híbrido $(\mathrm{m} 1+\mathrm{m} 2)$.

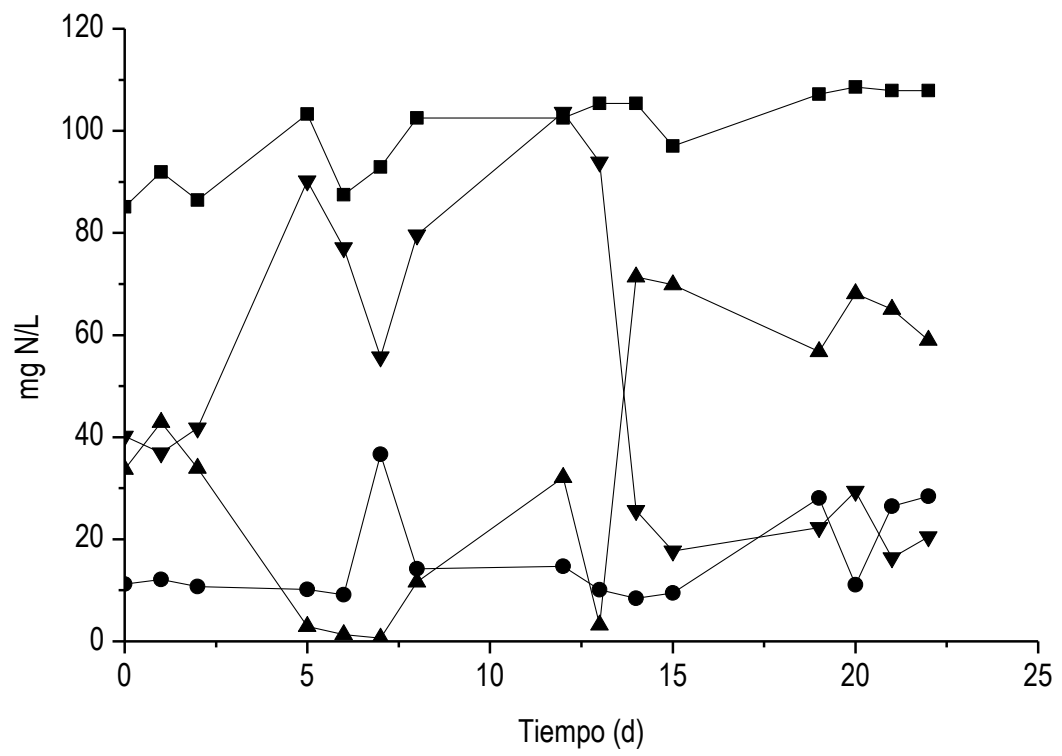

Figura 27. Perfil de los compuestos nitrogenados en el módulo nitrificante (m1).

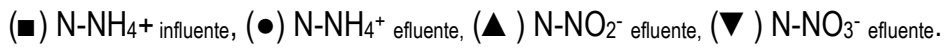

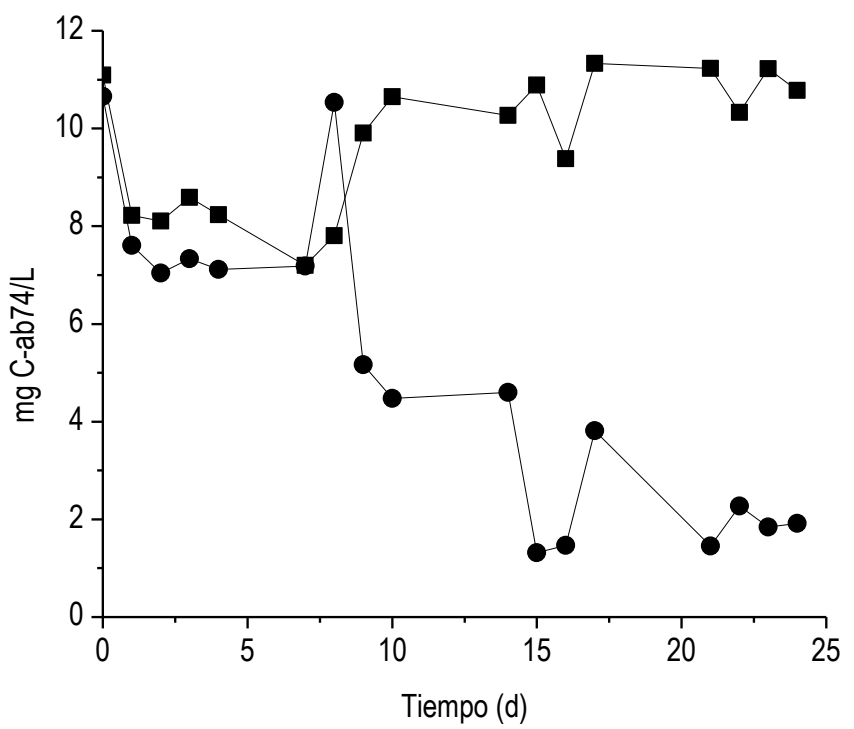

Figura 28. Perfil de carbono de ab74 en el módulo nitrificante (m1).

(घ) C-ab74 influente, (•) C-ab74 efluente 
7.2.2.2 Reactor híbrido (m1+m2)

En esta sección se muestran los resultados del acoplamiento de ambos módulos, es decir, del reactor híbrido. Operando en el módulo 1 el proceso nitrificante y la decoloración del ab74, mediante lodos activados y carbón activado, y el segundo módulo desnitrificante con lodos activados soportados en espuma de poliuretano, con el objetivo de oxidar simultáneamente el amonio y ab74 en el módulo aerobio (m1) y reducir los productos resultantes de este proceso $\left(\mathrm{NO}_{2}^{-}\right.$y $\left.\mathrm{NO}_{3}{ }^{-}\right)$en el módulo desnitrificante (m2) utilizando al ab74 residual o productos de la oxidación del ab74 (ácido isatín sulfónico ó ácido antranílico según la ruta reportada por Campos y col. (2001) y Fischer y col. (2005)), como donador de electrones en el proceso desnitrificante.

La Figura 29, muestra el perfil de concentración de los compuestos nitrogenados dentro del reactor

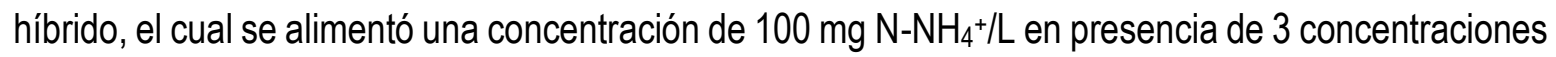
distintas de ab74 (30, 60 y 90 mg/L). Como se observa en el perfil, a partir del día 28 de operación, el reactor híbrido alcanzó el estado pseudo estacionario en el proceso acoplado nitrificantedesnitrificante, con un coeficiente de variación menor al $10 \%$ en la variable metabólica de respuesta de eficiencia de consumo de amonio. A partir de ese día se evaluó la estabilidad de ambos procesos respiratorios en presencia de $30 \mathrm{mg}$ ab74/L, con una eficiencia de consumo de amonio de $97.3 \pm 1.4$ $\%$ y un rendimiento de productos a la salida del módulo nitrificante de $0.4 \pm 0.3$ para el $Y_{\mathrm{NO} 2}$ y $0.4 \pm$ 0.1 para el $Y_{\text {NO3 }}$, y a la salida del módulo desnitrificante se observó una eficiencia de consumo de nitrito y nitrato de $63.5 \pm 26.8 \%$ y $54.8 \pm 28.6 \%$, respectivamente. Con base en la eficiencia de consumo de nitrato y nitrito y la alta eficiencia de consumo de amonio, estos resultados sugieren que el proceso nitrificante se acopló al proceso desnitrificante en una misma unidad experimental y se apreció la oxidación y adsorción simultánea del ab74 (Fig. 27) con una eficiencia de $66.6 \pm 5.6 \%$. El proceso desnitrificante también se corroboró mediante la oxidación del ab74, siendo utilizado como posible donador de electrones en el proceso desnitrificante mostrando una eficiencia de consumo de COT de $49.0 \pm 8.8 \%$ en el módulo anaerobio siendo $25 \%$ mayor el consumo de COT que en el módulo aerobio (m1). Algunos trabajos con lodos activados, han reportado a la cepa de Bacillus sp. con capacidad de oxidar el ab74 y desnitrificar, sin embargo, la evaluación del proceso respiratorio y la decoloración del ab74 la han realizado de manera individual para cada sustrato (Brycki y col., 2000). En el presente estudio, cabe destacar que la oxidación de ambos sustratos se logró de manera simultánea, en un proceso secuencial y en una misma unidad experimental. Por otra parte, cuando la concentración del colorante fue elevada (mayor a $30 \mathrm{mg} / \mathrm{L}$ ), el proceso nitrificante se mantuvo con alta eficiencia en el consumo de amonio de $99.0 \pm 0.3 \%$ y $98.6 \pm 0.5 \%$ en presencia de 60 y $90 \mathrm{mg}$ ab74/L respectivamente. Sin embargo, el rendimiento de la producción de nitrito fue nula a estas concentraciones de ab74, siendo el nitrato el único producto de la oxidación del amonio con

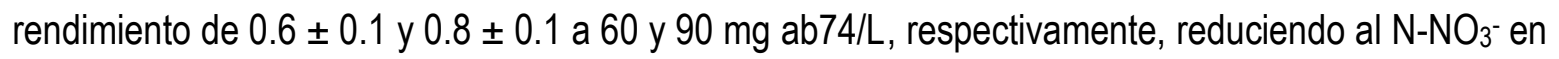
el módulo desnitrificante con una eficiencia de consumo de $15.6 \pm 6.9 \%$ a $60 \mathrm{mg}$ ab74/L y una E\%NO3 de $17.1 \pm 1.3 \%$ a $90 \mathrm{mg}$ ab74/L, donde la eficiencia de consumo del COT para cada concentración de ab74 evaluada fueron $18.0 \pm 14 \%$ y $11.7 \pm 3.3 \%$ respectivamente. Es decir, que el proceso 
desnitrificante en presencia de concentraciones mayores a $30 \mathrm{mg}$ ab74/L se vio disminuido alrededor de $30 \%$, respecto a la primera concentración de ab74 evaluada.

En la Tabla 11 y 12 se muestran las semireacciones de reducción y oxidación, así como el número de mili-equivalentes (meq) de electrones involucrados en los procesos biológicos. Se realizó un balance de electrones con los productos y sustratos residuales entrantes al módulo 2, considerando las semireacciones de la Tabla 11. Por ejemplo, a la primera concentración de $30 \mathrm{mg}$ ab74/L evaluada, la cantidad de ab74 residual, así como los intermediarios carbonados (ácido antranílico o isatín sulfónico) formados, dieron una cantidad de $2.8 \mathrm{meq}$ de electrones totales donados, mientras que las concentraciones de nitrato y nitrito cuantificadas dieron una cantidad de 20.2 meq de electrones totales aceptados, lo que indica un exceso de la fuente oxidante, es decir, suficiente aceptor de electrones para mineralizar completamente la materia orgánica (Tabla 13). En el efluente del reactor híbrido se detectaron residuales de materia orgánica y nitrato (Tabla 14), lo que indicó que la materia orgánica no fue completamente mineralizada a pesar del exceso de la fuente oxidante, lo que estaría sugiriendo fuertes efectos inhibitorios. A las otras dos concentraciones de ab74 evaluadas, se observó el mismo comportamiento redox.

Tabla 11. Semireacciones químicas

\begin{tabular}{|l|l|}
\hline Nitrato reducción & $\mathrm{NO}_{3}^{-}+6 \mathrm{H}^{+}+5 \mathrm{e}^{-} \rightarrow 0.5 \mathrm{~N}_{2}+3 \mathrm{H}_{2} \mathrm{O}$ \\
\hline Nitrito reducción & $\mathrm{NO}_{2}-4+4 \mathrm{H}^{+}+3 \mathrm{e}^{-} \rightarrow 0.5 \mathrm{~N}_{2}+2 \mathrm{H}_{2} \mathrm{O}$ \\
\hline Oxidación de ab74 (ab74) & $\mathrm{C}_{16} \mathrm{H}_{8} \mathrm{~N}_{2} \mathrm{O}_{8} \mathrm{~S}_{-}^{-2}+32 \mathrm{H}_{2} \mathrm{O} \rightarrow 16 \mathrm{CO}_{2}+2 \mathrm{SO}_{4}^{-2}+2 \mathrm{NH}_{4}^{+}+64 \mathrm{H}^{+}+64 \mathrm{e}^{-}$ \\
\hline Oxidación de isatín sulfónico (isa) & $\mathrm{C}_{8} \mathrm{H}_{4} \mathrm{NO}_{5} \mathrm{~S}^{-}+15 \mathrm{H}_{2} \mathrm{O}+28 \mathrm{e}^{-} \rightarrow 8 \mathrm{CO}_{2}+\mathrm{SO}_{4}^{-2}+\mathrm{NH}_{4}^{+}+30 \mathrm{H}^{+}$ \\
\hline Oxidación de ácido antranílico (ant) & $\mathrm{C}_{7} \mathrm{H}_{7} \mathrm{NO}_{2}+12 \mathrm{H}_{2} \mathrm{O} \rightarrow 7 \mathrm{CO}_{2}+\mathrm{NH}_{4}+27 \mathrm{H}^{+}+27 \mathrm{e}^{-}$ \\
\hline
\end{tabular}

Tabla 12. meq de electrones donados o aceptados por mol de sustrato

\begin{tabular}{|c|c|c|c|c|}
\hline $\begin{array}{c}\text { meq aceptados } \\
\mathrm{NO}_{3} \rightarrow \mathrm{N}_{2}\end{array}$ & $\begin{array}{c}\text { meq aceptados } \\
\mathrm{NO}_{2} \rightarrow \mathrm{N}_{2}\end{array}$ & $\begin{array}{c}\text { meq donados } \\
\mathrm{ab74} \rightarrow \mathrm{CO}_{2}\end{array}$ & $\begin{array}{c}\text { meq donados } \\
\text { isa } \rightarrow \mathrm{CO}_{2}\end{array}$ & $\begin{array}{c}\text { meq donados } \\
\text { ant } \rightarrow \mathrm{CO}_{2}\end{array}$ \\
\hline $5 \mathrm{e}^{-}$ & $3 \mathrm{e}^{-}$ & $64 \mathrm{e}^{-}$ & $28 \mathrm{e}^{-}$ & $27 \mathrm{e}^{-}$ \\
\hline
\end{tabular}

Tabla 13. Balance estequiométrico de electrones en el RCFA (meq)

\begin{tabular}{|c|c|c|c|}
\hline $\mathrm{mg}$ ab74/L & meq donados & meq aceptados & óxido-reducción \\
\hline 30 & 2.8 & 20.2 & Desbalanceado \\
\hline 60 & 8.2 & 23.8 & Desbalanceado \\
\hline 90 & 11.7 & 32.6 & Desbalanceado \\
\hline
\end{tabular}

Tabla 14. Eficiencia de consumo de carbono orgánico total (COT)

\begin{tabular}{|c|c|c|}
\hline $\mathrm{mg} \mathrm{ab74/L}$ & $\mathrm{E} \%$ сот $\mathrm{m} 1(\%)$ & $\mathrm{E} \%$ сот $\mathrm{m} 1+\mathrm{m} 2(\%)$ \\
\hline 30 & $25.5 \pm 3.4$ & $49.0 \pm 8.8$ \\
\hline 60 & $1.3 \pm 1.2$ & $18.0 \pm 1.4$ \\
\hline 90 & $3.6 \pm 0.5$ & $11.7 \pm 3.3$ \\
\hline
\end{tabular}


La eficiencia de consumo de COT (Tabla 14), sugirió que el proceso desnitrificante no se vio disminuido debido a una limitación de materia orgánica para acoplarse a la reducción del nitrato. Por el contrario, los resultados podrían estar indirectamente relacionados con la concentración del ab74, es decir, con los productos de la oxidación del ab74 (intermediarios). El ab74 es un colorante frecuentemente oxidado a isatín el cual es fácilmente hidrolizable a ácido antranílico que ha sido reportado como una sustancia tóxica para la vida acuática (Solís-Oba y col., 2009). Por lo que se ha supuesto que la concentración de este compuesto pudo tener un efecto negativo en la desnitrificación. No obstante, se ha reportado a cepas desnitrificantes como Pseudomonas sp. con capacidad de crecer en ácido antranílico a una concentración de 68.5 mg/L (Braun y Gibson, 1984; Loehmeyer y col., 1992), mientras que, en el presente trabajo, se evaluaron dos compuestos que posiblemente en conjunto contribuyan a la disminución del proceso desnitrificante. Por otra parte, como se observa en el perfil de concentración de carbono de ab74 (Fig. 22), la eficiencia decolorante a 60 y $90 \mathrm{mg}$ ab74/L se mejoró a $95.7 \pm 5.2 \%$ y $95.5 \pm 5.8 \%$ respectivamente (Tabla 15), es decir, que el incremento en la concentración del ab74 en el sistema híbrido fue directamente proporcional al incremento de la eficiencia de decoloración. Estos resultados se encuentran relacionados a una cinética de consumo de primer orden y a fenómenos difusivos del colorante, donde debido al gradiente de concentración se incrementan las áreas superficiales, mejorando así el proceso de adsorción del ab74 en el carbón activado.

Tabla 15. Eficiencia de decoloración

\begin{tabular}{|c|c|c|}
\hline $\mathrm{mg} a b 74 / \mathrm{L}$ & $\mathrm{E} \%$ ab74 $\mathrm{m} 1(\%)$ & $\mathrm{E} \%$ ab74 m1+m2 (\%) \\
\hline 30 & $61.9 \pm 8.7$ & $66.6 \pm 5.6$ \\
\hline 60 & $89.4 \pm 9.0$ & $95.7 \pm 5.2$ \\
\hline 90 & $85.5 \pm 13.0$ & $95.5 \pm 5.8$ \\
\hline
\end{tabular}

Recientemente, los sistemas híbridos se han propuesto como una herramienta innovadora para el mejoramiento de los espacios y costos de operación, como se observó en el presente trabajo. Diversos trabajos muestran la evaluación de combinar parámetros de cultivo para mejorar la operación del sistema, el cual posteriormente puede adoptarse a un sistema híbrido. González-Martínez y col. (2010) operaron un sistema de flujo ascendente, para la eliminación simultánea del colorante azo azul directo 2 y amonio de un agua municipal, con ciclos intermitentes de aireación, lo cual les permitió eliminar el colorante azo en los ciclos anaerobios y utilizar la DQO del agua real como un donador de electrones, incrementando la eficiencia de decoloración hasta $61 \%$ en presencia del agua real. Al mismo tiempo la eficiencia de eliminación del nitrógeno amoniacal, se notó favorecida $17 \%$ en presencia del agua municipal. 


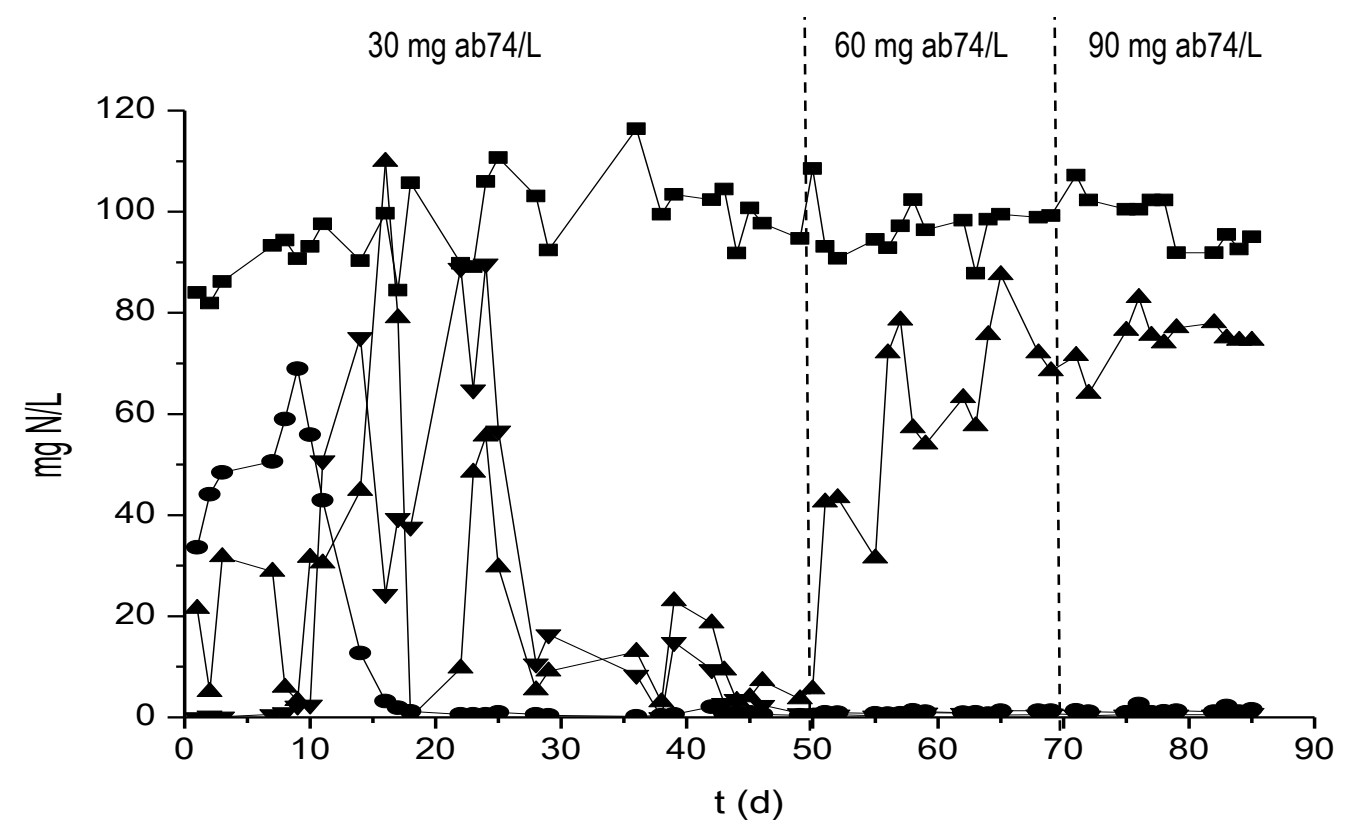

Figura 29. Perfil de los compuestos nitrogenados en el módulo reactor híbrido (m1+m2).

$(\boldsymbol{\bullet}) \mathrm{N}-\mathrm{NH}_{4}{ }^{+}$influente, $(\bullet) \mathrm{N}-\mathrm{NH}_{4}{ }^{+}$efluente, $(\boldsymbol{\nabla}) \mathrm{N}^{-\mathrm{NO}_{2}}{ }^{-}$efluente, $(\boldsymbol{\Delta}) \mathrm{N}^{-} \mathrm{NO}_{3}^{-}$efluente.

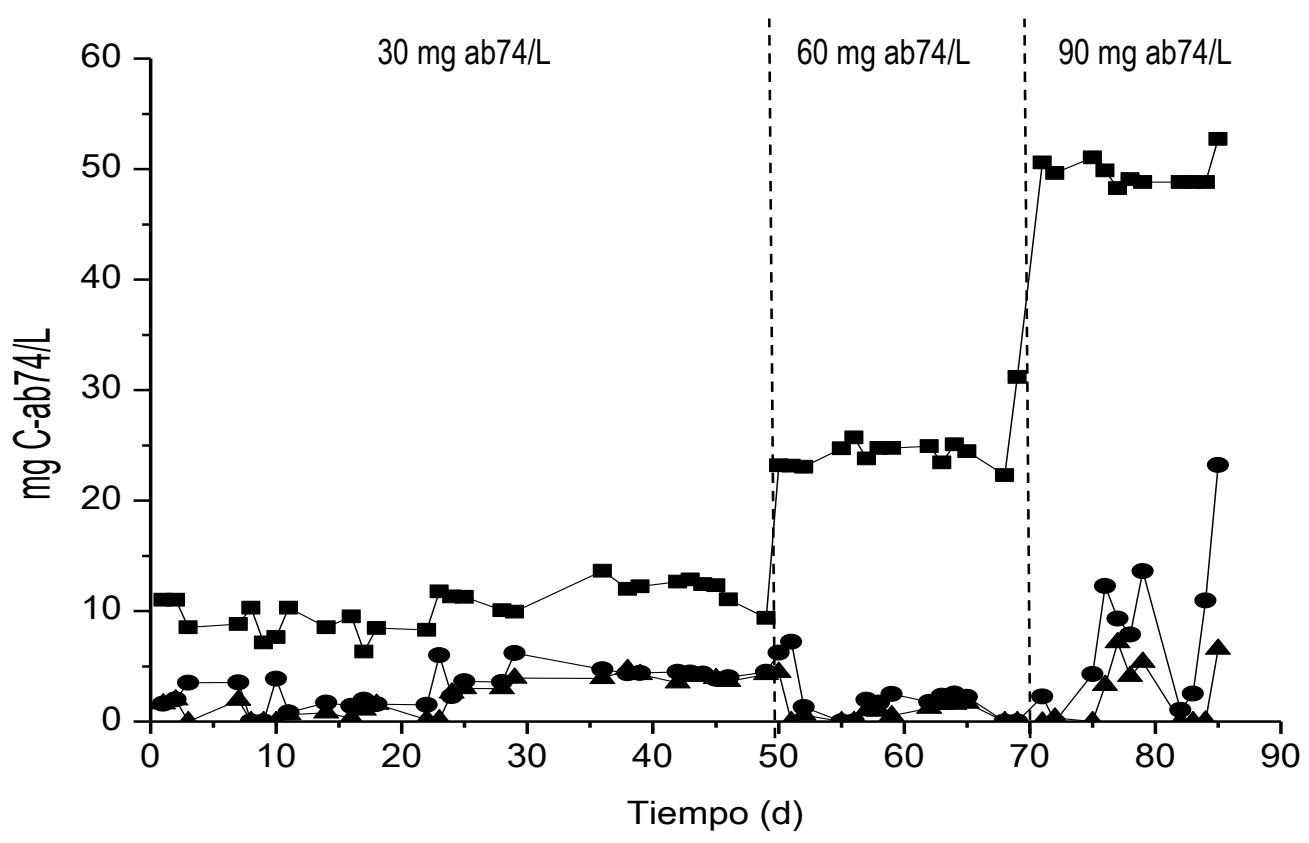

Figura 30. Perfil de carbono de ab74 en el reactor híbrido (m1+m2).

(घ) C-ab74 influente, (•) C-ab74 m1 effuente, ( $\mathbf{\Delta}$ ) C-ab74 m1+m2 efluente. 


\section{Conclusiones}

Mediante los estudios de decoloración en lote empleando enzima comercial lacasa, lodos activados y lodos pre-tratados, se mostró que bacterias contenidas en los lodos activados tuvieron la capacidad de eliminar el colorante azul ácido 74 . Estos microorganismos bacterianos mostraron la contribución de enzimas lacasa en un 20\%, que participaron de forma significativa en el proceso de decoloración del azul ácido 74. Por primera vez se contribuyó con información cuantitativa de la presencia de enzimas lacasa en lodos activados. La velocidad específica y la eficiencia de decoloración, pero esencialmente la regeneración in situ del carbón activado por lodos activados hacen que el tratamiento sinérgico de carbón activado con lodos activados $(C A+L A)$ sea un sistema atractivo para la decoloración de aguas residuales. Sin embargo, son necesarios estudios futuros, como el tiempo de vida del carbón activado, así como el número máximo de veces de regeneración del CA mediante LA, así como evaluar distintas concentraciones y/o TRH de las condiciones estudiadas, con la finalidad de mejorar los parámetros de ingeniería para ampliar esta tecnología.

La evaluación de la decoloración del azul ácido 74 y la oxidación y adsorción simultánea del nitrógeno de amonio en lote, así como la operación del reactor híbrido bajo condiciones decolorante-nitrificantedesnitrificante, dieron evidencia de la capacidad de la oxidación y adsorción simultánea del amonio y del colorante azul ácido 74 en una misma unidad experimental mediante la relación sinérgica de lodos activados y carbón activado, el cual presenta ventajas como la reducción de costos y espacios de operación. Así mismo, al acoplar el sistema híbrido nitrificante-desnitrificante en presencia de $30 \mathrm{mg}$ ab74/L, el sistema hibrido sugiere tener la capacidad de obtener productos inocuos al ambiente, reduciendo los productos de la oxidación del amonio. Sin embargo, es necesario realizar estudios como la identificación de intermediarios producidos en la oxidación del ab74, que podrían tener un efecto negativo en el proceso desnitrificante, esto para extender las condiciones de operación del reactor híbrido bajo concentraciones mayores de carbono y nitrógeno. 


\section{Referencias}

1) Ahmad R., Mondal P., Usmani S. (2010). Hybrid UASFB-aerobic bioreactor for biodegradation of acid yellow-36 in wastewater. Bioresource Technology, 101: 3787-3790.

2) Allen, S. J., Koumanova, B. (2005). Decolourisation of water/wastewater using adsorption. Journal of the University of Chemical Technology and Metallurgy, 40(3): 175-192.

3) Anshuman A., Kapley A., Purohit H. (2007). Simultaneous nitrification and denitrification by diverse Diaphorobacter sp. Applied Microbiology and Biotechnology (77): 403-409.

4) APHAIAWWA/WEF. (2005). Standard Methods for the Examination of Water and Wastewater, Washington DC, USA.

5) Arana-Cuenca A, Roda A, Téllez A, Loera O, Carbajo JM,Terrón MC, González AE. (2004). Comparative analysis of laccase-isozymes patterns of several related Polyporaceae species under different culture conditions. J. Basic Microbiol., 44: 67-79.

6) Arslan-Alaton I., Gursoy B., Schmidt J. (2008). Advanced oxidation of acid and reactive dyes: Effect of Fenton treatment on aerobic, anoxic and anaerobic processes. Dyes and Pigments, 78: 117130.

7) Ayed L., Ksibi l., Cheref A., Backhrouf A. (2012). Response surface methodology for optimization of the treatment of textile wastewater by a novel bacterial consortium: Enzymes and metabolites characterization. African Journal of Biotechnology, 11 (59): 12339-12355.

8) Balan, D. S., Monteiro, R. T. (2001). Decolorization of textile indigo dye by ligninolytic fungi. Journal of Biotechnology, 89(2): 141-145.

9) Baldrian, P., Gabriel, J. (2002). Copper and cadmium increase laccase activity in Pleurotus ostreatus. FEMS Microbiology letters, 206(1): 69-74.

10) Banat, I.M., Nigam, P., Singh, D., Marchant, R., (1996). Microbial decolorization of textile- dye containing effluents: a review. Bioresource Technology, 58: 217-227.

11) Barrios-Ziolo, L. F., Gaviria-Restrepo, L. F., Agudelo, E. A., Cardona-Gallo, S. A. (2015). Technologies for the removal of dyes and pigments present in wastewater. A review. Dyna, 82(191): 118-126.

12) Blume, T., Neis, U. (2004). Improved wastewater disinfection by ultrasonic pre-treatment. Ultrasonics sonochemistry, 11(5): 333-336.

13) Bock E., Koops H.P., Harms H. y Ahler B. (1991). The biochemistry of nitrifying organisms. Variations in autotrophic life. Editorial: Academic Press, San Diego. pp 171-200.

14) Bourbonnais R., Paice M G, Reid I D, Lanthier P., Yaguchi M. (1995). Lignin oxidation by laccase isozymes from Trametes versicolor and role of the mediator 2,2'-azinobis(3-ethylbenzthiazoline6-sulfonate) in kraft lignin depolymerization. Appl. Environ. Microbiol.61(5):1876.

15) Bozzola J., Russell L. (1991). Electron microscopy. Jhones \& Barlett. Subdury. MA. 
16) Braun, K., Gibson, D. T. (1984). Anaerobic degradation of 2-aminobenzoate (anthranilic acid) by denitrifying bacteria. Applied and environmental microbiology, 48(1): 102-107.

17) Brycki B., Seifert K., Szymanska K., Domka F. (2000). The Effect of Oxidizing Biocides on Desulfurication and Denitrification Processes. Polish Journal of Environmental Studies, 9 (5): 363367.

18) Castillo y Bárcenas. (1998). Pentaclorofenol: toxicología y riesgos para el ambiente. Madera y bosques 4:21-37.

19) Cervantes F. (2008). Reducción de colorantes azo por distintos grupos microbianos en consorcios anaerobios. BioTecnología 12: 6-20.

20) Cervantes-Carrillo F., Pérez J., Gómez J. (2000). Avances en la eliminación biológica del nitrógeno de las aguas residuales. Revista Latinoamericana de Microbiología 42: 73-82.

21) Chen K-C, Huang W-T, Wu J-Y, Houng J-Y. (1999). Microbial decolorization of azo dyes by Proteus mirabilis. Journal of Indusltrial Microbiology and Biotechnology 23:686-690.

22) Chen, K., Wu J., Liou D., H Wang, S. (2003) Decolorization of the textile dyes by newly isolated bacterial strains. Journal of Biotechnology, 101: 57-68.

23) Cho, E. A., Seo, J., Lee, D. W., Pan, J. G. (2011). Decolorization of indigo carmine by laccase displayed on Bacillus subtilis spores. Enzyme and microbial technology, 49(1): 100-104.

24) Chung, K.T., Stevens, S.E. (1993). Degradation of azo dyes by environmental microorganism and helminths. Environmental Toxicology and Chemistry, 12: 2121 - 2132.

25) Covarrubias-Vallejo J., Gonzalez-Blanco G., Prado-Barragán A., Beristain-Cardoso R. (2015). Removal of Ammonium and 4-Methylphenol from Synthetic Wastewater by Cell-Free Extracts of Nitrifying Sludge. Water Air Soil Pollut. 226:424.

26) Cristóvão R., Tavares A., Ferreira L., Loureiro J., Boaventura R., Macedo E. (2009). Modeling the discoloration of a mixture of reactive textile dyes by commercial laccase. Bioresource Technology 100: 1094-1099.

27) Cristóvão R., Tavares A., Ribeiro S., Loureiro J., Boaventura R., Macedo E. (2008). Kinetic modelling and simulation of lacasse catalyzed degradation of reactive textile dyes. Bioresource Technology 99: 4768-4774.

28) Daniel LMC, Pozzi E., Foresti E., Chinalia FA. (2009). Removal of ammonium via simultaneous nitrification-denitrification-nitrite shortcut in a single packed-bed batch reactor. Bioresource Technology. 100 (3): 1100-1107.

29) Davies K., Lloyd D., Boddy L. (1989). The Effect of Oxygen on Denitrification in Paracoccus denitrificans and Pseudomonas aeruginosa. Journal of General Microbiology (135): 2445-2451.

30) Davison J. (1999). Genetic exchange between bacteria in the environment. Plasmid 42: 73-91. Denitrifying Bacteria. Applied and Environmental Microbiology, 48 (1): 102-107.

31) Ferguson S. (1994). Denitrification and its control. Antonie van Leeuwenhoek (66): 89-110. 


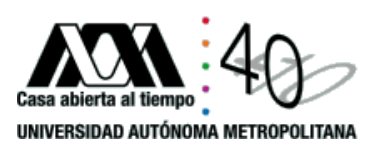

32) Fernández, N., Gómez, R., Amils, R., Sierra-Alvarez, R., Field, J. A., Sanz, J. L. (2006). Microbiological and structural aspects of granular sludge from autotrophic denitrifying reactors. Water science and technology, 54(2): 11-17.

33) Fersht A. (1980). Estructura y mecanismos de los enzimas. Ed. Reverte. Barcelona España. Pp.85-88.

34) Field J., Stams A., Kato M., Schraa G. (1995). Enhanced biodegradation of aromatic pollutants in cocultures of anaerobic and aerobic bacteria consortia. Antonie van Leeuwenhoek 67: 47-77.

35) Firestone M.K. y Davidson E.A. (1989). Microbiological Basis of NO and N2O Production and Consumption in Soil. Exchange of Trace Gases between Terrestrial Ecosystems and the Atmosphere. pp. 7-21.

36) Fischer-Colbrie, G., Maier, J., Robra, K. H., Guebitz, G. M. (2005). Degradation of the indigo carmine dye by an anaerobic mixed population. Environmental Chemistry, 289-294.

37) Foladori, P., Laura, B., Gianni, A., Giuliano, Z. (2007). Effects of sonication on bacteria viability in wastewater treatment plants evaluated by flow cytometry fecal indicators, wastewater and activated sludge. Water Resource 41, 235-243.

38) Forgacs E., Cserháti T., Oros G. (2004). Removal of synthetic dyes from wastewaters: a review. Environmental International, 30: 953-971.

39) Giardina P., Palmieri G., Scaloni A., Fontanella B., Faraco V., Cennamo G., Sannia, G. (1999). Protein and gene structure of a blue laccase from Pleurotus ostreatus. Biochemical Journal. 34: 655-663.

40) González-Blanco G., Beristain-Cardoso R., Cuervo-López F., Cervantes F.J., Gómez J. (2012). Simultaneous oxidation of ammonium and $p$-cresol linked to nitrite reduction by denitrifying sludge. Bioresource Technology, 103 (2012): 48-55.

41) González-Martínez S., Piña-Mondragón S., González-Barceló O. (2010). Treatment of the azo dye direct blue 2 in a biological aerated filter under anaerobic/aerobic conditions. Water Science and Technology. 61 (3): 789-796.

42) Greenpeace (2012) http://www.greenpeace.org/mexico/es/Campanas/Toxicos/Contaminacionde-nuestros-rios/Detox/Las-once-sustancias-quimicas-a-eliminar/\#a10 [Con acceso el 24/04/2014].

43) Gutiérrez E., Colín A. (2012). Remoción de colorantes por métodos sustentables. Enlace Químico UAEM 6: $19-23$.

44) Hammaini, A., González, F., Ballester, A., Blázquez, M. L., Munoz, J. A. (2007). Biosorption of heavy metals by activated sludge and their desorption characteristics. Journal of environmental management, 84(4): 419-426.

45) Hao O., Kim H., Chiang P. (2010). Decolorization of Wastewater. Critical Reviews in Environmental Science and Technology (30:4): 449-505. 
46) Hooper, A. B. (1984). Ammonia oxidation and energy transduction in the nitrifying bacteria. Microbial chemoautotrophy, 133.

47) Ibrahim, V., Mendoza, L., Mamo, G. y Hatti-Kaul, R. (2011). Laccase mediator system for activation of agarose gel: aplication for inmobilization of proteins. Process Biochemistry, 46:379-384.

48) Jadhav JP, Kalyani DC, Telke AA, Phugare SS, Govind SP. (2010). Evaluation of the efficacy of a bacterial consortium for the removal of color, reduction of heavy metals, and toxicity from textile dye effluent. Bioresour. Technol. 101:165-173.

49) Jeffords, D. L., Lance, P. H., \& Dewolf, W. C. (1977). Severe hypertensive reaction to indigo carmine. Urology, 9(2): 180-181.

50) Jensen H. L. (1950). Effect of Organic Compounds on Nitrosomonas. Nature 165: 974.

51) Jiménez R., Cervantes C. (2006). Determinación de la topología de Transportadores bacterianos*. Topología de Transportadores Bacterianos, 25 (1): 3-11.

52) Juretschko, S., Loy, A., Lehner, A., Wagner, M. (2002). The microbial community composition of a nitrifying-denitrifying activated sludge from an industrial sewage treatment plant analyzed by the full-cycle rRNA approach. Systematic and applied microbiology, 25(1): 84-99.

53) Kandelbauer A., Guebitz G. M. (2013). Bioremediation for the Decolorization of Textile Dyes - A Review. Ch 26. Environmental Chemestry. 269-288.

54) Khelifi, E., Gannoun, H., Touhami, Y., Bouallagui, H., Hamdi, M. (2008). Aerobic decolourization of the indigo dye-containing textile wastewater using continuous combined bioreactors. Journal of Hazardous Materials, 152(2): 683-689.

55) Kim, J.K., Park, K.J., Cho, K.S., Nam, S.W., Park, T.J., Bajpai, R. (2005). Aerobic nitrificationdenitrification by heterotrophic Bacillus strains. Bioresource Technology, 96: 1897-1906.

56) Jung J., Chun J., Park W. (2012). Genome sequence of extracellular-protease-producing Alishewanella jeotgali isolated from traditional Korean fermented seafood. Journal of bacteriology194:2097.

57) Knowles R. (1982). Denitrification. Microbiological Reviews, 46 (1): 43-70.

58) Koenig, A., Zhang, T., Liu, L. H., Fang, H. H. (2005). Microbial community and biochemistry process in autosulfurotrophic denitrifying biofilm. Chemosphere, 58(8): 1041-1047.

59) Kolekar Y.M., Konde P.D., Markad V.L., Kulkarni S.V., Chaudhari AU. (2013). Effective bioremoval and detoxification of textile dye mixture by Alishewanella sp. KMK6. Appl. Microbiol. Biotech, 97: $881-889$

60) Kositzi M., Poulios I., Samara K., Tsatsaroni E., Darakas E. (2007). Photocatalytic oxidation of Cibacron Yellow LS-R. Journal of hazardous materials 146: 680-685.

61) Kuo W. (1992). Decolorizing dye wastewater with Fenton's reagent. Water Research 26 (7): 881 886.

62) Laemmli UK. (1970). Cleavage of structural proteins during the assembly of the head of bacteriophage T4. Nature, 227: 680-685. 
63) Lakshmi U.R., Srivastava V.C., Mall I.D. (2009). Lataye DH, Rice husk as an effective adsorbent: Evaluation of adsorptive characteristics for Indigo Carmine dye. Journal of Environmental Management, (90): 710-720.

64) Lee Yong-Woo, Ong Say-Kee, Sato Chikashi. (1997). Effects of heavy metals on nitrifying bacteria. Water Science and Technology. 36 (12): 69-74.

65) Leigh, S. D. (1997). Alkaline serine protease Streptomyces griseus var. alkaliphus having enhanced stability against urea or guanidine. Official Gazette U.S. Pat. \&Trademark Office Pat. 1200(2): 1254.

66) Lesage N., Sperandio M., Cabassud C. (2008). Study of a hybrid process: Adsorption on activated carbon/membrane bioreactor for the treatment of an industrial wastewater. Chemical Engineering and Processing, 47: 303-307

67) LEVAPOR. (2017). Nitrification of Sewage in Full Scale Moving Bed Reactors Using Adsorbant Porous Biocarriers. LEVAPOR, Leverkusen, Germany.

68) Li B., Irvin S., Baker K. (2006). The variation of nitrifying bacterial populations sizes in a sequencing batch reactors (SBR) treating low/mid/high concentrated waste water. WEFTEC 06, 5008-5029.

69) Li J., Bishop P.L. (2002). In situ identification of azo dye inhibition effects on nitrifying biofilms using microelectrodes. Water science and technology. 46 (1-2): 207-2014.

70) Lin Y.M., Tay J-H., Liu Y. y Hung Y-T. (2009). Biological nitrification and denitrification processes. En: Biological treatment processes, volumen 8. Editorial: Humana Press. 539-580.

71) Loehmeyer C., Koch J., Fuchs G. (1992). Anaerobic Degradation of 2-Aminobenzoic Acid (Anthranilic Acid) via Benzoyl-Coenzyme A (CoA) and Cyclohex-1-Enecarboxyl-CoAin a Denitrifying Bacterium. Journal of Bacteriology, 174 (11): 3621-3628.

72) Lourenco, N. D., Novais, J. M., Pinheiro, H. M. (2000). Reactive textile dye colour removal in a sequencing batch reactor. Water Science and Technology, 42(5-6): 321-328.

73) Lowry O. H., Rosen Brough N. J., Farr A. L. y Randall R. J. (1951). Protein measurement with the folin phenol reagent. Department of pharmacology. Washington University School of Medicine. St. Louis. Missouri.

74) Luna, D., González, A., Gordon, M., Martín, N. (2007). Obtención de carbón activado a partir de la cáscara de coco. ContactoS, 64(10): 39-48.

75) Machado M., López C., Heras H., Rivas E. (2004). Osmotic response in Lactobacillus casei ATCC 393: biochemical and biophysical characteristics of membrane. Archives of Biochemistry and Biophysics. 422:61-70.

76) Madigan M.T. Martinko JM. (2005). Brock Biology of Microorganisms. 11 th Ed. Pearson Prentice Hall. 
77) Manu, B., Chaudhari, S. (2003). Decolorization of indigo and azo dyes in semicontinuous reactors with long hydraulic retention time. Process Biochemistry, 38(8): 1213-1221.

78) Martienssen M., Schops R. (1998). Population Dynamics of Denitrifying Bacteria in a Model Biocommunity. Water Research (33): 639-646.

79) Martínez-Gutiérrez E. (2013). Estudio fisiológico de la oxidación del 2-clorofenol por un lodo desnitrificante. Tesis Doctorado. Universidad Autónoma Metropolitana Iztapalapa.

80) McMullan G., Meehan C., Conneely A., Kirby N., Robinson T., Nigam P., Banat I., Marchant W. (2001). Microbial decolourisation and degradation of textil dyes. Appl Microbiol Biotechnol 56: 8187.

81) Méndez, L., Miyashiro, V., Rojas, R., Cotrado, M., Carrasco, N. (2004). Tratamiento de aguas residuales mediante lodos activados a escala de laboratorio. Revista del Instituto de Investigación de la facultad de geología, minas, metalurgia y ciencias geográficas, 7(14): 74-83.

82) Méndez-Hernández J. (2010). Decoloración del índigo carmín por medio de una estrategia basada en el cultivo sólido de Fomes sp. EUM1. Tesis Maestría. Universidad Autónoma MetropolitanaIztapalapa.

83) Méndez-Hernández J.E., Ramírez-Vives F., Solis-Oba M., Sobrino-Figueroa A.S., Loera O. (2013). Detoxification and mineralization of Acid Blue 74: Study of an alternative secondary treatment to improve the enzymatic decolourization. World Journal of Microbiology and Biotechnology (29): 805-814.

84) Miyahara, M., Kim, S.W., Fushinobu, S., Takaki, K., Yamada, T., Watanabe, A., Miyauchi, K., Endo, G., Wakagi, T., Shoun, H. (2010). Potential of aerobic denitrification by Pseudomonas stutzeri TR2 to reduce nitrous oxide emissions from wastewater treatment plants. Appl. Environ. Microbiol 14: 4619-4625.

85) Moosvi, S., Kher, X., Madamwar, D. (2007). Isolation, characterization and decolorization of textile dyes by a mixed bacterial consortium JW-2. Dyes and pigments, 74(3): 723-729.

86) Morales-Guzman F., Melgoza-Alemán R. (2009). Tratamiento del Colorante Azo Rojo Directo 23 mediante Reactores Discontinuos Secuenciados Anaerobios/Aerobios. Información Tecnológica, 20 (1): 73-82.

87) Munteanu F., Basto C, Gübitz, Cavaco A. (2007). Staining of wool using the reaction products of ABTS oxidation by Laccase: Synergetic effects of ultrasound and cyclic voltammetry. Ultrasonics Sonochemistry, 14: 363-367.

88) Navarro P., Vargas C. (2010). Efecto de las propiedades físicas del carbón activado en la adsorción de oro desde medio cianuro. Revista de Metalurgia (43): 227-239.

89) Nigam P., Armour G., Banat I., Singh D., Marchant R. (2000). Physical removal of textile dyes from effluents and solid-state fermentation of dye-adsorbed agricultural residues. Bioresource Technology 72: 219-226. 
90) O’Neill, C., Hawkes, F. R., Hawkes, D. L., Lourenço, N. D., Pinheiro, H. M., \& Delée, W. (1999). Colour in textile effluents-sources, measurement, discharge consents and simulation: a review. Journal of Chemical Technology and Biotechnology, 74(11): 1009-1018.

91) Ogawa $T$, Yatome $C$, Idaka E, Kamiya $H$. (1986) Biodegradation of azo acid dyes by continuous cultivation of Pseudomonas cepacia 13NA. Journal of the Society of Dyers and Colourists,102:1214.

92) Olivares G., Santos A., García-Ochoa F. (1997). Simulación de Reactores Enzimáticos sometidos a desactivación. Aplicación al hidrólisis de lactosa. Información Tecnológica 8 (4):

93) Ong, S. A., Uchiyama, K., Inadama, D., Ishida, Y., \& Yamagiwa, K. (2010). Treatment of azo dye Acid Orange 7 containing wastewater using up-flow constructed wetland with and without supplementary aeration. Bioresource technology, 101(23): 9049-9057.

94) Otero, M., Rozada, F., Calvo, L. F., Garcla, A. I., Moran, A. (2003). Elimination of organic water pollutants using adsorbents obtained from sewage sludge. Dyes and Pigments, 57(1): 55-65.

95) Oturkar, C. C., Nemade, H. N., Mulik, P. M., Patole, M. S., Hawaldar, R. R., Gawai, K. R. (2011). Mechanistic investigation of decolorization and degradation of Reactive Red 120 by Bacillus lentus BI377. Bioresource technology, 102(2), 758-764.

96) Paolo Maldoni, Donatella Davoli, Lorena Guglielmi. (1999). Response of SOUR and AUR to heavy metal contamination in activated sludge. Water Research 33 (10): 2459-2464.

97) Phelan R., Barret M., Cotte P., Connor P., Chen R., Morrissey J. (2013). Subtilomycin: a new lantibiotic from Bacillus subtilis strain MMA7 Isolated from the marine sponge Haliclona simulans. Mar. Drugs 11, 1878-1898.

98) Prosser J.I. (1989). Autotrophic nitrification in bacteria. Advances in microbial physiology, 30: 125181.

99) Puvaneswari N., Muthukrishnan J., Gunasekaran P. (2006). Toxicity assessment and microbial degradation of azo dyes. Indian journal of experimental biology, 44 (8): 618.

100) Quintero L., Cardona S. (2010). Technologies for the decolorization of dyes: Indigo and indigo carmine. Dyna, 162: 371-386.

101) Ramya, M., Anusha, B., Kalavathy, S. (2008). Decolorization and biodegradation of Indigo carmine by a textile soil isolate Paenibacillus larvae. Biodegradation, 19(2): 283-291.

102) Rannikko A. M., Dunleavy K., Rice A., Mahling R., Fealey M., Jaworski S., Hinderliter A. (2014). The Protein that Held Back the Dye: Annexin's Effect on Membrane Permeability. Biophysical Journal, 106 (2): 716a.

103) Richardson, M. L. (1983). Dyes - The Aquatic Environment and the Mess made by Metabolites. Coloration Technology, 99(7 - 8): 198-200.

104) Robinson, T., McMullan, G., Marchant, R., Nigam, P. (2001). Remediation of dyes in textile effluent: a critical review on current treatment technologies with a proposed alternative. Bioresource technology, 77(3): 247-255. 


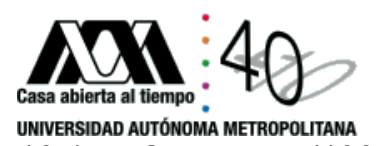

105) Sadana A. (1999). Fundamentals of Enzyme Deactivation Kinetics. Prentice Hall. New Jersey.

106) Silva, C.D., Gómez, J., Beristain-Cardoso R. (2011). Simultaneous removal of 2-chlorophenol,

phenol, $p$-cresol and $p$-hydroxybenzaldehyde under nitrifying conditions: Kinetic study. Bioresource Technology, 102: 6464-6468.

107) Solís-Oba M., Eloy-Juárez M., Teutli M., Nava J.L., González I. (2009). Comparison of Advanced Techniques for the Treatment of an Indigo Model Solution: Electro incineration, Chemical, Coagulation and Enzymatic. (2009). Revista Mexicana de Ingeniería Química, 8 (3): 275-282.

108) Stenstrom M., Poduska R. (1980). The effect of dissolved oxygen concentration on nitrification. Water Research, 14 (6): 643-649.

109) Tavares A., Cristóvão R., Loureiro J., Boaventura R., Macedo E. (2009). Application of statistical experimental methodology to optimize reactive dye decolourization by commercial laccase. Journal of Hazardous Materials, 168: 1255-1260.

110) Tchobanoglous G. y Burton F.L. (1991). Metcalf \& Eddy Wastewater engineering: Treatment, disposal and reuse. 3ra ed. McGraw-Hill, New York. pp. 735-740.

111) Téllez-Pérez S.K., Silva C.D., Texier A.C. (2013). Simultaneous Ammonium and pHydroxybenzaldehyde Oxidation in a Sequencing Batch Reactor. Revista Mexicana de Ingeniería Química, 12(1): 97-104.

112) Téllez-Téllez M., Fernández J.F., Montiel-Gonzalez A.M., Sánchez, C., Díaz G. (2008). Growth and laccase production by Pleurotus ostreatus in submerged and solid-state fermentation. Applied Microbial Biotechnology. 81: 675-679.

113) Teske A., Alm E., Reagan J.M., Toze S., Rittmann B.E. y Stahl D.A. (1994). Evolutionary relationships among ammonia and nitrite oxidizing bacteria. Journal of Bacteriology, 176(21): 6623-6630.

114) Third k., Burnett N., Cord-Ruwisch R. (2003). Simultaneous nitrification and denitrification using stored substrate (phb) as the electron donor in a SBR. Biotechnology and Bioengineering, 83: 706-720.

115) Thomas B., Aurora T., Wolfgang S. (2006). Electrochemical decolourization of dispersed indigo on boron-doped diamond anodes. Diam. Relat. Mater., 15: 1513-1519.

116) Topac F., Dindar E., Ucaroglu S., Baskaya H. (2009). Effect of a sulfonated azo dye and sulfanilic acid on nitrogen transformation processes in soil. Journal of Hazardous Materials, 170: 1006-1013.

117) Van Gils, H. W. (1965). Bacteriology of activated sludge. Antonie van Leeuwenhoek, 31(1): 222-222.

118) Wagner M., Rath G., Koops H-P., Flood J. y Amann R. (1996). In situ analysis of nitrifying bacteria in sewage treatment plants. Water Science and Technology, 34(1): 237-244. 


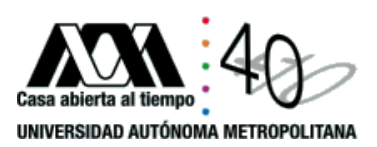

119) Wang, X., Wang, J. (2009). Removal of nitrate from groundwater by heterotrophic denitrification using the solid carbon source. Science in China Series B: Chemistry, 52(2): 236240.

120) Water Analysis Manual. (2000). Hach Company, Loveland, Colorado, EE. U.U.

121) Watson S.W., Bock E., Koops H.P. y Hooper A. (1989). Bergey's Manual of Systematic Bacteriology. Volumen 3. Editorial: The Williams and Wilkins, Baltimore. pp 1808-1834.

122) Wesenberg, D., Kyriakides, I., \& Agathos, S. N. (2003). White-rot fungi and their enzymes for the treatment of industrial dye effluents. Biotechnology advances, 22(1): 161-187.

123) Willmott, N., Guthrie, J., Nelson, G. (1998). The biotechnology approach to colour removal from textile effluent. Coloration Technology, 114(2): 38-41.

124) Wu J., Eiteman M., Law S. (1998). Evaluation of membrane filtration and ozonation processes for treatment of reactive-dye wastewater. Journal of Environmental Engineering 124, (3): 272-277.

125) Yu J., Wang X., Yue PL. (2001). Optimal decolorization and kinetic modeling of synthetic dyes by pseudomonas sitains. Wat. Res., 35: 3579-3586.

126) Zhang, W., Liu, W., Zhang, J., Zhao, H., Zhang, Y., Quan, X., Jin, Y. (2012). Characterization of acute toxicity, genotoxicity and oxidative stress posed by textile effluent on zebrafish. Journal of Environmental Sciences, 24: 2019-2027.

127) Zimmermann T, Gasser F, Kulla HG, Leisinger $T$ (1984) Comparison of 2 bacterial azoreductases acquired during adaption to growth on azo dyes. Arch Microbiol, 138:37-43. 
OXIDACIÓN Y ADSORCIÓN SIMULTÁNEA DEL AMONIO Y AZUL ÁCIDO 74 EN UN REACTOR HÍBRIDO DE FLUJO ASCENDENTE

UNIVERSIDAD AUYOUOARA RWETROPR?
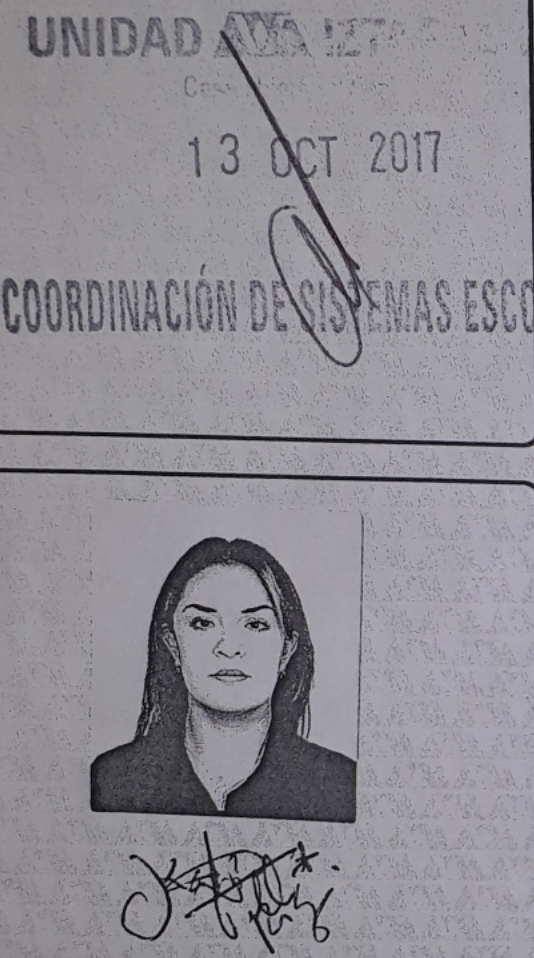

SYLVIA KARINA TELLEZ PEREZ ALUMNA

REVISO

LIC. JULIO CESAR DE LARA ISASSI DIRECTOR DE SISTEMAS ESCOLARES
En la Ciudad de México, se presentaron a las 12:00 horas del día 11 del mes de octubre del año 2017 en la Unidad Iztapalapa de la Universidad Autónoma Metropolitana, los suscritos miembros del jurado:

DR. CARLOS OMAR CASTILLO ARAIZA

DRA. GEHOVANA GONZALEZ BLANCO

DR. GUILLERMO QUIJANO GOVANTES

DR. CARLOS DAVID SILVA LUNA
Bajo la Presidencia del primero y con carácter de Secretario el último, se reunieron a la presentación de la Disertación Pública cuya denominación aparece al margen, para la obtención del grado de:

DOCTORA EN BIOTECNOLOGIA

DE: SYLVIA KARINA TELLEZ PEREZ

y de acuerdo con el artículo 78 fracción IV del Reglamento de Estudios Superiores de la Universidad Autónoma Metropolitana, los miembros del jurado resolvieron:

\section{APROBAR}

Acto continuo, el presidente del jurado comunicó a la interesada el resultado de la evaluación $y$, en caso aprobatorio, le fue tomada la protesta.
DIRECTORA DE LA DIVISIÓN DE CBS

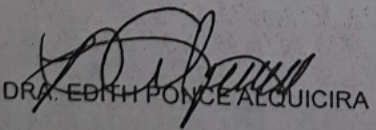

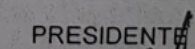

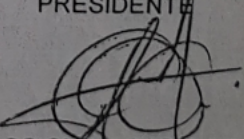

DR. CARLOS OMAARASTILLOARAIZA
VOCAL

Gehourra 0,5 DRA. GEHOVANA GONZALEZ BLANCO
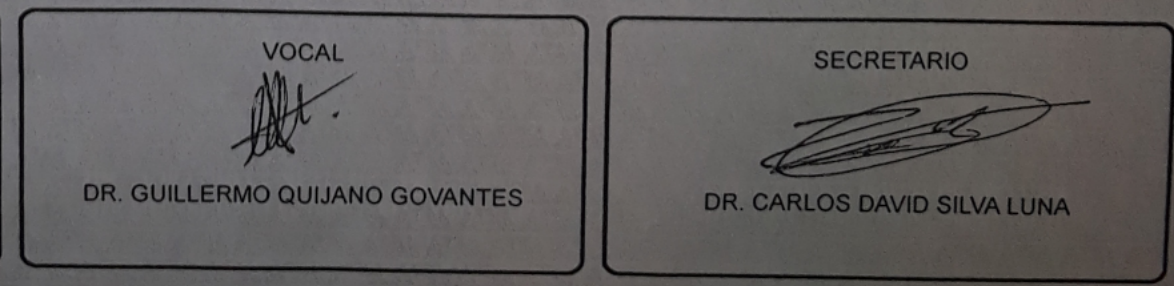